\title{
A Review of Developments in Carbon Dioxide Storage
}

\author{
Mohammed D. Aminu ${ }^{\mathrm{a}}$, Christopher A. Rochelle ${ }^{\mathrm{b}}$, Seyed Ali Nabavi ${ }^{\mathrm{a}}$, Vasilije Manovic ${ }^{\mathrm{a}, *}$ \\ ${ }^{a}$ Combustion, Carbon Capture and Storage Centre, Cranfield University, Bedford, \\ Bedfordshire, MK43 0AL, UK \\ ${ }^{\mathrm{b}}$ British Geological Survey, Environmental Science Centre, Nicker Hill, Keyworth, \\ Nottingham NG12 5GG, UK
}

*Corresponding author: Email: v.manovic@ @ cranfield.ac.uk, Tel: +44(0)1234754649

\begin{abstract}
Carbon capture and storage (CCS) has been identified as an urgent, strategic and essential approach to reduce anthropogenic $\mathrm{CO}_{2}$ emissions, and mitigate the severe consequences of climate change. $\mathrm{CO}_{2}$ storage is the last step in the CCS chain and can be implemented mainly through oceanic and underground geological sequestration, and mineral carbonation. This review paper aims to provide state-of-the-art developments in $\mathrm{CO}_{2}$ storage. The review initially discussed the potential options for $\mathrm{CO}_{2}$ storage by highlighting the present status, current challenges and uncertainties associated with further deployment of established approaches (such as storage in saline aquifers and depleted oil and gas reservoirs) and feasibility demonstration of relatively newer storage concepts (such as hydrate storage and $\mathrm{CO}_{2}$-based enhanced geothermal systems). The second part of the review outlined the critical criteria that are necessary for storage site selection, including geological, geothermal, geohazards, hydrodynamic, basin maturity, and economic, societal and environmental factors. In the third section, the focus was on identification of $\mathrm{CO}_{2}$ behaviour within the reservoir during and after injection, namely injection-induced seismicity, potential leakage pathways, and long-term containment complexities associated with $\mathrm{CO}_{2}$-brine-rock interaction. In addition, a detailed review on storage capacity estimation methods based on different geological media and trapping mechanisms was provided. Finally, an overview of major $\mathrm{CO}_{2}$ storage projects, including their overall outcomes, were outlined. This review indicates that although $\mathrm{CO}_{2}$ storage is a technically proven strategy, the discussed challenges need to be addressed in order to accelerate the deployment of the technology. In addition, beside the necessity of technoeconomic aspects, public acceptance of $\mathrm{CO}_{2}$ storage plays a central role in technology deployment, and the current ethical mechanisms need to be further improved.
\end{abstract}




\section{Contents}

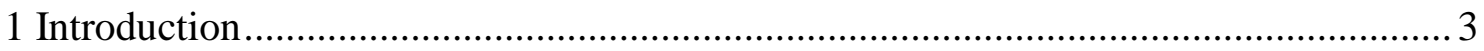

2 Options for $\mathrm{CO}_{2}$ Sequestration.........................................................................

2.1 Underground Geological $\mathrm{CO}_{2}$ Storage ......................................................... 7

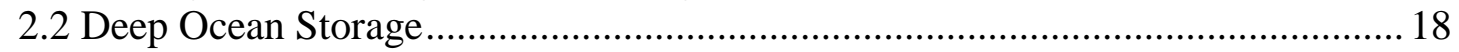

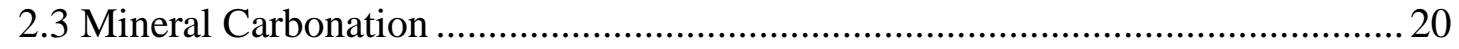

$3 \mathrm{CO}_{2}$ Storage Site Evaluation Criteria....................................................................2

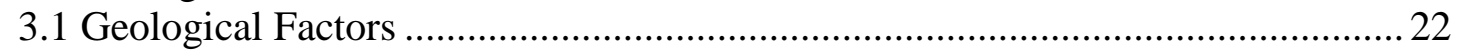





3.4 Hydrodynamic Factors .................................................................................... 25

3.5 Hydrocarbon Potential and Basin Maturity ………………………………….. 25

3.6 Economic, Societal and Environmental Issues ...................................................22

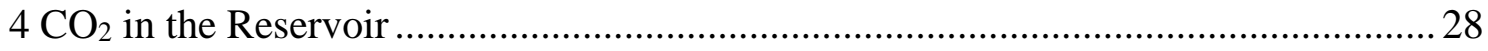



4.2 Induced Seismicity by Injection........................................................................... 31

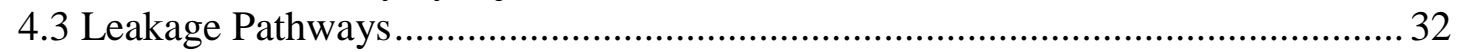

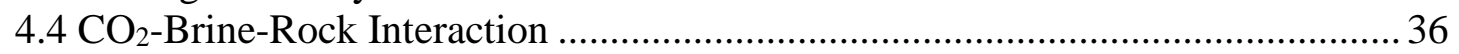

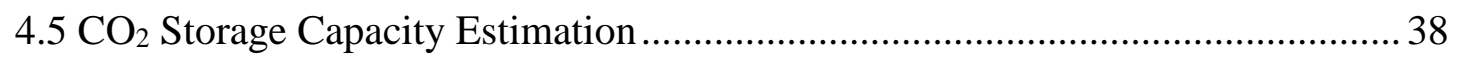

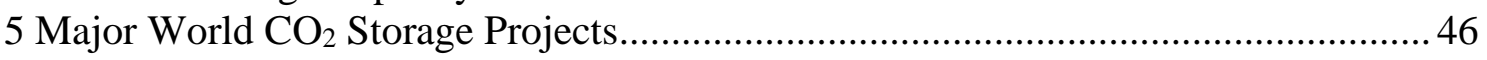

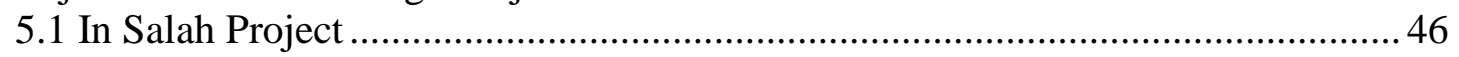



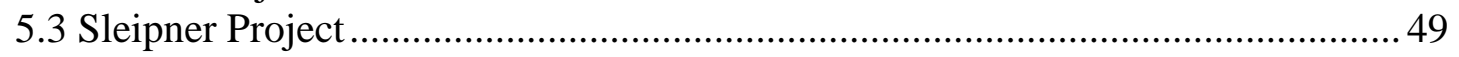

5.4 Weyburn - Midale Project ................................................................................ 51

5.5 Snøhvit Project......................................................................................... 52

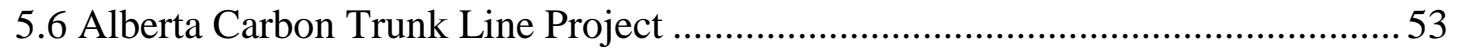

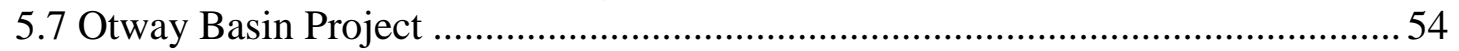

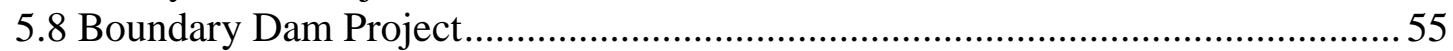

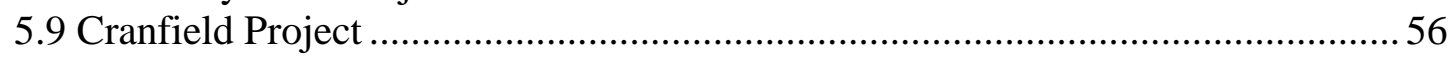

5.10 Frio Brine Pilot Project ................................................................................... 57

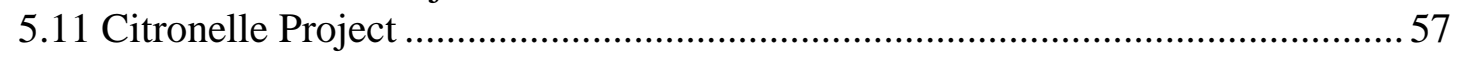

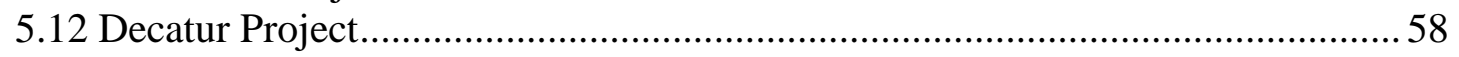

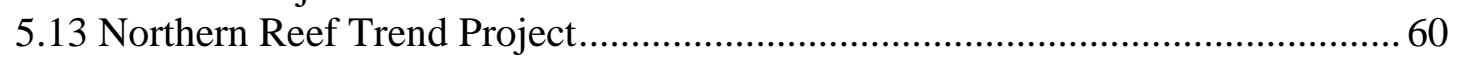

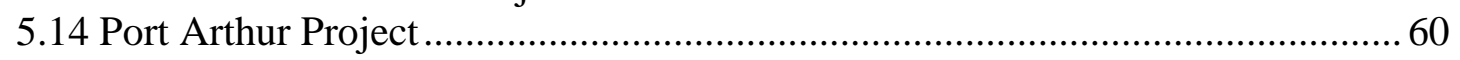

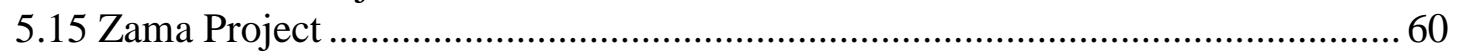

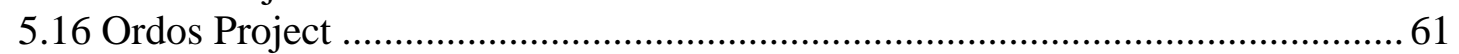

6 General Conclusions and Future Outlook for $\mathrm{CO}_{2}$ Storage .........................................66

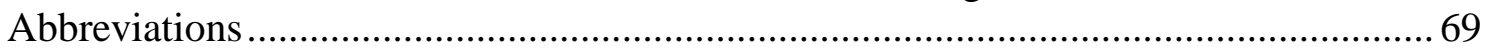

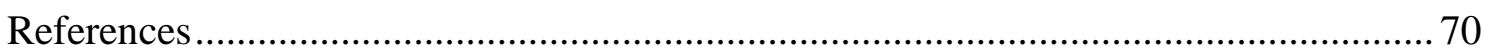




\section{Introduction}

The anthropogenic emissions of $\mathrm{CO}_{2}$ and other greenhouse gases (GHGs) have been identified as the main contributor to global warming and climate change [1]. The atmospheric concentration of $\mathrm{CO}_{2}$ has increased from $280 \mathrm{ppm}$, in the mid-1800s, to nearly $404 \mathrm{ppm}$ in 2016, and caused almost $1{ }^{\circ} \mathrm{C}$ increase in mean earth temperature, from pre-industrial levels [2,3]. This temperature rise, only between 1901 and 2010, led to a $20 \mathrm{~cm}$ increase in global mean sea level [4]. It is recognised that the mean earth temperature rise from pre-industrial levels should be kept well below $2{ }^{\circ} \mathrm{C}$ by 2100 in order to mitigate severe events of climate change [5]. Accordingly, European Union and the G8 have targeted to reduce GHG emissions by at least $80 \%$ from the 1990 baseline by 2050 [6-8].

Power plants and energy-intensive industries are considered as the major $\mathrm{CO}_{2}$ emitters, and are obligated to drastically cut their $\mathrm{CO}_{2}$ emissions. The high carbon intensity of the power sector $(42 \%)$ is attributed to the large share of coal-fired plants in the global electricity supply. In addition, the emergence of shale gas in North America has led to higher American exports of coal. Consequently, it caused a considerable reduction in coal price, which in turn led to a higher tendency for coal-based electricity production [9]. Hence, decarbonisation of power and industrial sectors is essential in order to meet emission reduction targets.

Carbon capture and storage (CCS) is considered as the key strategy for decarbonisation of the power and industrial sectors [10]. It is estimated that CCS alone can contribute almost 20\% reduction in emissions by 2050, and the exclusion of CCS can cause up to $70 \%$ increase in global cost of achieving emission reduction targets [11]. Permanent sequestration of $\mathrm{CO}_{2}$ is the last step in the CCS chain and can be implemented using a variety of strategies, mainly mineral carbonation, oceanic, and underground geological storage including saline aquifers, depleted oil and gas reservoirs, unmineable coal seams, and other geological media. The main characteristics of a feasible $\mathrm{CO}_{2}$ storage option are net reduction in $\mathrm{CO}_{2}$ emission, large storage capacity, long-term isolation of $\mathrm{CO}_{2}$ (at least several hundred years), reasonable cost and energy penalty, and minimised environmental impact [12]. On the other hand, public acceptance/embracing is another key factor that can significantly affect the deployment of the technology [13]. 
There have been several reviews that discussed different aspects of $\mathrm{CO}_{2}$ storage [14-33]; see

Table 1. However, some aspects have not been covered yet or analysed in detail. Despite $\mathrm{CO}_{2}$ storage being a technically proven technology, further deployment of the technology is delayed by some uncertainties and challenges associated with estimation of storage capacity, tracking verification and monitoring of $\mathrm{CO}_{2}$ during and after injection, characterisation of potential injected-induced seismicity, standardisation of storage evaluation criteria, and effective ethic mechanisms. In addition, $\mathrm{CO}_{2}$ storage is a fast-developing field and recent progress and development need to be reviewed and discussed.

Table 1: Summary of review studies on carbon storage

\begin{tabular}{ll}
\hline Source & Review Scope \\
\hline Bai et al. & Review on well integrity issues for $\mathrm{CO}_{2}$ storage and enhanced gas recovery \\
{$[\mathbf{1 4}]$} & highlighting mechanisms responsible for loss of well integrity, well integrity \\
& criteria, determination of well integrity for operational wells, and risk-based \\
& approaches for abandoned wells.
\end{tabular}
Abidoye Detailed review on geosequestration of $\mathrm{CO}_{2}$ in relation to two-phase flow in
et al. [15] porous media highlighting aquifer storage capacity, sealing integrity of caprock, displacement of brine by supercritical $\mathrm{CO}_{2}$, simultaneous flow of free and buoyant phases of $\mathrm{CO}_{2}$, and various trapping mechanisms.
Bachu Review of $\mathrm{CO}_{2}$ storage efficiency in deep saline aquifers highlighting storage
[16] efficiency and capacity, factors that affect $\mathrm{CO}_{2}$ injection and plume evolution (such as boundary conditions, driving forces and fluid properties, displacement characteristics of $\mathrm{CO}_{2}$-water systems in sedimentary rocks, and aquifer characteristics), storage efficiency coefficients for volumetric estimates of storage capacity, and pressure and time effects on storage efficiency.
De Silva Review of geochemical aspects of $\mathrm{CO}_{2}$ sequestration in deep saline aquifers
et al. [17] highlighting solubility trapping (effective factors for trapping, and experimental and modelling studies), and mineral trapping (trapping in sandstones, reactions in potassium- and sodium-rich feldspars, and experimental and modelling studies).


Boot- $\quad$ CCS update highlighting capillary trapping and multiphase flow (pore-scale Handford properties and natural analogues), regional assessment of storage capacity et al. [18] (definition of storage reservoirs and storage complexes, challenges to the concept of large-volume storage, and $\mathrm{CO}_{2}$-EOR (enhanced oil recovery)).

Burnside Review of $\mathrm{CO}_{2}$ /brine systems, highlighting estimates and measurements of and relative permeability and residual saturation (experimental procedures and Naylor experimental biases).

[19]

Carroll et Review of environmental issues for sub-seabed geological storage of $\mathrm{CO}_{2}$, al. [20] highlighting physical data processes (natural $\mathrm{CO}_{2}$ levels/concentrations and fluxes, shallow seabed geophysics and geology, $\mathrm{CO}_{2}$ seepage and seabed sediment-water chemistry, reservoir storage chemistry and water-rock reactions).

Godec et Review of the status and global potential for $\mathrm{CO}_{2}-\mathrm{ECBM}$ (enhanced coalbed al. [21] methane) highlighting factors influencing $\mathrm{CO}_{2}$ storage and enhanced gas recovery in coal seams, $\mathrm{CO}_{2}$-ECBM storage trials in San Juan Basin, USA, and estimate of global $\mathrm{CO}_{2}$ storage capacity in coal seams.

Humez et $\mathrm{CO}_{2}$ intrusion in freshwater aquifers highlighting isotopic $(\mathrm{C}$ and $\mathrm{O})$ methods as al. [22] tracer tools for $\mathrm{CO}_{2}$ presence, and potential application of 'non-traditional' isotopes of dissolved species to $\mathrm{CO}_{2}$ storage.

Tang et Review of $\mathrm{CO}_{2}$ sequestration projects and application in China highlighting al. [23] major geosequestration options.

Li et al. Review of progress in CCS in the Chinese Academy of Sciences (CAS) [24] highlighting identified major storage options and opportunities in China.

Song and Review of caprock sealing mechanisms in geological $\mathrm{CO}_{2}$ storage highlighting Zhang various leakage paths (diffusion, capillarity and faults).

[25]

Liu et al. Review of $\mathrm{CO}_{2}$-brine-caprock interactions and reactivity experiments with the [26] Eau Claire Formation, Midwest USA region, highlighting observed mineral reactions from laboratory experiments and safety function of caprocks from insights in geochemical modelling work.

Pires et A brief introduction to $\mathrm{CO}_{2}$ storage options.

al. [27] 


\begin{tabular}{ll}
\hline Zahid et & Review on present and future prospects for $\mathrm{CO}_{2}$ geological storage highlighting \\
al. [28] & major trapping mechanisms, capacity estimation of storage sites, monitoring \\
& techniques, and simulation tools used for storage projects. \\
\hline Zhang & Review of integrity of existing wells highlighting in-situ conditions for \\
and & geological storage, and determination of carbonation rates relevant to $\mathrm{CO}_{2}$ \\
Bachu & storage through laboratory and field studies. \\
[29] &
\end{tabular}

Shukla et Review of studies on $\mathrm{CO}_{2}$ sequestration and caprock integrity highlighting major al. [30] sequestration projects in operation, geosequestration systems, and $\mathrm{CO}_{2}$ migration in reservoir formation rocks ( $\mathrm{CO}_{2}$-brine-rock interaction, and caprock integrity).
Abu- $\quad$ Review of progress on $\mathrm{CO}_{2}$ sequestration with a brief introduction to geological Khader storage.
[31]
White et Review of $\mathrm{CO}_{2}$ sequestration in coal with ECBM recovery highlighting al. [32] monitoring and verification of geologically-sequestered $\mathrm{CO}_{2}$ (lessons from underground storage of methane, pressure monitoring and methods, leak detection using soil gas measurements, chemical tracers, and reservoir simulators).

Voormeij Technical review on geological, ocean, and mineral $\mathrm{CO}_{2}$ sequestration, and highlighting storage in oil and gas reservoirs, coal seams, deep ocean, salt Simandl caverns, and mineral carbonation.

[33]

This review aims at gathering information on past and recent developments, challenges, and uncertainties of $\mathrm{CO}_{2}$ storage to identify potential opportunities to assure timely deployment of the technology and CCS chain. The first part of the review will focus on different storage options and their associated challenges and opportunities. In the second part, the critical factors for selection of storage sites will be discussed. The third part will explain the associated issues with $\mathrm{CO}_{2}$ containment in the reservoir during and after injection, and review the past and recent proposed methods for estimation of storage capacity. Finally, the major $\mathrm{CO}_{2}$ storage projects worldwide, including their potential challenges and lessons learned, will be outlined. 


\section{Options for $\mathrm{CO}_{2}$ Sequestration}

In the CCS framework, the potential options for $\mathrm{CO}_{2}$ sequestration are underground geological storage, deep ocean storage, and mineral carbonation [5], in which underground geological storage itself comprises several options including saline aquifers, depleted oil and gas reservoirs, unmineable coal seams, hydrate storage, and $\mathrm{CO}_{2}$ within engineered geothermal systems [3436]. This section provides a comprehensive discussion on each storage strategy, and correspondingly, outlines the possible future studies that can advance the current understanding.

\subsection{Underground Geological $\mathrm{CO}_{2}$ Storage}

Underground geological storage has been considered as the most viable sequestration approach. There are several factors that make geological storage the superior sequestration strategy, in comparison with carbonation and oceanic storage, including economic aspects, site accessibility (in the case of ocean and mineral sequestration), and associated concerns regarding the security of stored $\mathrm{CO}_{2}$ and negative environmental impacts of mineralisation and ocean storage. There are several potential geological storage options (Figure 1) that will be comprehensively discussed in this section.

\subsubsection{Saline Aquifers}

$\mathrm{CO}_{2}$ storage in saline aquifers is considered as one of the most feasible technology deployment options [37-40], probably because it provides the largest potential storage volume [36]. In addition, the majority of saline aquifers are currently not suitable for other synergic or conflicting applications [41], particularly in the framework of densely populated countries [42]. However, from an economic aspect, many saline aquifers are currently less desirable as a storage option due to the absence of necessary infrastructure, such as injection wells, surface equipment and pipelines, and the capital cost associated with developing such infrastructure $[43,44]$.

There has been much research carried out around the world on the potential of $\mathrm{CO}_{2}$ storage in saline aquifers [45], mostly in conjunction with EOR fields (such as the Boundary DamApache case). These studies involve factors such as site selection criteria, site characterisation and future planning [46], as well as the variation of synergic and/or conflicting uses of the subsurface $[42,47]$. 




Figure 1: Some geological storage options for $\mathrm{CO}_{2}$ [48].

It is revealed that all deep-seated $(>1 \mathrm{~km})$ saline aquifers (perhaps excepting aquifers found between deeply-buried old lava flows) [36] of the world are located within sedimentary basins. Such basins can host enormous quantities of $\mathrm{CO}_{2}$ due to their large pore volume and high permeability that minimise the number of necessary injectors, and ease pressure dissipation [30]. Once supercritical $\mathrm{CO}_{2}$ enters the storage reservoir, it displaces saline pore water and then begins to react with groundwater, gas and rocks in the formation $[49,50]$, which eventually leads to precipitation of new minerals and/or dissolution of pre-existing minerals [51]. Formation and dissolution of minerals can affect the rock porosity and consequently change the capacity of the host reservoir [52].

The density of supercritical $\mathrm{CO}_{2}$ in saline reservoirs is about $0.6-0.7 \mathrm{~g} / \mathrm{cm}^{3}$, which is lower than the density of saline formation water, thus causing $\mathrm{CO}_{2}$ to rise towards the caprock due to buoyancy force $[53,54]$. To assure long-term $\mathrm{CO}_{2}$ storage, the host basin must be considerably large and the caprock must possess a good sealing capacity [55]. Fleury et al. [56] defined a caprock as a low- to very low-permeability formation above the $\mathrm{CO}_{2}$ storage formation, in which no $\mathrm{CO}_{2}$ migration should occur. This low-permeability caprock is essential to prevent $\mathrm{CO}_{2}$ from migrating out of the storage reservoir, and minimising the $\mathrm{CO}_{2}$ leakage. The presence of unrecognised fracturing or faulting is another critical factor that can result in loss of caprock integrity and in $\mathrm{CO}_{2}$ leakage. However, further research is needed to explore the effect of pervious faults on the caprock integrity [57]. 


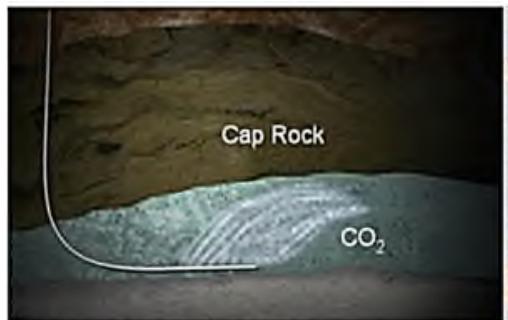

(a) Structural/stratigraphic trapping

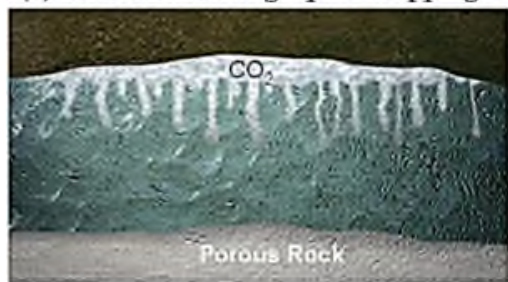

(c) Solubility trapping

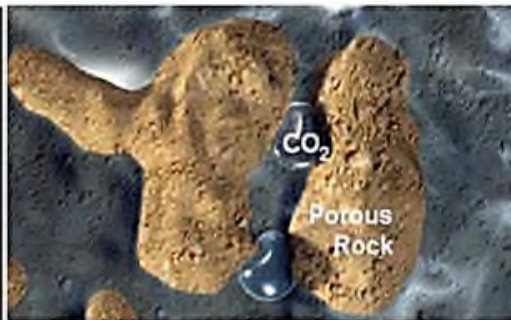

(b) Residual trapping

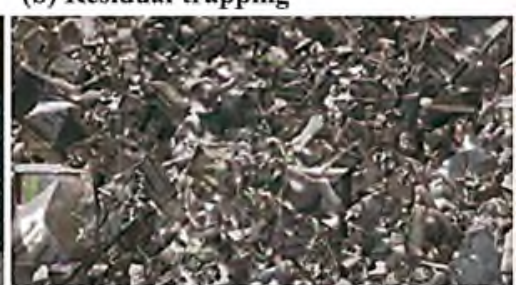

(d) Mineral trapping

Figure 2: The four main $\mathrm{CO}_{2}$ trapping mechanisms (reprinted with permission from $\mathrm{Zhao}$ et al. [58], Copyright 2017 Elsevier).

There are four main trapping mechanisms that can securely store $\mathrm{CO}_{2}$, namely, structural/stratigraphic, residual, solubility, and mineral trapping, Figure 2 [30,59].

(a) Structural/stratigraphic trapping: Once $\mathrm{CO}_{2}$ is injected, it can rise up to the top of geological structures and remain below an impermeable top seal [60], where it is stored as a high-density free phase that is unable to enter the pore space of the caprock, except through slow diffusion or through faults, Figure 2a [61]. This is the most dominant trapping mechanism.

(b) Residual trapping: In this mechanism, the injected $\mathrm{CO}_{2}$ initially displaces the fluid as it progresses through the porous rock. As $\mathrm{CO}_{2}$ continues to move, the displaced fluid returns and disconnects and traps the remaining $\mathrm{CO}_{2}$ within pore spaces, Figure 2b [59]. It is reported that the phenomenon does not happen within structural and stratigraphic traps, but only where water drainage occurs during $\mathrm{CO}_{2}$ injection [62].

(c) Solubility trapping: In this mechanism, $\mathrm{CO}_{2}$ dissolves in brine, reducing the volume of freephase $\mathrm{CO}_{2}$, Figure 2c. $\mathrm{CO}_{2}$ dissolution increases the brine density and can induce a gravitation instability, which accelerates the transfer of injected $\mathrm{CO}_{2}$ to $\mathrm{CO}_{2}$-lean brine [63]

(d) Mineral trapping: In this mechanism, $\mathrm{CO}_{2}$ is involved in geochemical reactions with saline water and minerals in host rock leading to the precipitation of carbonate phases that effectively lock up the $\mathrm{CO}_{2}$ in immobile secondary phases for geological timescales, Figure 2d [64]. This process is slower than solubility trapping and takes place over a longer geologic timescale [6567]. 


\subsubsection{Depleted Oil and Gas Reservoirs}

$\mathrm{CO}_{2}$ storage in depleted oil and gas reservoirs is considered as one of the most effective storage options because of several advantages including: (a) depleted oil and gas reservoirs have been extensively studied before and during the hydrocarbon exploration stage, including the storage capacity, (b) surface and underground infrastructure, e.g., injection wells and pipelines, already exist and can be utilised for the storage process either without or with only minor modifications [33,45,68-71], and (c) the injection of gases such as $\mathrm{CO}_{2}$ as an EOR technique has been widely known and employed within the oil and gas industry and, therefore, such experience can be used for the storage process [43]. In addition, oil and gas reservoirs are valuable hydrocarboncontaining analogues that can be used to demonstrate the effectiveness of caprock or seal over geological periods [72], since if this was not the case, the oil and gas in such reservoirs would have escaped long ago.

Storage in oil and gas reservoirs has many similarities to storage in saline aquifers, since the rock types are similar [73], and brine is present in both cases. On the other hand, oil and gas reservoirs can be potentially considered for EOR, which makes them economically more favourable than saline aquifers [74-76]. Since the global average factor for recovery in typical oilfields is approximately $40 \%$ [77], there is often a substantial amount of oil which is left in the reservoir. This is the main driver for deployment of EOR around the world. However, challenges of the technology deployment remain (mainly the dynamic nature of the downhole environment), although some of these uncertainties could have been considered and addressed during the early stages of a field's exploration and/or production.

Amongst existing options for EOR, including gas, thermal, chemical, or plasma-pulse injection methods, gas injection is the most commonly used technique. In the gas injection technique (typically $\mathrm{CO}_{2}$, nitrogen and natural gas), miscible gases are introduced into the reservoir to reduce the interfacial tension between oil and water and improve oil displacement, while maintaining reservoir pressure. $\mathrm{CO}_{2}$ is considered as the most suitable option, since it can reduce the oil viscosity, and also is cheaper compared to liquefied natural gas [78]. Since the advent of CCS technology, more $\mathrm{CO}_{2}$ for EOR is expected to be available from large point sources [5]. For example, it has been reported that the utilization of $\mathrm{CO}_{2}$ for EOR has led to additional production of almost 250,000 barrels of oil per day in the United States [79]. 
The main requirements for deployment of $\mathrm{CO}_{2}$-EOR projects are [80]: (i) additional characterisation of storage site by gathering key information on caprock integrity and abandoned wells, to determine the risk of leakage; (ii) additional measurements of fugitive and venting emissions from any surface processing facilities; (iii) enhanced monitoring and field surveillance to identify, and/or estimate leakage rates from sites to assess whether reservoir behaviour is as anticipated or not; and (iv) modifications to abandonment processes such as removal/retrofitting of any components of the well, to ensure such components can withstand effects of corrosion.

Nevertheless, in addition to the aforementioned requirements, governments need to consider legal issues and provide legislation that can cover storage site operation. These issues derive from different models of regulation for $\mathrm{CO}_{2}$-EOR and $\mathrm{CO}_{2}$ permanent storage, in which the former should be focused on resource recovery, and the latter on waste disposal [81]. For example, where recovery of hydrocarbon is prioritised, the effective decontamination of oil remaining in place after production ceases may cause legal issues. Such situation can be specific to jurisdiction, and may be particularly important where onshore mineral and storage rights are held privately (i.e., United States) [81].

The type and level of impurities in $\mathrm{CO}_{2}$ streams is one of the important factors that needs to be critically characterised prior to a $\mathrm{CO}_{2}-\mathrm{EOR}$ project. The impurities in the $\mathrm{CO}_{2}$ stream depend on the point source of $\mathrm{CO}_{2}$ and its corresponding capture technologies [82]. The acceptable impurities and their concentration are determined based on a combination of transport, storage, and economics-related parameters. Typically, the minimum acceptable purity of $\mathrm{CO}_{2}$ streams is around $90 \%$ vol [83]. Higher levels of impurities can shift the boundaries in the $\mathrm{CO}_{2}$ phase diagram to higher pressures, implying higher operating pressures are needed to maintain the $\mathrm{CO}_{2}$ in its dense phase. Moreover, it has been reported that non-condensable impurities often lead to a reduction in the $\mathrm{CO}_{2}$ storage capacity by a degree greater than the molar fraction of the impurities in the $\mathrm{CO}_{2}$ stream [84].

Corrosion is the main associated concern with impurities. Corrosive impurities (such as $\mathrm{CO}$, $\mathrm{NO}_{2}, \mathrm{SO}_{2}, \mathrm{H}_{2} \mathrm{~S}, \mathrm{Cl}$ ) can significantly impact the transport and injection facilities; thus, it is essential to limit the level of impurities on a case-specific basis, and to establish viable mitigation strategies regarding the potential challenges [82]. It should be pointed out that although some impurities are flammable in nature (such as $\mathrm{CO}, \mathrm{H}_{2}, \mathrm{H}_{2} \mathrm{~S}, \mathrm{CH}_{4}$ ), the $\mathrm{CO}_{2}$ stream 
would not be flammable due to relatively low concentrations of those impurities, and such safety concerns for flammability are usually not considered in the evaluation of safety procedures. The excessive concentration of $\mathrm{O}_{2}$ in $\mathrm{CO}_{2}$ streams is another factor that can affect efficiency of the $\mathrm{CO}_{2}$-EOR process. The presence of $\mathrm{O}_{2}$ can trigger microbial activity in the reservoir [82], and can eventually lead to operational issues such as injection blockage, and oil degradation and oil souring [85].

Environmental aspects of EOR are associated with production of large amounts of water which may contain radioactive substances and toxic heavy metals [86]. These substances can contaminate the sources of potable water if a proper waste management and disposal strategy is not adopted. Although regulations already exist, governments must assure that the operators adhere to existing regulations where reinjection of brine (deep into the ground) for recovery is authorised (such as in the United States) [87].

The Weyburn-Midale $\mathrm{CO}_{2}$ storage project in Canada is one of the examples in which the captured $\mathrm{CO}_{2}$ is successfully and effectively used for EOR and storage in the Weyburn oilfield. In this project, not only is a considerable amount of additional oil recovered [88], but also the life cycle of the oilfield is extended for 20-25 years [89]. $\mathrm{CO}_{2}$-EOR studies based on the Weyburn case history have been mainly focused on long-term monitoring [90,91], induced seismicity [92], core assessment of $\mathrm{CO}_{2}$ impact on the reservoir [93], and interaction of formation waters, oil and minerals [94]. Cantucci et al. [51] developed a geochemical model for $\mathrm{CO}_{2}$ storage in deep reservoirs using the Weyburn case history, and studied brine/oil geochemical equilibrium. They assessed reservoir evolution during $\mathrm{CO}_{2}$ injection, and predicted precipitation and dissolution processes over 100 years post injection. They found that $\mathrm{CO}_{2}$ and carbonate dissolution are the main chemical reactions in the reservoir, and this takes place within the first year of simulation. In addition, evolution of chemical features by time suggested that $\mathrm{CO}_{2}$ can be safely stored by both mineral and solubility trapping.

Although the $\mathrm{CO}_{2}$-EOR process has significantly increased oil recoveries, the following strategies can potentially lead to further improvement [95]: (i) increasing the amount of injected $\mathrm{CO}_{2}$ compared to the typical range - such as conducted in the San Joaquin basin, where a recent numerical model was developed and used to prove that it was possible to recover $67 \%$ of the original oil in place (OOIP) by injecting 2.0 HCPV (hydrocarbon pore volume) of $\mathrm{CO}_{2}$ [96]; (ii) utilising innovative flood design and well management to obtain a higher proportion of 
residual oil through strategies such as isolation of poorly swept reservoir intervals for $\mathrm{CO}_{2}$ injection, altering injection and production well patterns, and deploying much closer well spacing [97]; (iii) improving the mobility ratio by increasing the viscosity of water [98]; and (iv) minimising miscibility pressure using miscibility-enhancing agents [99].

\subsubsection{Unmineable Coal Seams}

Unmineable coal seams provide another option for storing anthropogenic $\mathrm{CO}_{2}$. The presence of cleats within the coal matrix provide some permeability to the system. In addition, the coal matrix contains a very large number of micro-pores which makes it capable of adsorbing significant amounts of gases. The $\mathrm{CO}_{2}$ trapping mechanism is based on the higher affinity of coal towards gaseous $\mathrm{CO}_{2}$ than methane. Therefore, the injected $\mathrm{CO}_{2}$ can replace previously adsorbed methane and be permanently stored, while enhancing methane production [30]. This provides the opportunity of storing large amounts of $\mathrm{CO}_{2}$ while still improving the profitability and efficiency of commercial operations of coalbed methane (CBM) [100,101]. It should be noted that $\mathrm{CO}_{2}$ accelerates $\mathrm{CBM}$ production, but the total amount of produced methane is not necessarily greater than that without $\mathrm{CO}_{2}$ injection. IEAGHG [102] outlined the principal technical criteria that are required for successful application of enhanced coal bed methane (ECBM) recovery, including: (i) reservoir homogeneity; (ii) minimal faulting/folding; (iii) optimal depth range; (iv) concentrated coal geometry; and (v) adequate permeability.

The ECBM approach has been tested at two demonstration sites, namely, the Alberta Carbon Trunk Line (ACTL) project in Canada, and the San Juan Basin pilot project, USA, [100]. At the completion of the Alberta project tests, key lessons learned were: (a) continuous injection of $\mathrm{CO}_{2}$ is possible even in tight reservoirs; (b) despite injectivity declines, injection can still proceed; (c) it is possible to predict significant enhanced CBM production; and (d) injected $\mathrm{CO}_{2}$ remains within the reservoir while sweep efficiency is increased [103]. For the San Juan Basin pilot project, the key conclusions were: (a) there was an increase in methane recovery over the estimated ultimate primary recovery; (b) given the prevailing gas prices at the time of implementation of the project (without considering any tax credit benefits), the pilot itself was uneconomic, although gas prices in the future may make it appear economically attractive; and (c) the injected $\mathrm{CO}_{2}$ causes a reduction in coal permeability and correspondingly $\mathrm{CO}_{2}$ injectivity, which in turn compromises any likely increment in methane recoveries and project economics. Another small-scale study on a CBM field is in the Central Appalachian Basin 
(Buchanan County, Virginia, USA) where several monitoring, verification and accounting (MVA) techniques are being used in improving the understanding of storage complexities $[101,104]$. In addition, the potential ECBM implementation and the major differences in production between close wells with the same stratigraphy (but different groundwater/bacterial presence) have been initially investigated (such as those in the Surat basin, Australia [105]). However, further exploration is required to fully characterise and depict those differences.

Although $\mathrm{CO}_{2}$-EOR is an established approach in the oil industry, utilisation of $\mathrm{CO}_{2}$ for ECBM is yet to be well understood. However, many of the uncertainties in ECBM recovery can be addressed based on the existing knowledge of the $\mathrm{CO}_{2}$-EOR process. For example, for recoverable reserves in ECBM production, it may be important to consider existing technologies from the oil industry which can be utilised with slight modification. For the well integrity in ECBM production, existing well materials can be considered as a benchmark and used after appropriate improvements. Additionally, field management strategies, including risk assessment and monitoring, can be adopted from established processes and applied throughout project lifecycles.

\subsubsection{Basalt Formations}

Deep basalt formations, found within large igneous provinces, have been proposed as a potential option for $\mathrm{CO}_{2}$ storage [106-108]. Basaltic rocks form approximately $8 \%$ of the continents and much of the ocean floor. Therefore, there is an enormous potential $\mathrm{CO}_{2}$ storage capacity in basaltic rocks [109]. The key positive aspects of their potential for $\mathrm{CO}_{2}$ storage are their high reactivity and abundance of divalent metal ions in such rock which can potentially fix $\mathrm{CO}_{2}$ for geological timescales [110]. However, basalt flows have highly heterogeneous permeability and porosity (including that of matrix and fractures), and typically consist of a low-permeability centre, with high permeability zones at the upper and lower portions. Thus, the key parts of a basalt sequence for $\mathrm{CO}_{2}$ storage are the rubbly zones between individual flows.

Injection of free-phase $\mathrm{CO}_{2}$ into deeply-buried basalts (such as the CarbFix pilot project in Iceland) can displace water in pore spaces and fractures [111]. The reduction in the amount of water can hinder carbonation and hydration of the basalt. Therefore, injection of $\mathrm{CO}_{2}$ with an optimum amount of water in the same reservoir may be a potential solution. Goldberg et al. 
[112] studied $\mathrm{CO}_{2}$ injection in deep sea basalt and reported that it: (i) facilities formation of stable carbonates in relatively short geologic time, and delays return of $\mathrm{CO}_{2}$ to the atmosphere; (ii) provides enough depth that allows denser $\mathrm{CO}_{2}$ liquid to sink; (iii) stops upward migration of acidified basement fluids through an impermeable sediment cover; and (iv) forms stable hydrate when $\mathrm{CO}_{2}$ escapes to shallower depths containing water with lower temperatures. It is important to note that sparse and rare $\mathrm{CO}_{2}$ leakage in a limited amount does not necessarily affect the sea bottom environments.

Due to the potential formation of secondary carbonate mineral and the possibility of long-term $\mathrm{CO}_{2}$ trapping in basalts, it is important to consider changes in rock volume and to determine whether there is the probability of self-healing of fractures. Such issues were numerically explored by Van Pham et al. [110]. They reported that at $40^{\circ} \mathrm{C}$, calcium was significantly consumed by oxide which could possibly be limited to the formation of siderite and ferromagnesium carbonates. However, at higher temperatures, $60-100^{\circ} \mathrm{C}$, magnesite formed together with ankerite and siderite. They also found that both carbonation and hydration reactions resulted in an increase in the volume of solids and blockage of available pores, and consequently a reduction in the maximum amount of stored $\mathrm{CO}_{2}$.

Alongside basalt mineral assemblages, there have been studies aimed at understanding the fundamentals of long-term $\mathrm{CO}_{2}$ storage through mineral carbonation reactions that involve common magnesium silicates in serpentinites. $\mathrm{CO}_{2}$ reacts with magnesium silicates in the form of serpentinites, which are both abundant and thermodynamically suitable rocks to form magnesium carbonates [113]. Andreani et al. [114] studied the carbonation process under optimal flow conditions and their study suggested that reduction in porosity and permeability is confined to diffusion-limited zones or reduced flow, although high flow rates result in armoring of mineral surfaces after initial dissolution.

The presence of fractures in the caprock layer of basalt formations has also been a source of uncertainty. There is a possibility for leakage through the fractures, which may imply that basalts appear unlikely to be suitable for $\mathrm{CO}_{2}$ storage. On the other hand, the migrating $\mathrm{CO}_{2}$ through the fractures can potentially undergo mineralisation before reaching the surface, and be stored within the formation [115]. Thus, comprehensive exploration is needed to characterise the kinetics of $\mathrm{CO}_{2}$-basalt interactions. 


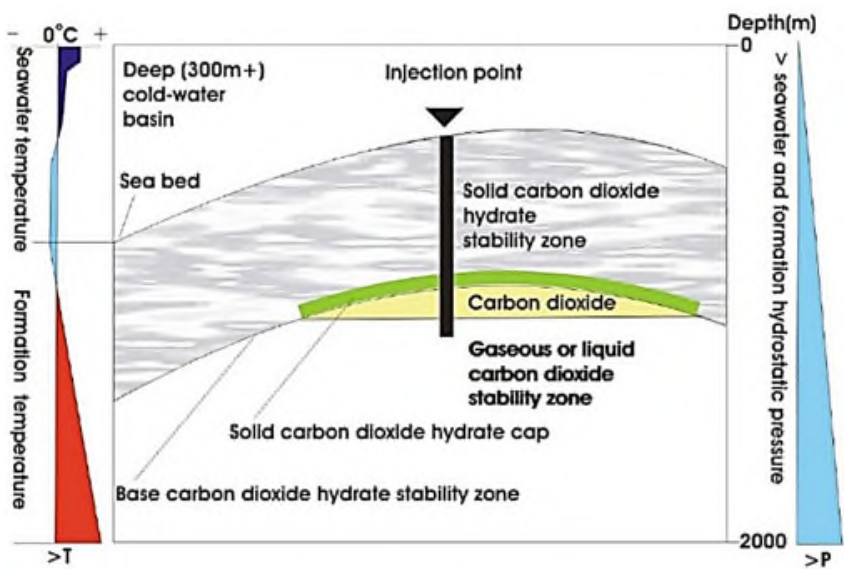

Figure 3: Schematic of hydrate storage and associated 'cap' of $\mathrm{CO}_{2}$ hydrate (adapted with permission Rochelle et al. [116], Copyright 2017 Geological Society of London).

\subsubsection{Hydrate Storage of $\mathrm{CO}_{2}$ within the Subsurface Environment}

Subsurface storage of $\mathrm{CO}_{2}$ as hydrates is also a promising, novel option which aims to use $\mathrm{CO}_{2}$ hydrate to trap $\mathrm{CO}_{2}$ molecules in a lattice of water molecules [35]. $\mathrm{CO}_{2}$ hydrate can rapidly form in the presence of water (that is abundant underground) and the appropriate pressure and temperature conditions [117]. In addition, its fast formation kinetics may potentially allow a degree of self-sealing in the unlikely event of fracture formation in the hydrate cap. Formation of $\mathrm{CO}_{2}$ hydrates is applicable in both underground geological and oceanic storage. However, since the hydrates are stable only at elevated pressures and temperatures below $10^{\circ} \mathrm{C}$ [116], its applicability is limited to a few environments, including shallower sediments that are beneath cold waters, and below thick permafrost, where there may not be large sources of $\mathrm{CO}_{2}$ nearby.

The $\mathrm{CO}_{2}$ hydrate storage mechanism is mainly based on the formation of an impermeable $\mathrm{CO}_{2}$ hydrate cap over a large amount of buoyancy-driven migrating liquid $\mathrm{CO}_{2}$, Figure 3. In this method, the liquid $\mathrm{CO}_{2}$ is injected into deep-water or sub-permafrost sediments, beneath the $\mathrm{CO}_{2}$ hydrate stability zone. Migration of the rising liquid $\mathrm{CO}_{2}$ to the cooler hydrate stability zone leads to precipitation of $\mathrm{CO}_{2}$ hydrates within rock pore spaces and formation of an impermeable layer of $\mathrm{CO}_{2}$ hydrates, that blocks the upward migration beneath liquid $\mathrm{CO}_{2}$ [116]. Alternatively, a hydrate storage strategy based on $\mathrm{CO}_{2}$-EGR (enhanced gas recovery) was proposed by US DOE (Department of Energy). In this approach, the $\mathrm{CO}_{2}$ is injected into methane hydrate-bearing sediments in order to release the methane from methane hydrates, and subsequently form $\mathrm{CO}_{2}$ hydrates instead [37]. However, $\mathrm{CO}_{2}$-EGR is a relatively new concept 
and its viability has not yet been fully explored. One of the main associated concerns with $\mathrm{CO}_{2}$ EGR is the possibility of mixing of the injected $\mathrm{CO}_{2}$ with existing methane which in turn may degrade the resources [118].

$\mathrm{CO}_{2}$ hydrate storage is still at a relatively low technology readiness level (TRL), and the majority of the work has been focused on theoretical modelling [119,120] and lab-scale experiments [121-123]. Therefore, there are uncertainties that remain, particularly in respect to $\mathrm{CO}_{2}$-EGR. Drilling through hydrate-bearing sediments can change local temperature and pressure, and may eventually destabilise the hydrate [124]. The key remaining issues that need to be addressed in order to advance the assessment of hydrate storage feasibility are the demonstration of hydrate cap formation, and understanding of the $\mathrm{CO}_{2}$-methane hydrate exchange mechanism and its impact on methane production.

\subsection{6 $\mathrm{CO}_{2}$-based Enhanced Geothermal Systems}

The thermal properties of dense-phase $\mathrm{CO}_{2}$, like water, make it capable of transporting significant amounts of heat. However, it also possesses some superior physical properties, such as significantly lower viscosity, higher compressibility and expansivity [125-128]. Therefore, $\mathrm{CO}_{2}$ can be applied for the extraction of heat from the subsurface, and used for geothermal power production. Owing to its low viscosity, $\mathrm{CO}_{2}$ can effectively access the rock mass, and can be particularly utilised as a working fluid for enhanced geothermal systems (EGS) $[34,128]$. One of the drawbacks of using water as the heat transmission fluid in EGS is its inevitable loss during fluid circulation. Since water is considered a valuable commodity, its loss is associated with economic liability. On the other hand, the loss in $\mathrm{CO}_{2}$-based EGS would offer the possibility of geological storage of $\mathrm{CO}_{2}$ underground, and can be considered as an ancillary benefit [128].

For an effective and successful storage strategy based on $\mathrm{CO}_{2}$-EGS, the $\mathrm{CO}_{2}$-filled rock mass needs to remain separate from the surrounding water-filled rock mass, and the stored $\mathrm{CO}_{2}$ should be isolated. The key mechanism that can ensure the aforementioned criteria is based on fast $\mathrm{CO}_{2}$-water-rock reactions that result in precipitation of carbonate minerals at the interface between the $\mathrm{CO}_{2}$-filled core of the EGS and the surrounding water-filled regions. In terms of geographical aspects, this approach would only be appropriate for countries which have subsurface formations with sufficiently high temperatures at economically-drillable depths. In 
addition, in densely populated countries, the synergic use of subsurface can be more challenging, and requires a high level of coordination [42].

In general, the technique is currently at a relatively low TRL, and the majority of conducted work has been mainly limited to theoretical modelling [129], and laboratory experiments [130]. The key barrier for further advance of this technology is associated with uncertainty in effectiveness of sealing around the $\mathrm{CO}_{2}$-filled zone. In addition, the $\mathrm{CO}_{2}$-rock interaction at elevated temperature is not clearly known, and further studies are required to characterise the effect of $\mathrm{CO}_{2}$ on dissolution and precipitation, and consequently variation in fracture permeability and EGS operation.

\subsection{Deep Ocean Storage}

An alternative strategy for sequestration of anthropogenic $\mathrm{CO}_{2}$ is to deliberately inject the $\mathrm{CO}_{2}$ into deep ocean water. Oceans cover $70 \%$ of the earth's surface with an average depth of 3.8 $\mathrm{km}$ [131], and have absorbed almost a third of cumulative anthropogenic $\mathrm{CO}_{2}$ emission from the atmosphere over the industrial period [132]. Mathematical models have shown that injected $\mathrm{CO}_{2}$ could remain in the ocean for several hundred years [131]. These cold (ca. $1^{\circ} \mathrm{C}$ ) and deep (ca. 4-5 km) waters move slowly, and can remain isolated from the atmosphere for millennial timescales.

The main proposed approaches for ocean storage are based on direct dissolution of $\mathrm{CO}_{2}$ into the seawater. In the first approach, liquid $\mathrm{CO}_{2}$ is directly discharged to the seafloor and forms rising droplet plumes. Alternatively, liquid $\mathrm{CO}_{2}$ is injected into a column, where it can react with seawater, at a controlled rate, to form hydrate [131]. There is, however, opposition regarding deep ocean storage of $\mathrm{CO}_{2}$ due to the potential local acidification of seawater around the $\mathrm{CO}_{2}$ injection point $[133,134]$, and correspondingly, possible negative impact on benthic organisms. In addition, it is not yet clear whether international regulations will allow ocean storage projects [24]. In 1996, the London Convention on the Prevention of Marine Pollution by Dumping of Wastes and Other Matter (also known as the London Convention) prohibited disposal of industrial wastes into the sea [135]. Therefore, if $\mathrm{CO}_{2}$ is considered as an industrial waste, disposing it beneath the sea is prohibited. However, there has not been agreement whether $\mathrm{CO}_{2}$ is regarded as industrial waste or not, even though in 2006, there was an amendment to the London Protocol, in which $\mathrm{CO}_{2}$ is included in the "reverse list" allowing it to be considered for storage below the seabed. In parallel, the Convention for the Protection of 
the Marine Environment of the North-East Atlantic (also known as the 'OSPAR Convention') pointed out that " $\mathrm{CO}_{2}$ can be only stored in accordance with an authorisation or permit given by the Party's competent authority" [136]. Thus, the uncertainties associated with the oceanic sequestration and its environmental aspects need to be evaluated and possible mitigation strategies should be specified.

The main key parameters that can be used to evaluate the efficiency of oceanic sequestration are injection depth, residence time (time-scale at which the stored $\mathrm{CO}_{2}$ returns to atmosphere), and the distribution of $\mathrm{CO}_{2}$ concentration. $\mathrm{Xu}$ et al. [137] studied the potential of storing $\mathrm{CO}_{2}$ in the North Pacific by developing a regional ocean general circulation model with different parameters of sub-grid mesoscale mixing, and assuming a zero air-sea $\mathrm{CO}_{2}$ exchange. Their results showed that the storage depth is one of the key parameters for isolating the stored $\mathrm{CO}_{2}$ and minimising its return to the atmosphere. It was determined that to store $\mathrm{CO}_{2}$ in the ocean over a few hundred years, an injection depth of over $1000 \mathrm{~m}$ is necessary. In addition, it was revealed that after 50 years of continuous $\mathrm{CO}_{2}$ injection (at different locations and a maximum depth of $5750 \mathrm{~m}$ ) more than $10 \%$ of dissolved $\mathrm{CO}_{2}$ would return to the atmosphere, which can be considered as a source of leakage. Hill et al. [138] evaluated the storage efficiency by means of mean residence time for impulse injections based on several scenarios, using an ocean circulation model. It was found that the North Atlantic is more efficient for sequestration of $\mathrm{CO}_{2}$ over timescales of several hundred years and longer, while the Pacific basin is more efficient for shorter timescales. It should be noted that this study was based on relatively small magnitudes and the effect of air-sea $\mathrm{CO}_{2}$ exchange was neglected; however, for large boundaries, the significance of this effect is unknown and needs to be investigated.

The distribution of $\mathrm{CO}_{2}$ concentration after injection can be used to assess the sequestration site selection. The ideal site is referred to where the $\mathrm{CO}_{2}$ is efficiently diluted and has the least negative impact on biota. Masuda et al. [139] studied the local distribution of $\mathrm{CO}_{2}$ concentration as a function of injection rate and eddy activity distribution, by simulating $\mathrm{CO}_{2}$ injection into several sites around Japan using an oceanic general circulation model. It was revealed that the maximum concentration of $\mathrm{CO}_{2}$ can differ by a factor of 10 amongst sites, and this discrepancy is mainly attributed to the local distribution of eddy activity. Further, it was determined that no chronic impact on biota would be caused if injection rates are limited to $20 \mathrm{Mt} / \mathrm{a}$. 
According to aforementioned discussions, there are several improvements and uncertainties that need to be considered and addressed in future research in order to enhance the evaluation of oceanic sequestration, including: (i) improving the current numerical model by including an air-sea $\mathrm{CO}_{2}$ exchange mechanism for better evaluation of storage efficiency; (ii) further investigating the determination and quantification of ocean site selection criteria; and (iii) further quantification and demonstration of the viability of transporting large amounts of $\mathrm{CO}_{2}$ in the Pacific Ocean.

\subsection{Mineral Carbonation}

The concept of $\mathrm{CO}_{2}$ mineral carbonation (mineralisation) as an alternative $\mathrm{CO}_{2}$ sequestration strategy was first proposed by Seifritz [113]. In this method, the captured $\mathrm{CO}_{2}$ is sequestered through the process of mineralisation where $\mathrm{CO}_{2}$ is reacted with alkaline earth metal oxides or hydroxides, such as calcium- and magnesium-rich minerals to produce stable carbonates, Eq. (1) and (2).

$$
\begin{aligned}
\mathrm{CaO}_{(\mathrm{s})}+\mathrm{CO}_{2(\mathrm{~s})} & \rightarrow \mathrm{CaCO}_{3(\mathrm{~s})}, \quad \Delta \mathrm{H}=-179 \mathrm{~kJ} \cdot \mathrm{mol}^{-1} \\
\mathrm{MgO}_{(\mathrm{s})}+\mathrm{CO}_{2(\mathrm{~s})} & \rightarrow \mathrm{MgCO}_{3(\mathrm{~s})}, \quad \Delta \mathrm{H}=-118 \mathrm{~kJ} \cdot \mathrm{mol}^{-1}
\end{aligned}
$$

There are two methods of mineral carbonation: in-situ and ex-situ. The in-situ method involves the production of carbonates through the injection of $\mathrm{CO}_{2}$ into a geologic formation, while the ex-situ method is carried out above ground in an industrial plant using previously mined or local rock $[140,141]$. In-situ mineral carbonation would typically be considered in basalts or ophiolite rocks which are enriched in magnesium, iron, and calcium silicates [140]. Major advantages for the in-situ mineral carbonation method stem from the fact that no extensive mining is needed as only a few boreholes are required for the process. On the other hand, there can be major uncertainties such as lack of geological characteristics or unknown caprock or seal potential. In addition, geochemical reactions may act to reduce reactivity, porosity, and permeability, which in turn can cause lining of the initially formed flow paths. Ex-situ mineral carbonation can be done through either direct (gas- and aqueous-based) or indirect processes. In the direct gas-based method, gaseous $\mathrm{CO}_{2}$ is reacted with minerals to produce carbonates $[142,143]$. The gas-solid carbonation reaction typically takes place at temperatures below $650^{\circ} \mathrm{C}[113,144,145]$, and the main limiting factors are the reaction rate and rock storage capacity. In the direct aqueous-based method, $\mathrm{CO}_{2}$ is reacted with minerals in the presence of an aqueous solution, usually taking place in a single step [142]. Sanna et al. [140], Olajire [146] 
and Bobicki et al. [142] reported that constraints like mineral dissolution, $\mathrm{CO}_{2}$ dissolution, and product layer diffusion are the main factors that make direct mineral carbonation less viable for commercial deployment and development.

Matter and Kelemen [147] studied permanent $\mathrm{CO}_{2}$ storage in geological reservoirs by mineral carbonation using natural analogues. Results from their study showed that the rate of mineralisation is high in host rocks rich in magnesium- and calcium-bearing minerals. Their results also showed that precipitation of carbonate minerals can clog pre-existing voids, although stress induced by rapid precipitation may also lead to fracturing and increased pore volume. The local environment may also be affected through mining, as certain types of calcium- and magnesium-rich mineral deposits may contain asbestiform phases and other health-depleting impurities [5].

Although magnesia $(\mathrm{MgO})$ and lime $(\mathrm{CaO})$ are the most naturally abundant alkali and alkaline earth metal oxides, they do not exist as binary oxides in nature and are usually bonded up as silicate, such as serpentine [18]. Cipolli et al. [148] and Bruni et al. [149] studied $\mathrm{CO}_{2}$ interactions with serpentine from spring waters in Genova (Italy). After geochemical analysis of the high-pH waters from serpentinites and reaction path modelling for sequestration in aquifers containing serpentinites, Cipolli et al. [148] confirmed that the progressive reaction of ultramafic rocks with meteoric waters is affected by serpentinisation. This initially led to the formation of $\mathrm{MgHCO}_{3}$ waters when the system is exposed to $\mathrm{CO}_{2}$ and subsequently the formation of $\mathrm{Na}-\mathrm{HCO}_{3}$ and $\mathrm{Ca}-\mathrm{OH}$ type waters upon further interaction with the host rock under highly reducing closed-system conditions. After simulating high-pressure $\mathrm{CO}_{2}$ injection into deep aquifers by reaction path modelling, their results indicated that serpentinites have good capacity for $\mathrm{CO}_{2}$ sequestration, mainly because of the formation of carbonate minerals. It should be noted that this process caused a reduction in porosity of the aquifer under closed system conditions. This suggests that such implications need to be carefully evaluated by further field and laboratory tests.

From a survey of spring waters in the Genova province using irreversible water-rock mass transfer, Bruni et al. [149] reported that many neutral $\mathrm{Mg}-\mathrm{HCO}_{3}$ and some high-pH Ca-OH waters were found to be associated with serpentinites. They explored the viability of using serpentinite dissolution and calcite precipitation under open- and closed-system conditions for long-term $\mathrm{CO}_{2}$ sequestration. From their study, the interaction of these waters, which are of 
meteoric origin (as indicated by stable isotopes of water and dissolved $\mathrm{N}_{2}$ and Ar), show a progressive evolution in chemistry of the aqueous phase from immature magnesium-rich, $\mathrm{SO}_{4} \mathrm{Cl}$ facies of low salinity to intermediate $\mathrm{Mg}-\mathrm{HCO}_{3}$ facies and to some mature $\mathrm{Ca}-\mathrm{OH}$ facies. Further, the high-pH Ca-OH water can absorb $\mathrm{CO}_{2}$ and form calcite deposits, suggesting that the process can be utilised for the sequestration of anthropogenic $\mathrm{CO}_{2}$.

On the other hand, the less attractive aspects of mineral carbonation are the potential environmental and human concerns. Mineral carbonation processes have the potential for terrain alteration through large-scale mining operations, and subsequent disposal of the reacted materials. In addition, certain types of calcium- and magnesium-rich mineral deposits may contain asbestiform phases and other health-depleting impurities [5].

According to the reviewed literature, future studies, that potentially help to evaluate the viability of $\mathrm{CO}_{2}$ sequestration by mineral carbonation, can be focused on: (i) mineral carbonation with respect to mineral and $\mathrm{CO}_{2}$ dissolution; (ii) product layer diffusion; (iii) the possibility of less terrain alteration; and (iv) handling mineral impurities in the sequestration process.

\section{$3 \mathrm{CO}_{2}$ Storage Site Evaluation Criteria}

Before the deployment of storage technology, it is important to identify key storage site evaluation criteria that allow assessing whether the technology is credible, safe, reliable, trustworthy, environmentally benign, and economically viable. This is especially important if the ethics management mechanisms are not established. The identification of key evaluation criteria and recommendations in the site evaluation process should provide clear inputs for costs-risks-investment business decisions [150]. Studies on site-selection and -evaluation criteria for $\mathrm{CO}_{2}$ storage in geological formations have highlighted that the main criteria to be considered are geological, geothermal, geohazards, hydrodynamic, hydrocarbon potential and basin maturity, and economic, societal, and environmental issues [36,151-156].

\subsection{Geological Factors}

The most suitable $\mathrm{CO}_{2}$ storage strategy has been currently attributed to sedimentary basins, where sedimentary rocks, containing appropriate porosity and permeability, are often located at or near to power stations and energy-intensive industries [157]. This implies the importance of the distance between point sources of $\mathrm{CO}_{2}$ and storage sites, in order to minimise the cost of 
transportation. Thus, for point sources of $\mathrm{CO}_{2}$ that are not located close to ideal sedimentary formations, the high cost of transportation can be avoided by selecting an alternative storage option.

The key geological parameters for storage site evaluation are aquifer properties such as reservoir volume/porosity/permeability, pressure and temperature, sweep efficiency (which is a function of heterogeneity of formation), caprock permeability, entry and fracture pressures, quantities of reactive minerals, thickness of formation for $\mathrm{CO}_{2}$ injection, $\mathrm{CO}_{2}$ solubility in saline water, potential for seismogenic faults, and stress regime. Injectivity is another factor that is used to evaluate both the economic and technical suitability of a storage site, and enhance the security of storage $[152,153]$. Injectivity itself is a function of several parameters such as vertical and horizontal permeability, rock compressibility, effective thickness, reservoir heterogeneity, reservoir and fracture pressures, and depth of injection [152].

The Bunter Sandstone formation in the UK's southern North Sea is a specific case where detailed $\mathrm{CO}_{2}$ containment studies were conducted on both reservoir storage capacity and caprock integrity. Heinemann et al. [72] numerically simulated the injection of $\mathrm{CO}_{2}$ into the formation over a period of 30 years and at a rate of $1 \mathrm{Mt} / \mathrm{a}$ of $\mathrm{CO}_{2}$ for each well. They reported that since there are few producing fields, information about reservoir and caprock is sparse, but can be evaluated through legacy borehole records which were targeting deeper horizons. They found that approximately 3.8-7.8 Gt of $\mathrm{CO}_{2}$ can be stored in the reservoir, depending on the maximum safe pressure of injection, and the seal is capable of effectively retaining $\mathrm{CO}_{2}$.

Geological site assessment can be further improved upon using systematic, yet generally accepted approaches that consider and focus on injection capacity and risks of containment. A possible way to achieve these improvements is to adopt experiences from the oil and gas industry, especially by utilising numerical models that can quantify the roles of dominant $\mathrm{CO}_{2}$ trapping mechanisms for basins. In addition, there are only a few studies on geophysical and geochemical risk assessments that are prerequisites to induced seismicity and potential leakage and, thus, learn-by-doing methods [42] should also be considered in future studies.

\subsection{Geothermal Gradient}

With regard to the critical point of $\mathrm{CO}_{2}\left(7.38 \mathrm{MPa}\right.$ and $31.1^{\circ} \mathrm{C}$, equivalent to a hydrostatic head of $738 \mathrm{~m}$ ) a slight variation in geothermal gradient by depth can cause $\mathrm{CO}_{2}$ to enter supercritical 
conditions. Assuming the pressure distribution within a sedimentary basin is hydrostatic, the associated minimum threshold depth for injecting $\mathrm{CO}_{2}$ in the supercritical state at a geothermal gradient of $30^{\circ} \mathrm{C} / \mathrm{km}$ and surface temperature of $10^{\circ} \mathrm{C}$ is around $800 \mathrm{~m}[158,159]$, Figure 4 . Nevertheless, hydrodynamic and geothermal conditions are not always constant across all basins, and for the same basin, are not the same from place to place. The limiting factors for geothermal regime in any sedimentary basin may include: (i) basin type, age and tectonism; (ii) basement heat flow, (iii) thermal conductivity and heat production in the sedimentary succession, and (iv) temperature at the top of the sedimentary succession. For ECBM projects, the minimum depth can be $<800 \mathrm{~m}$ only if $\mathrm{CO}_{2}$ is adsorbed by coal. A pilot $\mathrm{CO}_{2}$ storage experiment at depth $<800 \mathrm{~m}$ is the Ketzin Project [160]. However, this project did not receive positive public acceptance due to concerns on the possibility of leakage [161].

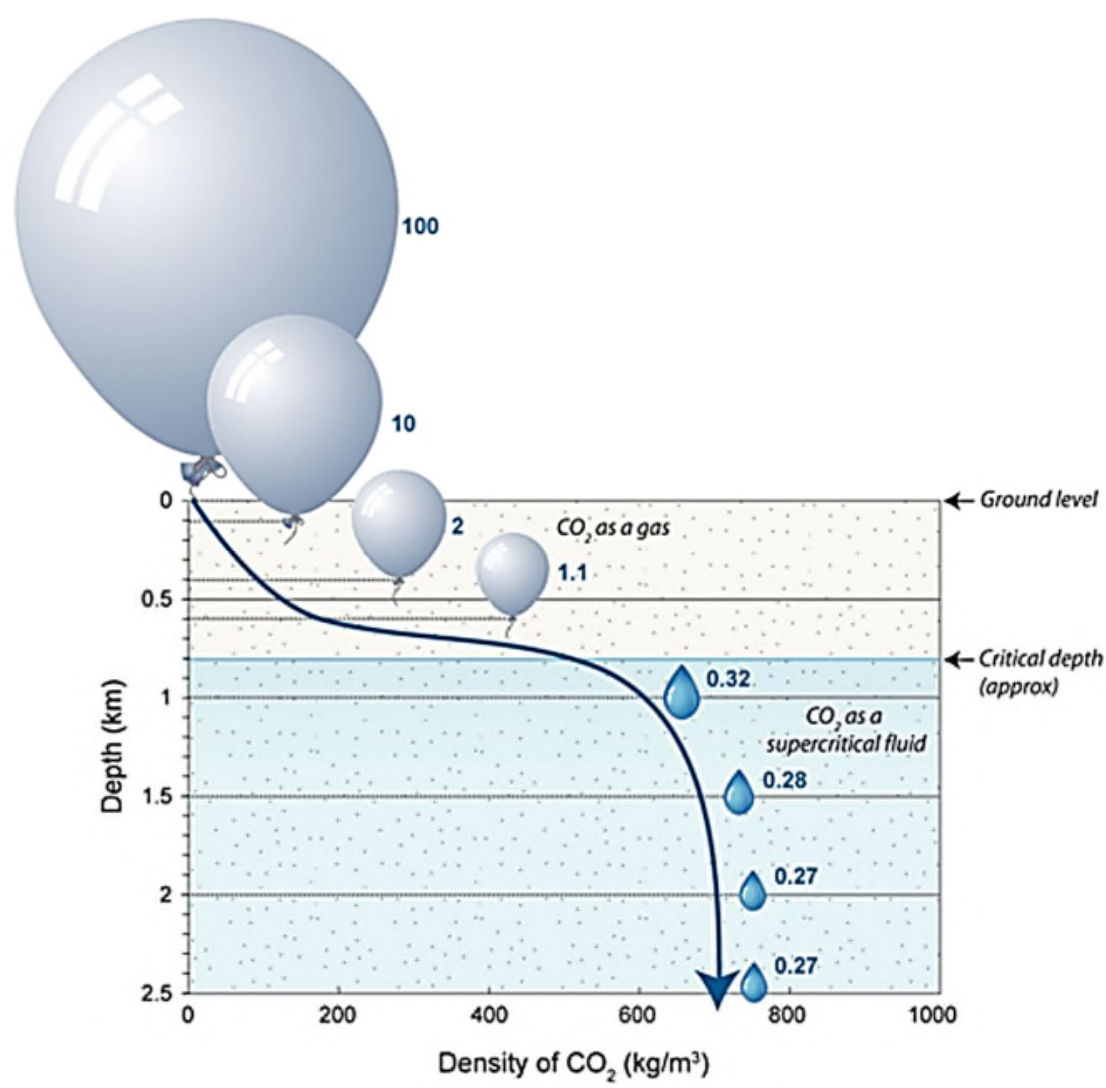

Figure 4: Relative volumes of $\mathrm{CO}_{2}$ stored underground as a function of depth in storage reservoirs [162]. Note: Blue numbers in this figure represent relative volume of $\mathrm{CO}_{2}$ at each depth. 


\subsection{Geohazards}

Geohazards are attributed to the short- and long-term geological and environmental conditions that can potentially cause widespread damage to storage systems, and are necessary to be appraised as part of storage site selection criteria. Accordingly, for effective $\mathrm{CO}_{2}$ containment after injection, geologically hazardous areas should be avoided. For storage systems, the geohazards are mainly associated with seismicity, landslides and volcanic activity. In a study on the geo-database of caprock quality and the distributions of deep saline aquifers for geological $\mathrm{CO}_{2}$ storage in Italy by Buttinelli et al. [57], it was highlighted that shallow and deep seismicity, magmatism, presence of degassing structures and anomalous thermal flux, are some geodynamical domains that can negatively affect storage systems. They identified the primary geological risks that are needed to account for selection of a potential injection structure, namely: (i) seismogenic sources and areas, as identified through geophysical and geological studies; (ii) historical and recent distribution of seismic events; and (iii) natural diffuse degassing structures. This study can be used as a benchmark for identification of local geohazards.

\subsection{Hydrodynamic Factors}

The hydrodynamic regime of formation water (including local pressure, salinity, and flow velocity) is very crucial for $\mathrm{CO}_{2}$ storage, especially when injection is done in depleted oil and gas reservoirs [36], where the movement of $\mathrm{CO}_{2}$ plume within the reservoir is influenced by hydrodynamic trapping. There is a close relationship between basin type and formation water flows. For example, in intracratonic and foreland basins which have undergone some uplift and erosion, the formation water flow is affected by lateral and vertical erosional rebound. This can make aquifers significantly under-pressured [163], as was seen in the Alberta basin in Canada [164]. Under-pressurised formations are the best for geological confinement and storage of $\mathrm{CO}_{2}$ as they have a greater ability to cope with increasing pressure during injection operations. The role of faults in hydrodynamic regime and their permeability structure are still to be evaluated as a consequence of sealing processes inside the fault bodies [165].

\subsection{Hydrocarbon Potential and Basin Maturity}

In basins with limited or no known resource potential (such as hydrocarbon reservoirs) [166], there are several reasons that may constrain $\mathrm{CO}_{2}$ storage, namely because [36]: (i) most of the hydrocarbon resources are still undiscovered, thus there is concern about likelihood of 
contamination; (ii) being immature with respect to development means there are no depleted oil and gas reservoirs yet; and (iii) limited exploration means the geology and hydrogeology of basins are not understood. Certainly, since occurrence of energy reserves in such basins is not identified, it is not practical to proceed based on $\mathrm{CO}_{2}$ storage in oil and gas formations (both for EOR and permanent storage). However, since there is still the possibility of having deep saline aquifers in such basins, storage may still be feasible only after evaluating detailed environmental and economic considerations [36]. For basins with relatively recent geological history and known hydrocarbon potentials that are still under exploration and production, contamination of hydrocarbons with $\mathrm{CO}_{2}$-related impurities are the main source of concern that must be addressed before technology deployment. This also involves the early stages of primary production in $\mathrm{CO}_{2}$-EOR. For basins which are either under development stage or for which limited exploration data exist, the lack of in-depth subsurface information is a limiting factor for storage site evaluation. Nevertheless, for all cases, 3D geophysical and geochemical modelling can improve the limited knowledge of such basins. On the other hand, $\mathrm{CO}_{2}$ storage in mature basins is highly applicable for several reasons, including availability of ample data on the geothermal regime, hydrocarbon reserves, and coal beds [36].

The extent of basin development is another important factor that should be considered for site selection, given that many of the factors that make a reservoir suitable for an oil/gas reservoir also make it suitable for $\mathrm{CO}_{2}$ storage. Strategic planning is also required to ensure that hydrocarbon extraction operations and $\mathrm{CO}_{2}$ storage operations do not interfere with each other. For a well-explored basin with hydrocarbon potential, significant information exists on the rocks, reducing geological uncertainty. The presence of oil/gas may also allow for $\mathrm{CO}_{2}$ EOR/EGR, and this may help reduce the cost of $\mathrm{CO}_{2}$ storage. However, the presence of potentially thousands of hydrocarbon wells (some possibly several decades old), may increase uncertainties in long-term storage due to a greater potential for borehole-related $\mathrm{CO}_{2}$ leakage.

\subsection{Economic, Societal and Environmental Issues}

Economic considerations in $\mathrm{CO}_{2}$ geological storage usually revolve around existing or required infrastructure, and are dependent on ongoing climate change policy. In mature continental basins, the infrastructure such as pipelines, wells, and access roads may already be in place. In immature basins, infrastructure may be either missing or very limited [36]. In offshore basins, a major challenge is that $\mathrm{CO}_{2}$ injection and storage may be very expensive, due to the necessity 
for construction of new infrastructure, including long pipeline routes. Therefore, a specific mandatory carbon tax might be considered, such as the one for features, events and processes (FEPs). However, it is important that the development of infrastructure and regulatory models for $\mathrm{CO}_{2}$ storage should reflect expectations and attract government attention, while not compromising storage security and its impact on the environment. Achieving these key purposes is crucial for storage economics, since meeting technology deployment capable of substantially reducing anthropogenic $\mathrm{CO}_{2}$ would greatly depend on decades of extensive investments.

Many suitable sedimentary basins for $\mathrm{CO}_{2}$ storage are in developing countries (e.g., India and Nigeria). In the majority of developing countries, the top priority in development targets is to increase the living standards of their population, which may be rated higher than climate change and deployment of CCS $[36,167]$. This can imply that $\mathrm{CO}_{2}$ storage in geological media may be economically more acceptable in developed countries such as those in North America and Europe [36]. In addition, the distribution of cities and natural resources, such as coal and oil/gas, are some aspects of environmental monitoring and ethics management that can affect the deployment of $\mathrm{CO}_{2}$ storage. Development of storage projects in heavily-farmed areas can lead to challenges such as land access and right-of-way for facilities, which need to be considered during site characterisation activities. In addition, $\mathrm{CO}_{2}$ storage can potentially influence the quality of natural resources such as oil and gas, metals and non-metals [152]. Therefore, it is important to consider preliminary regional planning on synergic and conflicting subjects of concern.

A substantial reduction in anthropogenic $\mathrm{CO}_{2}$ can only be achieved if the majority of countries, including developing countries, participate in the implementation of $\mathrm{CO}_{2}$ storage technology soon. Thus, it is important for stakeholders in the CCS industry to embark on technology transfer to build national capability. The awareness campaigns need to highlight the global importance of storage deployment for the local public. Furthermore, $\mathrm{CO}_{2}$ storage should be promoted as an environmentally benign activity, and as a measure to address the environmental problems of communities.

In summary, the associated factors for assessment of storage site selection were discussed. A combination of these factors determines the feasibility of a potential storage site. Although the aforementioned principal factors need to be considered for evaluation of storage sites, there 
may be additional aspects which are specific to particular storage sites. These additional factors can include (but are not limited to): (i) size and nature of site for potential future expansion; (ii) political aspects, such as the possibility of future regional development plans; and (iii) cultural heritage aspects, such as the existence of Native Title Claims where a person or a group may claim that they hold rights and interests in a given land or area according to traditional customs and laws.

\section{$4 \mathrm{CO}_{2}$ in the Reservoir}

The candidate technology for development of $\mathrm{CO}_{2}$ storage in the subsurface should potentially assure a minimum residence time of 1000 years and a leakage rate of less than $0.1 \%$ per year [5]. Therefore, one of the most important aspects of $\mathrm{CO}_{2}$ storage is to have a clear understanding of the mid- to long-term behaviour of $\mathrm{CO}_{2}$ in the reservoir. The $\mathrm{CO}_{2}$ behaviour in the reservoir is a complex process (Figure 5) which depends on a variety of components within the reservoir system, including geochemistry, mineralogy, fractures, pore fluid dynamics, and variation in geochemical effects such as dissolution and precipitation of minerals $[30,168]$, and can continue for thousands of years, until the stored $\mathrm{CO}_{2}$ is immobilised as solid carbonate precipitates. There are several factors that influence containment of $\mathrm{CO}_{2}$ within the reservoir, including $\mathrm{CO}_{2}$-rock interaction, induced seismicity during the injection, and the potential risk of leakage that will be comprehensively discussed in this section. In addition, accurate estimation of reservoir storage capacity is one of the key prerequisite parameters for evaluating the suitability of a storage site, and will be covered in this section.

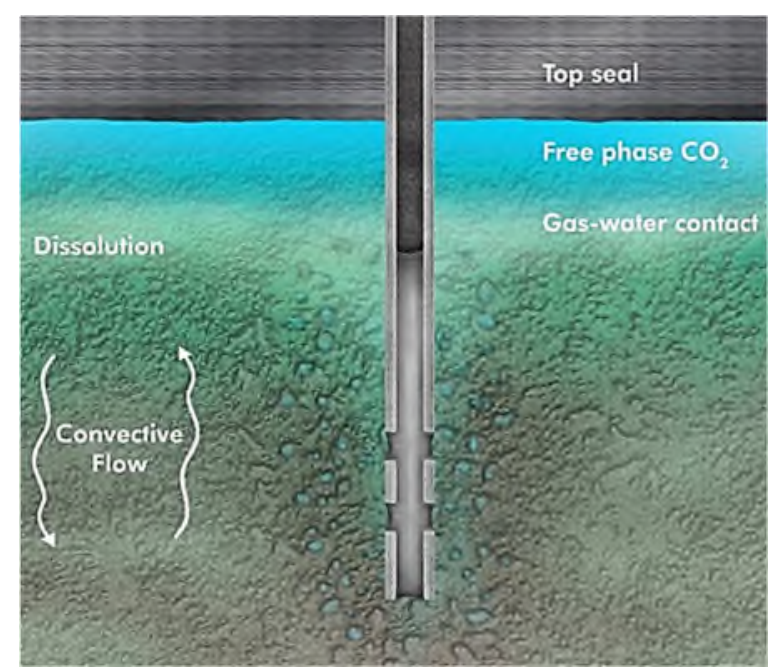

Figure 5: Post-injection dispersion of $\mathrm{CO}_{2}$ in the reservoir [169]. 


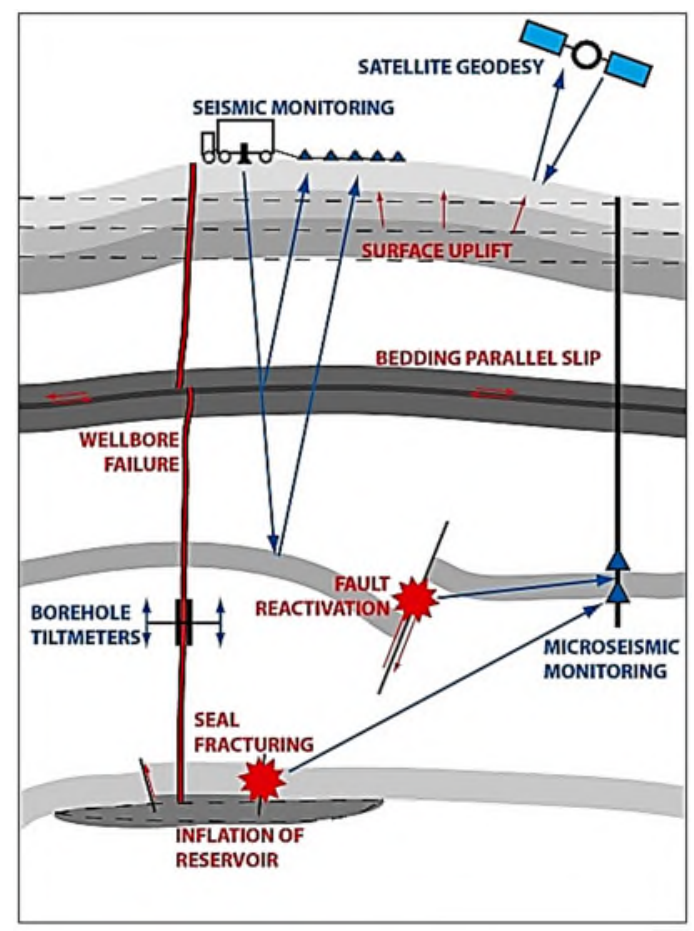

Figure 6: Schematic description of geomechanical deformation in $\mathrm{CO}_{2}$ storage sites (in red text) with potential monitoring options (blue text), (reprinted with permission from Verdon et al. [176], Copyright 2017 Proceedings of the National Academy of Sciences).

\section{1 $\mathrm{CO}_{2}$ Natural Analogue}

$\mathrm{CO}_{2}$ analogue cases can be used to advance our understanding of the behaviour of $\mathrm{CO}_{2}$ in reservoirs, and to further improve reservoir management strategies [165,170,171]. Much research has been conducted on different aspects of $\mathrm{CO}_{2}$ analogues by means of $\mathrm{CO}_{2}$ storage, including natural accumulations [172], gas migration along fault systems [173], $\mathrm{CO}_{2}$ leakage [170], seal efficiency [165,174], and storage security in natural reservoirs [175]. In many natural analogues, where the $\mathrm{CO}_{2}$ is ultimately generated from volcanic and mafic processes, and sometimes from the mantle [165,174], some seals have been capable of securely trapping $\mathrm{CO}_{2}$ for up to several million years in sedimentary formations. Whilst the mode of formation of these $\mathrm{CO}_{2}$ analogues may differ from that in a $\mathrm{CO}_{2}$ storage project, many of their features are analogous to man-made storage schemes, which implies the feasibility of long-term $\mathrm{CO}_{2}$ storage [171].

Pearce et al. [172] reported that natural $\mathrm{CO}_{2}$ accumulations occur in many basins across Europe, suggesting that it is possible to identify the potential $\mathrm{CO}_{2}$ leaks and to predict the long- 
term geomechanical and geochemical behaviour of a storage site, Figure 6. They found that although volcanic activity and seismically active areas allow $\mathrm{CO}_{2}$-rich fluids to migrate to the surface, stratigraphic traps allow accumulation of $\mathrm{CO}_{2}$ below limestone, evaporites, and mudstone caprocks. In areas where reactivation of fractures allows migration of $\mathrm{CO}_{2}$-rich fluids, some degree of limited self-healing may occur through calcite precipitation. In addition, a comparative study between reservoir sandstone and equivalent formations nearby indicated that feldspar dissolution in reservoir sandstones can potentially increase the secondary porosity [172]. Annunziatellis et al. [173] studied gas migration along fault systems and through the vadose zone in the Latera caldera of central Italy, by integrating near-surface gas geochemistry and structural geology surveys, to understand the migration behaviour of $\mathrm{CO}_{2}$. Their results revealed the pattern of gas migration along high-permeability pathways within faults with discharge occurring typically from spatially restricted gas vents. However, the distribution, size and strength of vents seemed to be controlled by both the evolution and deformation style of the fault, which in turn is associated with rheology of lithological units cut by fault. It implies that the gas migration may be changed drastically along a strike.

Jeandel et al. [177] reported the lessons learned from natural and industrial analogues for storage of $\mathrm{CO}_{2}$. Initially, they sampled gases from natural analogues in the Colorado Plateau and the French carbo-gaseous provinces from both leaking and well-confined sites. Furthermore, they performed a tracing study for two years on subsurface natural gas storage. It was pointed out that since in natural analogues, geochemical fingerprints depend on geological context and containment criteria, these analogues are sufficient tools for the detection of deeply-seated $\mathrm{CO}_{2}$ toward the surface.

Quattrocchi et al. [170] conducted research on strategic $\mathrm{CO}_{2}$ natural analogues from slightly anomalous leakage of $\mathrm{CO}_{2}, \mathrm{CH}_{4}$ and radon along the main activated faults of the strong L'Aquila earthquake (magnitude 6.3, Italy), using soil gas survey and groundwater sampling approaches. Their study also highlighted the implications for risk assessment monitoring tools and public acceptance of $\mathrm{CO}_{2}$ and $\mathrm{CH}_{4}$ underground storage. It was revealed that the geochemical measurements from soils can be successfully used for discrimination of activated seismogenic segments. In addition, it was highlighted that the geochemical anomalies are not deleterious to human health. Therefore, there is no associated concern with the $\mathrm{CO}_{2}-\mathrm{CH}_{4}$ explosion during the recurrence of strong earthquakes (such as L'Aquila), where gases are 
stored naturally in the subsurface at a depth of 1-2 km. A comprehensive natural $\mathrm{CO}_{2}$ reservoir dataset, consisting of $76 \mathrm{CO}_{2}$ natural analogues around the world, was developed by Miocic et al. [175]. Their analysis highlighted that the key controlling factors for successful retention of $\mathrm{CO}_{2}$ are thick and multiple caprock, dense $\mathrm{CO}_{2}$ phase, and a minimum reservoir depth of 1200 $\mathrm{m}$. In addition, although the faults can securely isolate $\mathrm{CO}_{2}$, it is important to fully characterise the sealing ability of faults during the storage site assessment.

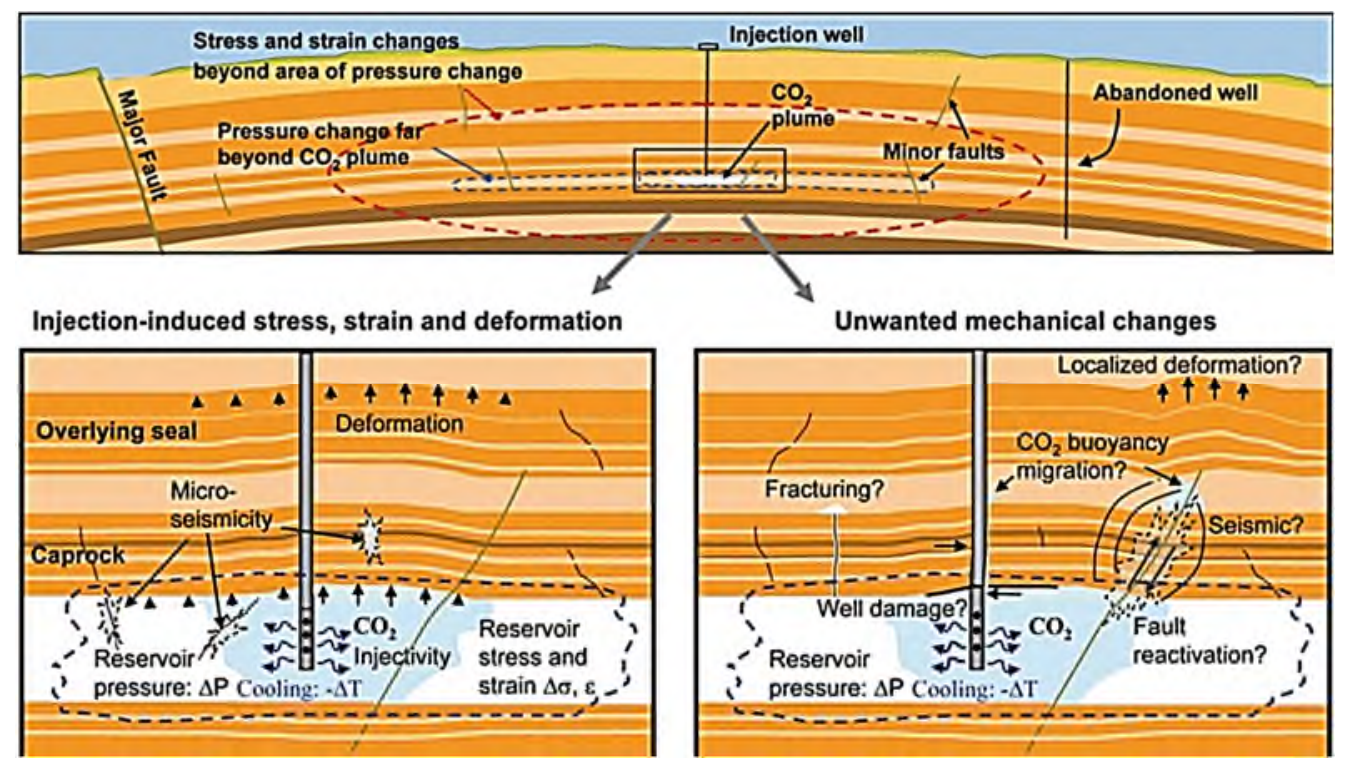

Figure 7: Some geomechanical processes and key technical issues with geological carbon storage in sedimentary formations (reprinted with permission from Rutqvist [178], Copyright 2017, Springer).

\subsection{Induced Seismicity}

Extensive injection experience in oil and gas operations has demonstrated that $\mathrm{CO}_{2}$ injection procedures must be carefully monitored, otherwise undesirable side effects can be caused. These include both short-term (such as induced seismicity) and long-term geomechanical effects (Figure 7), that in turn may affect the caprock integrity (as the seal) and, consequently efficiency of storage $[179,180]$. The $\mathrm{CO}_{2}$ injection can potentially affect subsurface stress and lead to changes in in-situ fluid pressure and induced seismicity [181]. Fluid pressures are known to play a key role in seismicity, as pore pressures act against tectonic and gravitational forces. Thus, excessive increase in fluid pressures may cause rock failure, and consequently induced seismicity [182]. Induced seismicity is also associated with hydraulic fracturing when a rock is fractured purposely by injection of water at high pressures to increase permeability of 
reservoirs such as in enhanced geothermal activities or shale gas production, and the disposal of oilfield waste fluids.

Nevertheless, there may be some similarities in seismicity induced by $\mathrm{CO}_{2}$ and by water [183186]. It is reported that there were similar rates and magnitudes of induced seismicity between the two fluids; however, there is a difference when fluid is injected into low or high pressure. Verdon et al. [185] suggested that since the viscosity and bulk modulus of $\mathrm{CO}_{2}$ are lower than water, induced seismicity is less likely to occur. Although from a geomechanical outlook, the key factor that leads to fault reactivation is change in the stress acting on the fault, which is influenced mainly by pore pressure changes caused by injection. Thus, it confirms that the increase in pore pressure across a reservoir is predominantly determined by pore volume occupied by the injected fluid.

The potential risk of induced seismicity caused by $\mathrm{CO}_{2}$ injection has been outlined above. Accordingly, the following mitigation strategies can be considered [187]: (i) selection of sites with high porosity and permeability, (ii) estimating stress state of potential sites, (iii) selecting sites which are associated with no evidence of faulting, and (iv) selection of sites in regions with low rates of natural seismic activity.

\subsection{Leakage Pathways}

In an ideal storage site, $\mathrm{CO}_{2}$ will be permanently confined to its host formation. However, in the unlikely event of migration and leakage, there are various potential modes in which $\mathrm{CO}_{2}$ can escape from the storage formation. Leakage pathways for $\mathrm{CO}_{2}$ can correspond to well leakage, diffusive loss, induced migration by capillary pressure, and escape through faults and fracture networks. However, it should be mentioned that there has been no report that proves noticeable leakage of $\mathrm{CO}_{2}$ from any known storage sites.

\subsubsection{Well Leakage and Abandoned Orphaned Wells}

Leakage of buoyant $\mathrm{CO}_{2}$ up the wells is possible when the integrity of the well plug or caprockcement seal is compromised $[29,188,189]$. Therefore, the presence of high-quality well sealing (and eventual plugging) is a pre-requisite for both hydrocarbon exploration and production, and for $\mathrm{CO}_{2}$ storage [190]. The American Petroleum Institute (API) standardised a procedure and cement composition for well plugging in 1952. Accordingly, the wells in the United States are classified in three categories: wells not plugged with cement, wells plugged before 1952, 
and wells plugged after 1952 [191]. The wells plugged after 1952 are associated with the least potential leakage due to modern technology and strict regulation. However, the possibility of cement degradation should be considered. Slightly acidic $\mathrm{CO}_{2}$-rich brine can react with alkaline borehole cement, breaking down cement minerals, and forming carbonate minerals and silica. These reactions may be sufficient to block porosity, especially if the volume of secondary solids exceeds that of the original phases. However, if fluid flow were maintained (e.g., through a larger flow feature in a poorly-completed well), there is the possibility for dissolution of the carbonated cement. Factors such as extensive rains, temperature, cement type, rock composition, presence of aggressive impurities such as $\mathrm{H}_{2} \mathrm{~S}$ and brine concentration control the degree of reaction, and hence degree of degradation [190,191], and consequently alter the lifespan of the cements. This issue can be escalated especially for old abandoned wells.

Connell et al. [192] studied the integrity of wellbore cement in $\mathrm{CO}_{2}$ storage using core flooding experiments and simulations. Their experimental results showed that the degradation of cement occurs in two stages: the first stage is the precipitation of carbonates from various cement phases, and the second stage is erosion of cement as the calcium carbonate dissolves in formation water. It was revealed that considerable erosion can occur only when the water flow (which is under-saturated in carbonate and calcium ions) across cement dissipates the dissolved calcium carbonate. Thus, even if the bottom of a cement seal reacts initially, the reaction may soon stop if the borehole is well-sealed. On the other hand, if the seal is poor, the continuous fluid flow allows progressive reactions to increase the initial permeability. Thus, assuring the quality of the initial seal is crucial to long-term well-sealing performance. However, this is not usually the case for older infrastructure. Moreover, in some countries, there has been extensive experience in plugging $\mathrm{CO}_{2}$-leaking wells, even though it is still important to evaluate and monitor wells depending on case-specific instances [193].

Upon completion of injection and well closure, most abandoned wells are plugged such that $\mathrm{CO}_{2}$ escape is unlikely. However, abandoned wells are associated with high permeability, and there is a potential risk if the monitoring strategy is not properly deployed. The potential risk is more likely associated with abandoned orphaned wells that are no longer under jurisdiction of the operating company, and the liability is left to the state. In such events and processes, the current regulatory measures may not be adequately sufficient, which may impose a potential 
risk for security of storage [191,194]. Thus, adopting appropriate regulatory measures for abandoned orphaned wells is necessary and should be considered accordingly.

\subsubsection{Diffusion}

A gradient in $\mathrm{CO}_{2}$ concentration can cause the $\mathrm{CO}_{2}$ to migrate through and into the watersaturated pore spaces of rocks by molecular transport [25]. For an intact caprock, the $\mathrm{CO}_{2}$ transport is limited to a very slow molecular diffusion. Therefore, a very small amount of $\mathrm{CO}_{2}$ can enter the caprock, which in turn limits the reaction rate of mineralisation in the reservoir, and may potentially alter the porosity and permeability due to induced degradation. On the other hand, for the permeable host rock, the advection of flow is more dominant (at the presence of pressure gradient), meaning larger amounts of $\mathrm{CO}_{2}$ can pass through, and consequently the impact of long-term reaction and mineral trapping is significant $[195,196]$.

Wang and Peng [197] developed a numerical model to simulate the $\mathrm{CO}_{2}$-brine interaction in the fracture network, and evaluated the caprock sealing efficiency based on deformation, gas diffusion, advection and sorption of $\mathrm{CO}_{2}$. It was revealed that the diffusion process results in initial swelling and later shrinking of the shale matrix through sorption of $\mathrm{CO}_{2}$ and alters the porosity/permeability of the fracture network. However, in their model geochemical reaction kinetics were not implemented, and should be considered to further improve the accuracy of the simulations. It should be highlighted that although diffusion is an important factor when the potential leakage in $\mathrm{CO}_{2}$ storage systems is considered, the advection flow induced by temperature and pressure build-up during $\mathrm{CO}_{2}$ injection can be a source of concern [198], especially for storage systems within fractured fields [170].

\subsubsection{Capillary Leakage}

Capillary leakage is another factor by which $\mathrm{CO}_{2}$ can affect the sealing efficiency of caprock. Capillary leakage occurs when the pressure of accumulated $\mathrm{CO}_{2}$ within brine-saturated caprock exceeds the capillary entry pressure, $P_{c, \mathrm{CO}_{2}}$ (pressure required for a fluid to enter the caprock pores) [199]. Therefore, capillary entry pressure is the maximum permitted overpressure, and should be considered as a measure for sealing efficiency of the caprock. Capillary entry pressure is a function of brine $/ \mathrm{CO}_{2}$ interfacial tension, $\gamma_{w, \mathrm{CO}_{2}}$, wettability of caprock (associated with contact angle, $\theta$, of brine/ $\mathrm{CO}_{2} /$ mineral system), and pore size, $R_{\text {pore }}$, within 
caprock, Eq. (3). Thus, any change in these parameters can alter the capillary pressure and may consequently affect the sealing efficiency.

$$
P_{c, \mathrm{CO}_{2}}=\frac{2 \gamma_{w, \mathrm{CO}_{2}} \cos \theta}{R_{\text {pore }}}
$$

Caprocks undergo a change of wettability when exposed to $\mathrm{CO}_{2}$ [200-202]. Li et al. [43], Li et al. [203] and Hildenbrand et al. [204] described the relationship between sealing capacity of caprock and interfacial tension, and reported that the interfacial tension between $\mathrm{CO}_{2}$ and water is lower than that between oil and water and also much lower than that between methane and water. It implies that sealing efficiency of any given caprock should be lower with regard to $\mathrm{CO}_{2}$ than the hydrocarbons.

\subsubsection{Faults and Fracture Networks}

Pre-existing fractures and faults can serve as either fast fluid conduits (that allow flow) or flow barriers [25], and need to be regarded as a potential source of leakage. Seismogenic sources can be used as reference for evaluating the fractures and faults in seismogenic country rocks [57]. It is reported that although the potential for seismic activity is higher in locations with pre-existing faults, the stress rate of rocks can be influenced by confining pressure around the rock, or pore pressure [205]. Excessive injection rate during the injection operation can cause a local pore pressure build-up. Consequently, pre-existing fractures can be reactivated and may cause the formation of small new cracks. In addition, reactions within the caprock and reservoir system, such as mineral dissolution, may impact the sealing capacity of pre-existing faults and fractures. For example, the reactions can cause the dissolution of fracture-filling carbonate minerals, which in turn can potentially widen $\mathrm{CO}_{2}$ flow paths, and increase the permeability. Therefore, downhole pressures and $\mathrm{CO}_{2}$ injection rates should be carefully monitored during, and shortly after, active injection operations. It is also important to measure soil gas and $\mathrm{CO}_{2}$ flux above and near $\mathrm{CO}_{2}$ storage sites such as in the case of the Weyburn project [206].

It is worth noting that the anisotropic nature of fault rock permeability may cause a discrepancy in $\mathrm{CO}_{2}$ migration in different orientations. In a study by Farrell et al. [207] the anisotropic permeability values were measured parallel to fault dips and were found to be up to 10 times greater than the permeability along fault strike. Therefore, it is important to take anisotropic permeability into consideration when $\mathrm{CO}_{2}$ migration and leakage within faults and fracture 
networks are determined. In addition, the mechanism of permeability anisotropy by grain-scale deformation within the faulting is not well-quantified and needs to be highlighted.

\section{4 $\mathrm{CO}_{2}$-Brine-Rock Interaction}

Once $\mathrm{CO}_{2}$ dissolves in formation water, it forms a weak acidic solution and this initiates a cascade of geochemical reactions that may ultimately trap the $\mathrm{CO}_{2}$ as solid carbonate minerals. Initially, $\mathrm{CO}_{2}$ is trapped as dissolved species (such as $\mathrm{CO}_{2}(\mathrm{aq})$ and $\mathrm{HCO}_{3}{ }^{-}$ions). Dissolution of silicate minerals rich in $\mathrm{Ca}$ or $\mathrm{Mg}$ can release these elements into solution and, if the $\mathrm{pH}$ is high enough, can lead to the precipitation of secondary carbonate phases, trapping the $\mathrm{CO}_{2}$ in secondary minerals. The involved reaction processes have many similarities to weathering reactions (though at different pressures and temperatures).

The extent of $\mathrm{CO}_{2}$-water-rock reactions and proportion of free-phase $\mathrm{CO}_{2}$ versus dissolved $\mathrm{CO}_{2}$ versus mineralised $\mathrm{CO}_{2}$ depend on the amounts of reactive minerals in the storage formation and their rates of reaction, and will thus vary from site to site. However, also crucial is the extent to which $\mathrm{CO}_{2}$ can mix with water and rock. In terms of injection operations, this could be enhanced by varying well injection to sweep the $\mathrm{CO}_{2}$ plume through a large rock volume as much as possible. In terms of natural processes, the descent of plumes of $\mathrm{CO}_{2}$-rich pore water (denser than $\mathrm{CO}_{2}$-free pore water) would be aided by high vertical permeability and the absence of laterally-extensive permeability barriers.

$\mathrm{CO}_{2}$-brine-rock interaction enables both mineral dissolution and generation of secondary minerals. In terms of rates of dissolution/corrosion, carbonate minerals dissolve/corrode faster than feldspar, with quartz being more resistant [208]. Since $\mathrm{CO}_{2}$-brine-rock interaction affects the pore structure, it is possible that after interaction, permeability of the rock as well as displacement pressure could either increase or decrease, and this will have a consequent impact on $\mathrm{CO}_{2}$ migration rates.

The dawsonite formation during storage and its potential role in trapping $\mathrm{CO}_{2}$ in reservoirs has been controversial for more than a decade [209]. While natural occurrences in previously $\mathrm{CO}_{2-}$ charged reservoirs showed a lack of dawsonite, numerical studies revealed the possibility of large-scale storage in these reservoirs. In addition, Hellevang et al. [210] reported that based on thermodynamic calculations, dawsonite can be potentially formed at high $\mathrm{CO}_{2}$ pressure during the injection, while it is not stable once the pressure decreases upon completion of 
injection. Although exact conditions for formation of dawsonite $\left(\mathrm{CO}_{2}\right.$ pressure, temperature, alkalinity, ionic strength) are highly uncertain, experience from natural occurrences, such as in the sequences of the Songliao and Hailaer basins in China, showed that dawsonite can be formed under $\mathrm{CO}_{2}$ storage conditions. Despite the available aforementioned evidence on formation of dawsonite during $\mathrm{CO}_{2}$ storage, its formation mechanism, including nucleation (retention time) and growth rate under storage reservoir conditions are not clearly known, and should be addressed in future studies. On the other hand, the presence of $\mathrm{SO}_{2}$ or $\mathrm{H}_{2} \mathrm{~S}$ as impurities in the $\mathrm{CO}_{2}$ stream may also liberate and reduce iron from mineral grain coatings [211]. The presence of $\mathrm{Fe}^{2+}$ in solution can lead to iron-rich carbonate precipitation and enhance $\mathrm{CO}_{2}$ mineral trapping. However, the presence of such impurities in the $\mathrm{CO}_{2}$ stream can raise environmental concerns, and may not be acceptable for $\mathrm{CO}_{2}$ transport processes [212].

Several studies have investigated $\mathrm{CO}_{2}$-brine-rock interactions in the context of $\mathrm{CO}_{2}$ storage, by focusing on flood characteristics and fluid-rock interactions of different formations, including South West Hub of Western Australia [213], Lower Tuscaloosa formation (United States) [214], the Zaosie anticline reservoir, central Poland [220]; [215], and the Weyburn site (Canada) [216]. Saeedi et al. [213] investigated sandstone samples for in-situ multiphase flow characteristics using laboratory measurements. The samples were obtained from the Triassic Lesueur Sandstone (Wonnerup Member) in the South West Hub of Western Australia which is currently being considered for $\mathrm{CO}_{2}$ storage. The results showed that samples possess favourable characteristics in terms of residual capillary trapping. Although absolute gas permeability of the post- $\mathrm{CO}_{2}$-flood samples is between $25-60 \%$, this degree of permeability alteration did not significantly affect the petrophysical properties of rock. They proposed that the reduction in permeability can be attributed to formation damage by fines which originated from kaolinite particles occurring within the pore space of rock samples. Soong et al. [214] explored geochemical interactions in a static system for $\mathrm{CO}_{2}$-brine-rock similar to saline aquifers with samples from the Lower Tuscaloosa formation, Jackson County, Mississippi, United States. After continuous exposure to $\mathrm{CO}_{2}$ for six months, various analytical techniques were utilised to ascertain permeability values for the sandstone core samples before and after the exposure. Results show that the sandstone permeability decreased due to $\mathrm{CO}_{2}$ exposure, suggesting that it can have implications for long-term reservoir behaviour. Tarkowski et al. [215] also performed petrophysical analysis through $\mathrm{CO}_{2}$-brine-rock interaction experiments using samples from the potential Zaosie anticline reservoir in central Poland. The objective of 
their study was to determine any induced changes in reservoir rock properties and sealing rocks. In-situ conditions were used to test the samples, and to characterise them by means of specific surface area, porosity, pore size and distribution. It was revealed that both rock matrix and cements were partially dissolved; however, reservoir rock properties did not change significantly, and it had a negligible effect on $\mathrm{CO}_{2}$ storage.

Cantucci [216] performed geochemical modelling of water-rock interaction to evaluate effects of short- and medium-term disposal of $\mathrm{CO}_{2}$ in deep geological formations, based on the Weyburn (Canada) site case. Results show that after 100 years of injection, $\mathrm{CO}_{2}$ can be neutralised by solubility (as $\mathrm{CO}_{2}(\mathrm{aq})$ ) and mineral trapping through precipitation of dawsonite. Liu et al. [26] also tested $\mathrm{CO}_{2}$-brine-caprock interaction to assess the long-term security of stored $\mathrm{CO}_{2}$ in deep geological reservoirs in the Eau Claire formation (United States). They carried out batch experiments of the caprock in brine at $200{ }^{\circ} \mathrm{C}$ and 300 bar to test the extent of fluid-rock reactions. The results showed minor dissolution of anhydrite and K-feldspar, and precipitation (pore-filling and pore-bridging) of clay minerals (smectite and/or illite) and siderite in the vicinity of pyrite.

The $\mathrm{CO}_{2}$-brine-rock interaction in deep coal seams was numerically and experimentally studied by Wang et al. [217]. Their leachate chemistry analysis showed significant mobilisation of major elements because of dissolution of silicate and carbonate minerals in the coal measure strata. For lithic sandstone (after reaction with $\mathrm{CO}_{2}$-brine and $\mathrm{CO}_{2}$-free brine), the amounts of quartz, plagioclase, chlorite and illite increased considerably, whereas the amounts of biotite, kaolinite, illite/smectite decreased. However, calcareous mudstone (reacted with $\mathrm{CO}_{2}$-brine and $\mathrm{CO}_{2}$-free brine) showed major alteration of minerals after 12 days of treatment. In addition, it was revealed that $\mathrm{CO}_{2}$ was permanently trapped as dolomite and siderite. Although their geochemical simulation can indicate the dissolution and precipitation of mineral to some extent, the results did not agree well with experiments. It was suggested that a better prediction can be achieved by further implementing and improving the effect of fluid flow, geochemical reactions and geomechanics in the model.

\section{5 $\mathrm{CO}_{2}$ Storage Capacity Estimation}

Estimation of the $\mathrm{CO}_{2}$ storage capacity in potential geological formations is one of the main prerequisites that assures effective and safe implementation of CCS. Several authors have either outlined or deployed various methods for the estimation of storage capacity [16,57- 
59,62,218-224]. The strategies for estimation of capture capacity can be classified into static and dynamic approaches. The static methods use volumetric and compressibility-based algorithms. On the other hand, the dynamic methods are based on transient numerical or analytical models and are used for prediction of injected $\mathrm{CO}_{2}$ behaviour within the formation over a desired time period $[219,224]$ and can be used to predict and assess injectivity, wellbore pressure, and tracking of $\mathrm{CO}_{2}$ saturation within the formations during and after the injection period [225-227].

Quantification of $\mathrm{CO}_{2}$ storage capacity is mainly correlated with the type of geological formations and their associated trapping mechanisms that act over different timeframes, as well as the boundary conditions (open versus closed) [5,219,220,224]. In this section, the available methodologies for estimation of theoretical, $G_{t}$, and effective, $G_{e}$, storage capacities for different geological formations will be outlined. It should be noted that theoretical capacity provides a maximum upper limit to the storage estimation, while effective capacity (as a subset of theoretical capacity) presents a more realistic measure by taking into account a range of technical cut-off limits [62].

\subsubsection{Estimation of $\mathrm{CO}_{2}$ Storage Capacity in Saline Aquifers}

Estimation of storage capacity in saline aquifers is very complex due to the different physical and chemical trapping mechanisms, including structural and stratigraphic, solubility, residual, and mineral trapping that simultaneously occur at different rates and timescales [220]. However, to the best of our knowledge, the mineral trapping mechanism has not been taken into account by any storage capacity estimation approach, due to complexity of the process and poorly understood timeframes [219].

\subsubsection{The CSLF method}

The Carbon Sequestration Leadership Forum (CSLF) [228] provided individual models for estimation of the storage capacity of saline aquifers based on different trapping mechanisms, namely, structural and stratigraphic, solubility, and residual trappings. The CSLF method for structural and stratigraphic trap is a volumetric approach that assumes complete displacement of native formation water down to the spill point [224], and is calculated using Eq. (4):

$$
G_{e}=G_{t} C_{c}=A H \varphi \rho_{C O_{2}}\left(1-S_{w i r r}\right) C_{c}
$$


where $A, H, \varphi, \rho_{\mathrm{CO}_{2}}, S_{\text {wirr }}$ are trap area, average thickness, porosity, $\mathrm{CO}_{2}$ density, and irreducible water saturation, respectively. $C_{c}$ in Eq. (4) is a capacity coefficient associated with cumulative effects of trap heterogeneity, $\mathrm{CO}_{2}$ buoyancy, and sweep efficiency. The term (1$\left.S_{\text {wirr }}\right) C_{c}$ is equivalent to storage efficiency factor (E) and is provided by Cantucci et al. [224].

The CSLF method for solubility trapping is a time-dependent (dynamic) approach and needs to be accompanied by numerical simulations at the local- and site-scale for a given period of time [62] and can be calculated by Eq. (5) [228]:

$$
G_{e}=G_{t} C=A H \varphi\left(\rho_{w_{s}} X_{s}^{C O_{2}}-\rho_{w_{0}} X_{0}^{C O_{2}}\right) C
$$

where $X^{\mathrm{CO}_{2}}$ and $\rho_{w}$ are the $\mathrm{CO}_{2}$ content (mass fraction) in formation water and density of formation water, respectively, and the subscript 0 and s denote the initial and saturation (at the specified time) state. $C$ is a coefficient that accounts for all factors that affect the spread and dissolution of $\mathrm{CO}_{2}$ in the entire volume of the aquifer.

The CSLF method for residual trapping is a time-dependent approach and needs to be coupled with numerical simulations. The method is based on irreducible $\mathrm{CO}_{2}$ saturation in the pore space after completion of the injection step, and is calculated using Eq. (6) [224,228]:

$$
G_{t}=\Delta V_{\text {trap }} \rho_{\mathrm{CO}_{2}} \varphi S_{\mathrm{CO}_{2, t}}
$$

where $\Delta V_{\text {trap }}$ and $S_{C O_{2, t}}$ are the volume of trap $\mathrm{CO}_{2}$ and trap $\mathrm{CO}_{2}$ saturation and can only be specified using numerical simulation at the local- and site-scale and for a given time [228].

\subsubsection{The US-DOE method}

The US-DOE (United States Department of Energy) method [219] is a volumetric and compressibility-based approach. It only includes the physical trapping mechanism, namely, structural and stratigraphic trapping, for estimation of effective storage capacity of saline aquifers, and is given by Eq. (7):

$$
G_{e}=A H \rho_{\mathrm{CO}_{2}} \varphi E_{\text {saline }}
$$

where $E_{\text {saline }}$ is storage efficiency factor that indicates the fraction of pore volume that will be eventually occupied by injected $\mathrm{CO}_{2}$. The calculated values of $E_{\text {saline }}$ for different cases are provided by Bachu [16,219]. 


\subsubsection{The pressure-limit method}

The pressure-limit approach estimates the effective storage capacity of saline aquifers based on the maximum possible amount of $\mathrm{CO}_{2}$ that can be injected before reaching a maximum allowed pressure [224]. Zhou et al. [218] proposed a quick assessment method for estimation of saline storage capacity of closed and semi-closed boundary systems at early stages of site selection. This method assumes that the displaced native brine, by cumulative injected $\mathrm{CO}_{2}$, occupies additional pore volume within the formation which in turn results in pore and brine compressibility and correspondingly transient (dynamic) pressure build-up, $\Delta p(t)$, that can be readily estimated [218], Eq. (8):

$$
G_{e}(t)=A H \rho_{C O_{2}} \varphi \Delta p(t)\left(\beta_{p}+\beta_{w}\right)
$$

where $t$ is time, and $\beta_{p}$ and $\beta_{w}$ are pore and native brine compressibility, respectively.

Szulczewski et al. [229] developed a time-dependent estimated approach for both open and closed boundary systems, by taking into account $\mathrm{CO}_{2}$ displacement to brine, residual and solubility trapping, Eq. (9):

$$
G_{e}(t)=H W \rho_{\mathrm{CO}_{2}} \sqrt{\frac{k Z T}{\mu_{w}}} \frac{P_{f}-\left(P_{0}-\rho_{w} g D\right)}{4 \tilde{P}_{\max }}
$$

where $k, Z, T, g$, and $\mu_{w}$ are permeability, compressibility factor, temperature, gravitational acceleration, and brine viscosity, respectively, $W$ and $D$ are width of the well array and depth to aquifer, $P_{f}, P_{0}$, and $\widetilde{P}_{\max }$ are fracture, initial, and maximum non-dimensional pressures, respectively. $\widetilde{P}_{\text {max }}$ is determined based on a numerical second-order finite-volume method.

\subsubsection{The USGS method}

United States Geological Survey (USGS) [230,231] developed an estimation method by considering both residual trapping in the open part of the aquifer and buoyant trapping, Eq. (10):

$$
G_{e}=\rho_{C O_{2}} V_{b} E_{b}+\sum_{i=1}^{3}\left[\rho_{C O_{2}}\left(A H \varphi-V_{b}\right) R_{w} R_{i, s e} E_{i, r}\right]
$$


where $V_{b}$ is the buoyant trapping pore volume, $R_{w}$ is the fraction of available area for storage, $E_{b}$ and $E_{i, r}$ are buoyant and residual trapping storage efficiency, respectively, and $R_{i, s e}$ is residual trapping storage-resources based on residual trapping injectivity classes ( $\mathrm{i}=1-3)$.

\subsubsection{Estimation of $\mathrm{CO}_{2}$ Storage Capacity in Depleted Oil and Gas Reservoirs}

The estimation of storage capacity in oil and gas reservoirs is the most straightforward and almost the simplest compared to other formations, due to the well-known characteristics of oil and gas reservoirs derived from industry experience [228]. The storage capacity is associated with the reservoir characterisation (such as temperature, effective volume, and pressure), resources (such as original gas in place, OGIP, and original oil in place, OOIP, and recovery factor), and $\mathrm{CO}_{2}$ properties at the reservoir [224].

\subsubsection{The CSLF method}

CSLF [228] developed two approaches for estimation of theoretical storage capacity. The first method is based on OGIP and OOIP, Eq. (11) and (12), respectively, at surface conditions and is associated with the available storage volume that was previously occupied by gas and oil and can be replaced by $\mathrm{CO}_{2}$.

$$
\begin{gathered}
G_{t}=\rho_{C O_{2}, r} R_{f}\left(1-F_{I G}\right) O G I P\left[\frac{P_{s} Z_{r} T_{r}}{P_{r} Z_{s} T_{s}}\right] \\
G_{t}=\rho_{C O_{2}, r}\left[\frac{R_{f} O O I P}{B_{f}}-V_{i w}+V_{p w}\right]
\end{gathered}
$$

where $R_{f}$ is the recovery factor, $F_{I G}$ is fraction of injected gas, $\rho_{\mathrm{CO}_{2}, r}$ is $\mathrm{CO}_{2}$ density at the reservoir, and subscripts s and $\mathrm{r}$ stand for reservoir and surface conditions, respectively. $V_{i w}$ and $V_{p w}$ are the volumes of injected and produced water, respectively, and $B_{f}$ is the formation volume fraction that brings the volume of oil from standard to in-situ conditions.

The second method is based on the geometry (volume) of the reservoir, and is given by Eq. (13):

$$
G_{t}=\rho_{C O_{2}, r}\left[A H \varphi R_{f}\left(1-S_{w}\right)-V_{i w}+V_{p w}\right]
$$

where $S_{w}$ is water saturation. 
One of the main assumptions to derive Eq. (11) - (13) is that the evacuated pores during the production of the recoverable hydrocarbons should be filled with the injected $\mathrm{CO}_{2}$ [232] However, if the reservoirs are underlain by aquifers, water can invade the pores during the production of hydrocarbons. In this event, the pores occupied with water may not all be available for the injected $\mathrm{CO}_{2}$, and the storage capacity can decrease. Correspondingly, an effective storage capacity can be calculated using Eq. (14) [228]:

$$
G_{e}=C_{e} G_{t}
$$

where $C_{e}$ is a capacity coefficient that accounts for cumulative effects of $\mathrm{CO}_{2}$ mobility, $\mathrm{CO}_{2}$ buoyancy on oil and water, reservoir heterogeneity, water saturation, and aquifer strength.

\subsubsection{The US-DOE method}

The US-DOE [219] proposed a volumetric algorithm for the estimation of storage capacity, based on the standard industry approach for calculation of OGIP and OOIP [219,233], given by Eq. (15):

$$
G_{e}=\rho_{C O_{2}, s t d} A H \varphi B\left(1-S_{w}\right) E_{o i l / g a s}
$$

where $B$ is the initial oil or (and) gas formation volume factor, and $E_{\text {oil/gas }}$ is storage efficiency factor that indicates the fraction of total pores associated with produced oil and gas, that can be occupied by injected $\mathrm{CO}_{2}$. E $E_{\text {oil/gas }}$ can be calculated from local $\mathrm{CO}_{2}-\mathrm{EOR}$ experience, or alternatively from reservoir simulation as standard volume of $\mathrm{CO}_{2}$ per volume of OOIP [219].

\subsubsection{The Zhao-Liao method}

Zhao and Liao [221] proposed a model for estimation of $\mathrm{CO}_{2}$ storage capacity of highly watersaturated oil fields, by considering two new terms in the CSLF method for $\mathrm{CO}_{2}$ solubility trapping in oil and water [228], Eq. (16):

$$
G_{e}=\rho_{\mathrm{CO}_{2}, \mathrm{r}} \mathrm{AH} \varphi \mathrm{S}_{\mathrm{CO}_{2}}
$$

where $\mathrm{S}_{\mathrm{CO}_{2}}$ is the sequestration factor and indicates $\mathrm{CO}_{2}$ solubility in oil and water, $\mathrm{CO}_{2}$ sweep efficiency, $\mathrm{CO}_{2}$ displacement, $\mathrm{CO}_{2}$ recovery factor of oil and water, and can be specified using the local $\mathrm{CO}_{2}$-EOR experience, or reservoir simulations (such as the stream tube simulation method). 


\subsubsection{The IEA-GHG method}

IEA Greenhouse Gas R\&D program (IEA-GHG) provided a model for estimation of storage capacity of gas reservoirs by assuming the reservoir can be refilled with $\mathrm{CO}_{2}$ until the formation returns to its original reservoir pressure (pre-production pressure), Eq. (17) [102].

$$
G_{e}=\rho_{C O_{2}, r} U P R_{g, s t p} B E_{g a s}
$$

In Eq. (17) $U P R_{g, s t p}$ is the ultimately recoverable reserves of gas at standard pressure and temperature.

\subsubsection{Estimation of $\mathrm{CO}_{2}$ Storage Capacity in Unmineable Coal Seams}

The estimation of storage capacity in unmineable coal seams involves the displacement of coal bed methane (CBM), and assumes that since the coal has a higher affinity towards gaseous $\mathrm{CO}_{2}$ than $\mathrm{CH}_{4}$, the $\mathrm{CH}_{4}$ in coal will be replaced by injected $\mathrm{CO}_{2}[219,224]$.

\subsubsection{The CSLF method}

In the CSLF method [228], the estimated storage capacity is determined based on the initial gas in place, IGIP and reservoir gas deliverability $\left(C^{\prime} R_{f}\right)$, Eq. (18):

$$
G_{e}=\rho_{C O_{2}, s t d} R_{f} I G I P C^{\prime}
$$

where $C^{\prime}$ is the completion factor.

\subsubsection{The US-DOE method}

The US-DOE [219] provided a volumetric algorithm for estimation of storage capacity, Eq. (19):

$$
G_{e}=A H \rho_{\mathrm{CO}_{2}, \mathrm{std}} C_{\mathrm{CO}_{2}} E_{\text {coal }}
$$

where $\mathrm{C}_{\mathrm{CO}_{2}}$ is the maximum adsorbed volume of $\mathrm{CO}_{2}$ at standard conditions (Langmuir isotherm volume constant), and $E_{\text {coal }}$ is storage capacity factor. $E_{\text {coal }}$ is a function of available volume for $\mathrm{CO}_{2}$ storage and displacement, and indicates the total fraction of bulk coal that accommodates the injected $\mathrm{CO}_{2}[219,224]$. 


\subsubsection{The ZLH method}

The Zhao-Liao-He (ZLH) method [222] was developed from a model for estimation of storage capacity of the coal bed in the presence of water. The model is based on the $\mathrm{CO}_{2}$ adsorption in the coal bed, $\mathrm{CO}_{2}$ displacement to formation water, and $\mathrm{CO}_{2}$ solubility in water, Eq. (20):

$$
\begin{gathered}
G_{t}=10^{-7}\left(A H \rho_{c o a l, b} g_{c s} R_{f} C_{E R} \rho_{C O_{2}, s t d}\right)+\left[A H \varphi\left(1-S_{w}\right)\left(1-R_{w}\right) C_{C O_{2}, w}\right] \\
+\left[A H \varphi S_{w} R_{w} \rho_{C O_{2}}\right]
\end{gathered}
$$

where $C_{E R}$ is the replacement coefficient of $\mathrm{CH}_{4}$ by $\mathrm{CO}_{2}$ in the coal bed, $R_{w}$ is the recovery factor of reservoir water, $g_{c s}$ is coal bed gas content, and $C_{C O_{2}, w}$ is the $\mathrm{CO}_{2}$ solubility coefficient in water.

\subsubsection{Assessment of Estimation Approaches}

National Energy Technology Laboratory (NETL) [234] conducted a comprehensive comparative study by applying CSLF [228], US-DOE [219], Zhou et al. [218], Szulczewski et al. [229], and USGS [230] methods on 13 saline formation data sets in the identical conditions. It was reported that the lowest and largest storage capacity estimation methods were presented by Zhou et al. [218] and USGS [230], respectively. Cantucci et al. [224] developed a case study (Italian case study) to assess the estimation approaches by applying CSLF [228], Eq. (4), USDOE [219], and Zhou et al. [218] methods on a potential reservoir in Po Plain (Northern Italy). In this study, the effect of residual and solubility trapping was rather small, and not considered in the calculations. The largest and lowest storage capacities were obtained by CSLF and Zhou et al. [218] methods, respectively. Although the difference between storage efficiency factor obtained from CSLF and US-DOE methods was relatively small, there was a considerable discrepancy with the Zhao et al. [218] model. However, as it was pointed out by Goodman et al. [219], the uncertainty in estimation of storage capacity arises from variability and characterisation of aquifers and is much more significant than uncertainty in selection of estimation method. Therefore, estimation and evaluation of specific geologic formation characteristics, rather than utilisation of arbitrary and constant values, is critical and needs to be taken into account. In addition, although the volumetric approaches are helpful for identification of the prospective $\mathrm{CO}_{2}$ storage in pre-feasibility studies, further numerical modelling is needed to advance the characterisation, and assess the dynamics of $\mathrm{CO}_{2}$ storage based on operational and regulatory factors. 
On the other hand, it was noticed that no methodology has been developed to account for the mineral trapping mechanism for estimation of $\mathrm{CO}_{2}$ storage capacity. The significance of mineralisation on overall storage capacity in comparison with other trapping mechanisms is not well-understood. Thus, considering the mineralisation trapping may lead to a more accurate determination of long-term storage capacity.

\section{Major World $\mathrm{CO}_{2}$ Storage Projects}

This section provides an overview of current and past major large-scale $\mathrm{CO}_{2}$ projects worldwide, Table 2. In most of these projects $\mathrm{CO}_{2}$ has been stored in saline aquifers or used for EOR. In addition, other $\mathrm{CO}_{2}$ storage projects worldwide which are in planning, under construction, or have operated for only a shorter period are provided in the supplementary material, Table $\mathbf{S 1 .}$

The most important factor that assures the success of storage projects depends on the security of containment. Accordingly, it is necessary to continually improve site selection and characterisation, technical operation parameters, monitoring and verification tools and quantitative risk assessments. Addressing these factors holistically will form the basis for appropriate technical regulations and the enactment of positive public perception to enable unhindered deployment of large-scale $\mathrm{CO}_{2}$ storage operation.

\subsection{In Salah Project}

The In Salah storage project (Figure 8), is located in Algeria, and is jointly operated by a consortium of British Petroleum, Statoil and Sonatrach. This project is a fully operational world-pioneering onshore gas field which receives $\mathrm{CO}_{2}$ from the In Salah oil field [235]. This formation is a depleted oil and gas reservoir, found at $1800 \mathrm{~m} \mathrm{[236],} 1850 \mathrm{~m} \mathrm{[237],} 1900 \mathrm{~m}$ $[238,239]$ in the subsurface (Figure 9). The project has been operated since $2004[236,238]$. It is estimated that total capacity of the formation is about $17 \mathrm{Mt}$ of $\mathrm{CO}_{2}[89,237]$, and a total of $4 \mathrm{Mt}$ has already been injected between 2004 and 2011 [240]. During the injection, almost $4000 \mathrm{t}$ of $\mathrm{CO}_{2}$ per day [30] was injected into the 20-m-thick methane-producing Carboniferous sandstone Krechba formation via three wells [237,238,241]. The injection cost approximately $\$ 6 / t$ of $\mathrm{CO}_{2}$, and the total cost of storage was estimated around US\$2.7 billion [242-245]. 


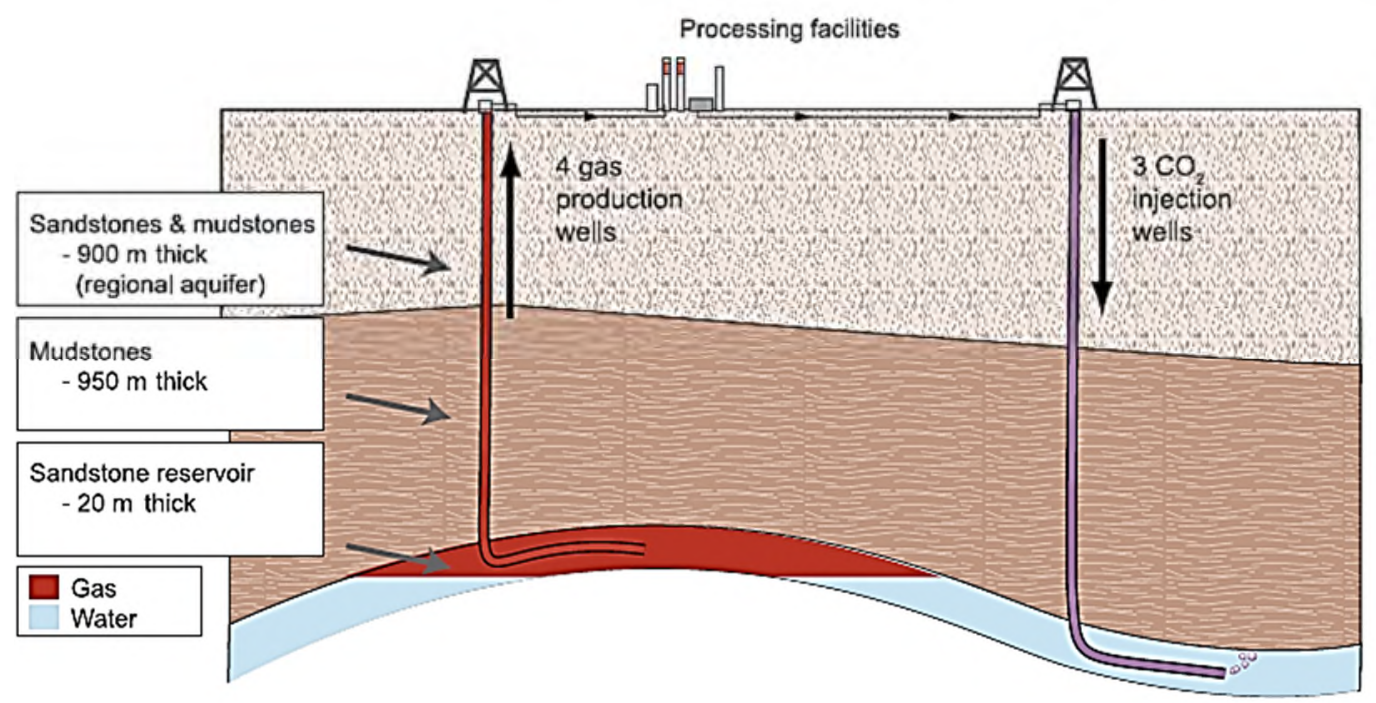

Figure 8: $\mathrm{CO}_{2}$ storage in the Krechba formation, In Salah Gas Project [5].

The project site has been carefully monitored using satellite InSAR (Interferometric Synthetic Aperture Radar), and time-lapse seismic and micro-seismic data. All collected monitoring data have been used in refining and updating the geological, flow dynamic and geomechanical models of the storage project. The injection was suspended in June 2011 over fears about the integrity of the caprock [236,246]. Although, there was $\mathrm{CO}_{2}$ migration from reservoir into the overburden, no $\mathrm{CO}_{2}$ leakage into the atmosphere was envisaged [240]. In addition, Verdon [185] noted that $\mathrm{CO}_{2}$ injection caused substantial induced seismic activity. Since then, injection strategies for the future have been reviewed, and comprehensive site monitoring strategies outlined through an intensified research and development program. Although the reviewed site monitoring strategies are yet to be fully disclosed in the open literature, the new scheme should include a detailed and improved microseismic monitoring array that provides real-time and intensive geomechanical response surveillance that would allow operators to quickly adjust injection parameters to ensure safe operation of the project [242]. Such monitoring strategies should equally improve understanding of geological and geomechanical characterisation of reservoir and overburden [235]. Experience from the In Salah project can be relevant in understanding injectivity of $\mathrm{CO}_{2}$ in other settings around the world where storage is either ongoing or intended in clastic reservoirs with low permeability. 


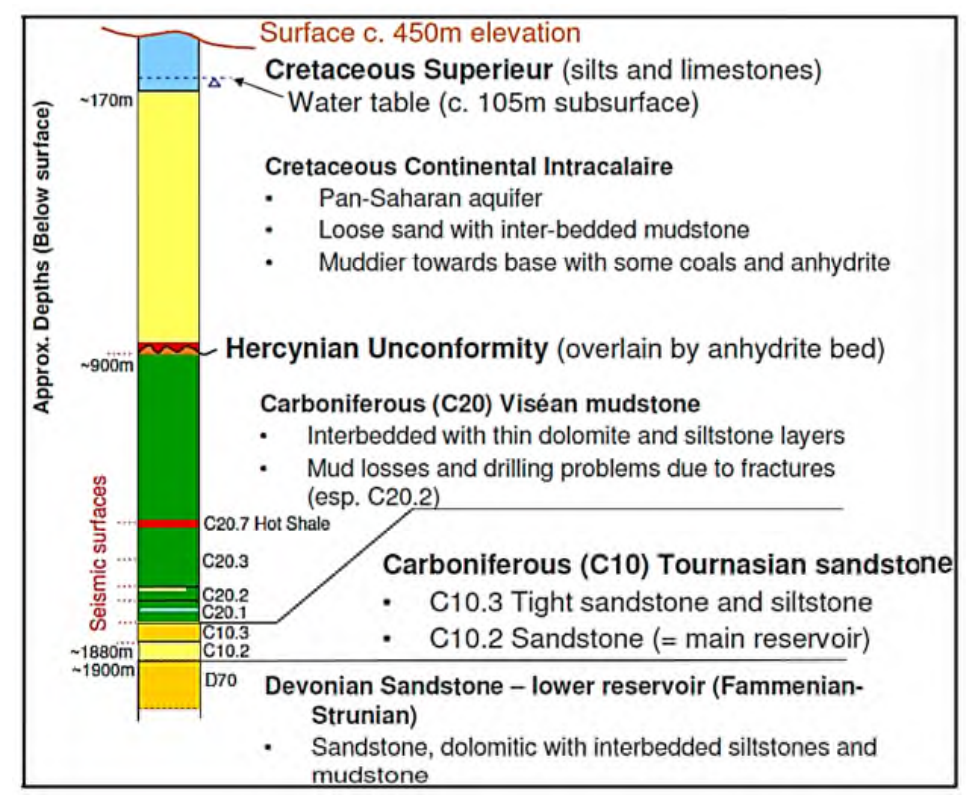

Figure 9: Krechba Stratigraphic Column, In Salah Gas Project (reprinted with permission from Pamukcu et al. [236], Copyright 2017, Elsevier).

\subsection{Ketzin Project}

The Ketzin storage project is located in Ketzin, Germany, was led by The Helmholtz Centre Potsdam GFZ German Research Centre for Geosciences and Ketzin Partners, started in 2008 and was completed in 2009. The project, which operated for a relatively short period when compared to other projects reviewed here, was sought to store $\mathrm{CO}_{2}$ in the subsurface so that it could be monitored to provide information relevant for future policy and environmental regulations. This project was known as the first onshore $\mathrm{CO}_{2}$ storage project in Europe. A continental Triassic siliciclastic unit called the Stuttgart formation (Figure 10), which is characterised by sandstones, was used as the $\mathrm{CO}_{2}$ reservoir [89,247-251]. The source of $\mathrm{CO}_{2}$ for the project was a hydrogen production and oxyfuel pilot plant (Schwarze Pumpe). The $\mathrm{CO}_{2}$ was transported by a pipeline and stored in a saline sandstone formation aquifer at approximately $630 \mathrm{~m}$ in the subsurface. By the end of the project, a total of $67,271 \mathrm{t}$ of $\mathrm{CO}_{2}$ was successfully stored in the reservoir. Even though $\mathrm{CO}_{2}$ was stored at a relatively low depth in the Ketzin project reservoir, experience from monitoring of $\mathrm{CO}_{2}$ flow behaviour in the subsurface did not suggest detectable leakage throughout the period of injection. 


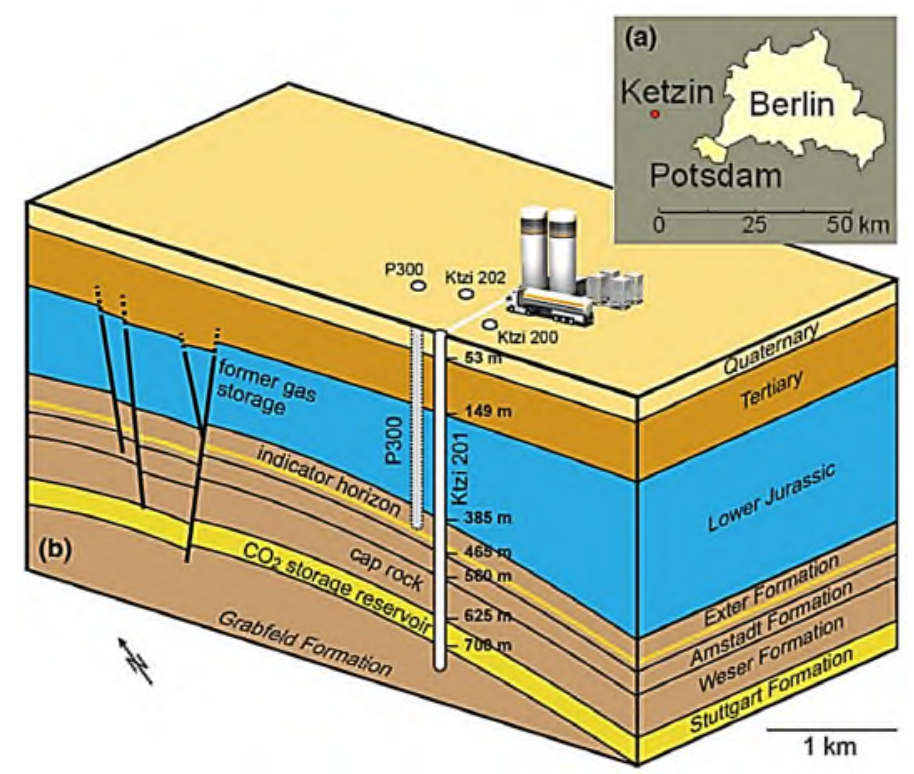

Figure 10: (a) Location of the Ketzin $\mathrm{CO}_{2}$ project; (b) schematic block diagram of the Ketzin $\mathrm{CO}_{2}$ target reservoir and other structural features (reprinted with permission from Martens et al. [252], Copyright 2017, Springer).

\subsection{Sleipner Project}

The Sleipner storage project, located in the mid-central North Sea (Figure 11), is operated by Statoil. This project is the first commercial-scale $\mathrm{CO}_{2}$ injection project in the world [253-255]. The project was conceived by the need to evade Norwegian carbon tax, that would be payable if $\mathrm{CO}_{2}$ had vented [256,257]. Injection began in 1996 and uses a North Sea Norwegian saline aquifer found between $800-1000 \mathrm{~m}$ below the sea floor. The storage formation is of the late Cenozoic age and called the Utsira formation [258-261]. The Utsira formation is a 200 to 250 $\mathrm{m}$ thick massive sandstone, with $15.5 \mathrm{Mt}$ of injected $\mathrm{CO}_{2}$ since the project started until June 2015 [89]. The source of Sleipner's $\mathrm{CO}_{2}$ is the captured $\mathrm{CO}_{2}$ through scrubbing from the natural gas processing field located at Sleipner West [256,262,263]. The stored $\mathrm{CO}_{2}$ is prevented from escaping to the surface by a 200-300 m thick layer of shale called the Nordland shales, which acts as caprock [36,258,264]. Mackenzie et al. [265] reported the occurrence of a $50 \mathrm{~m}$ deep confined wedge of sandstone, which is found closer to the lower seal of the Utsira formation, that provides additional capacity for storage in the reservoir.

Although there is no evidence of leakage at the sea bottom, as 3D seismic monitoring has confirmed (Figure 12), the $\mathrm{CO}_{2}$ plume has risen through eight thin shale rock layers within the aquifer and reached the caprock in less than three years since the start of injection and storage. 
However, the shales are very efficient in enhancing mixing and consequently $\mathrm{CO}_{2}$ dissolution. These will hopefully address major challenges and improve risk management in the lifecycle of $\mathrm{CO}_{2}$ storage projects in all stages and elements.

Nevertheless, while it is true that extensive experience on storage has been gained from $\mathrm{CO}_{2}$ storage projects like Sleipner, given the natural heterogeneity of geologic formations that vary from place to place, more far-reaching experience is needed to attain maturity in areas such as site selection, $\mathrm{CO}_{2}$ flood engineering and reservoir management, workflow integration, monitoring and remediation and regulatory development.

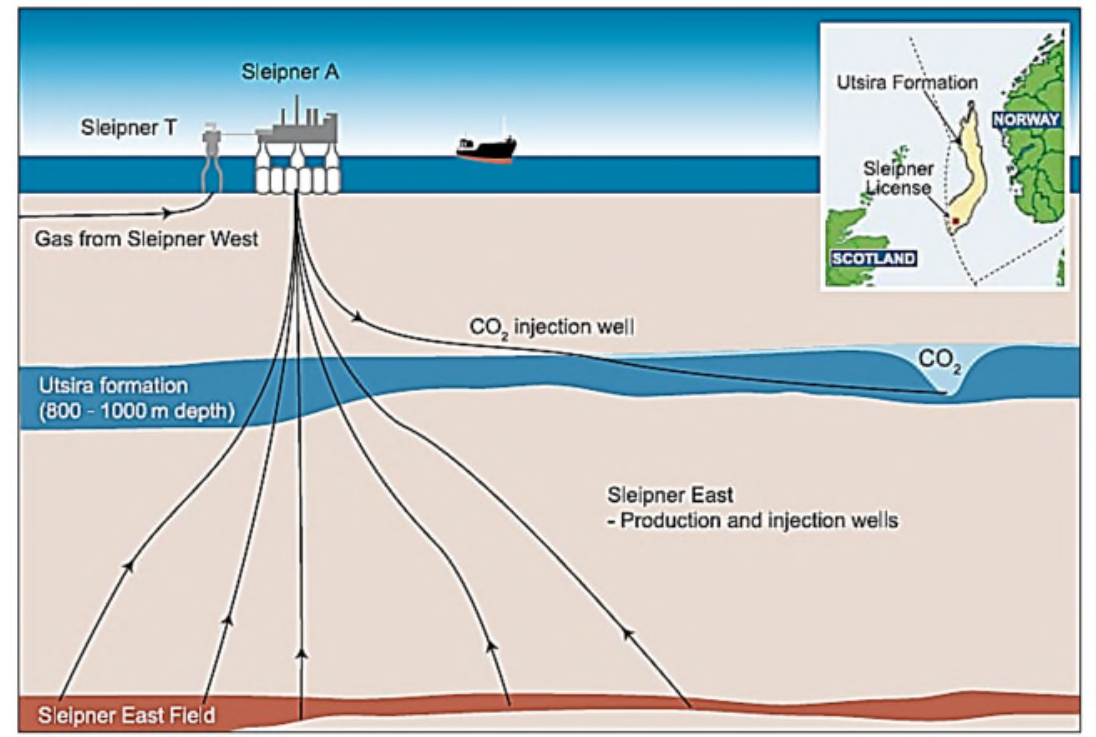

Figure 11: A simplified diagram of the Sleipner $\mathrm{CO}_{2}$ storage project, with an inset depicting the extent of the Utsira formation [5].

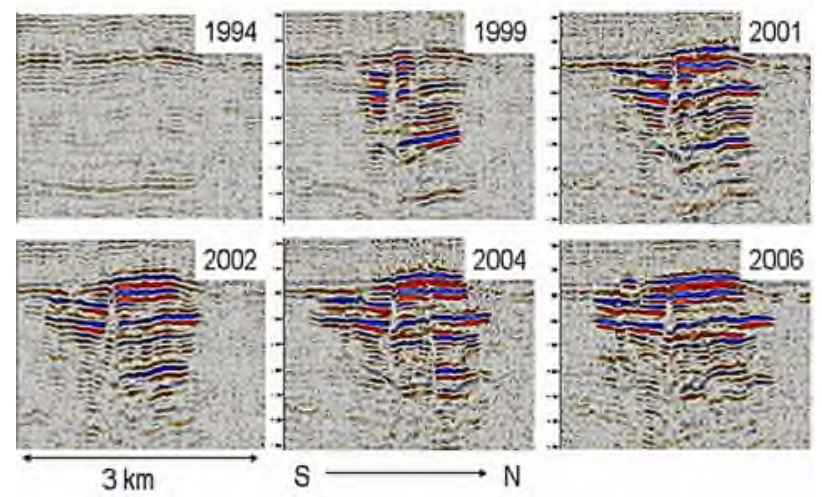

Figure 12: Vertical seismic sections of $\mathrm{CO}_{2}$ plume in the Utsira sandstone, Sleipner gas field, North Sea [266]. 


\subsection{Weyburn - Midale Project}

The Weyburn-Midale storage project, located in south central Saskatchewan (Canada), is operated by Cenovus Energy [267], Apache Canada [268], and collectively managed by Petroleum Technology Research Centre (PTRC) [269,270]. The motivation for the project was to increase oil production $\left(\mathrm{CO}_{2}\right.$-EOR) [271] and further research and development in the area [272]. Before the commencement of the Alberta Carbon Trunk Line (ACTL) as the world's largest storage project which was expected to commence injection in 2018 [273], the WeyburnMidale project, which started in 2000, had been the world's largest storage project [274]. The injection of $\mathrm{CO}_{2}$ is taking place at rates of about 3000 to $5000 \mathrm{t} / \mathrm{d}$ [89] which optimises EOR and increases production [271]. The project is expected to have a lifespan of about 20 to 25 years [30]. It has been estimated that the total amount of $\mathrm{CO}_{2}$ to be stored in the field by 2025 to 2030 is $20 \mathrm{Mt}[36,275]$. The operating cost is currently about US $\$ 20 / \mathrm{t}$ of $\mathrm{CO}_{2}$ [89].



Figure 13: Schematic NE-SW cross section through the Weyburn field with underlying geologic formations (adapted with permission from Riding and Rochelle [276], Copyright 2017, Geological Society of London).

There are two different aquifers in the Midale carbonate reservoir (Figure 13) of the Weyburn project field, namely the vuggy and marly beds [30,216,277,278]. The vuggy beds have suitable reservoir properties in the lower regions, while the upper regions are limestone dominated and characterised by a relatively low permeability but high porosity [30]. The marly beds are a dolostone unit, characterised by low permeability and high porosity. Both aquifer formations are sealed by an anhydrite caprock [275], implying that both vuggy and marly beds 
can store more fluid or gas than they can transmit. Other information on the geology of the Weyburn area is provided by Wegelin [279] and Rah [280].

In 2011, there was an unsubstantiated claim by a farmer that Weyburn was leaking $\mathrm{CO}_{2}$ at the surface, from evidence of gas bubbles, dead animals and algal blooms found around a pond in a farm (Kerr farm) near the injection site. This created a controversy in the media but investigations using gas monitoring, $\mathrm{CO}_{2}$ isotopic analysis and other techniques revealed that there was no leakage of $\mathrm{CO}_{2}$ from Weyburn [206,281,282].

\subsection{Snøhvit Project}

The Snøhvit project, located in offshore Norway, is operated by Statoil ASA and partners [283] which comprise Petoro AS, GDF Suez E\&P Norge AS, Total E\&P Norge AS, Hess Norge, and Norsk Hydro. Like the Sleipner project, the motivation for $\mathrm{CO}_{2}$ storage in the Snøhvit project is carbon tax exemption from the Norwegian government [256,284]. Snøhvit started in late 2007, and is the first offshore field where oil is produced without the use of offshore installations. The Snøhvit project sources its $\mathrm{CO}_{2}$ from an $\mathrm{LNG}$ processing project. The $\mathrm{CO}_{2}$ is captured by a scrubbing approach [285], transported via pipeline from onshore to offshore (Figure 14), and stored in the saline Tubaen sandstone formation reservoirs at $2600 \mathrm{~m}$ deep with a thickness of 45 to $75 \mathrm{~m}$ [89]. The total storage capacity of sandstone reservoir formation is estimated around 31 to $40 \mathrm{Mt}$, and about $0.7 \mathrm{Mt}$ of $\mathrm{CO}_{2}$ has been safely stored per year.

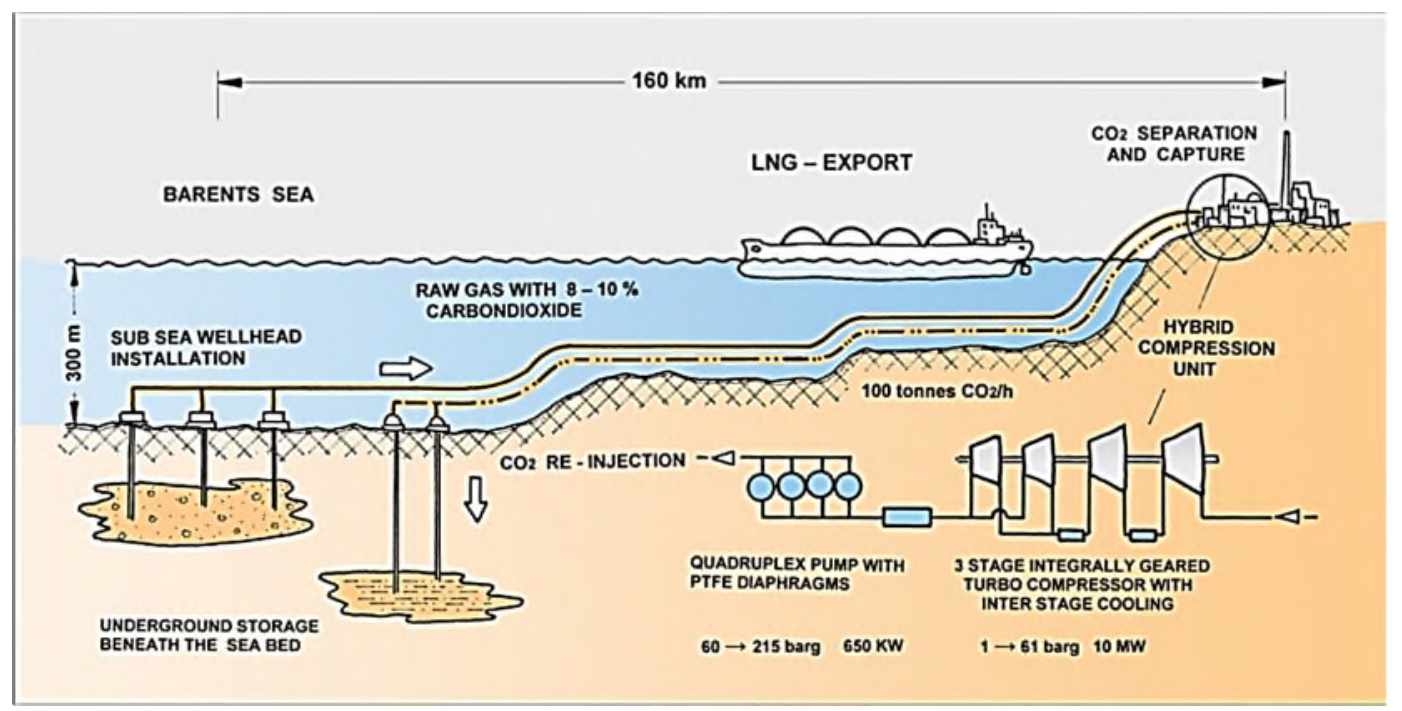

Figure 14: Schematic of the Snøhvit storage project showing fluid transport [286]. 
However, in early 2010 Statoil reported that the storage capacity is lower than that initially expected for Snøhvit, and the possibility of increasing the capacity by drilling new holes or increasing porosity/permeability of the formation by fracturing techniques has been considered. A program has also been set up to monitor and investigate the behaviour of stored $\mathrm{CO}_{2}$ within the reservoirs of Snøhvit [89]. It is reported that injection of $\mathrm{CO}_{2}$ ended in April 2011 but injection continued at normal levels in a fall-back reservoir [235].

\subsection{Alberta Carbon Trunk Line Project}

The Alberta Carbon Trunk Line (ACTL) project $\left(\mathrm{CO}_{2}-\mathrm{EOR}\right)$ is in the industrial heartland of Alberta, Canada (Figure 15), and is operated by Enhance Energy Inc. It is currently the world's largest CCS project, consisting of a 240-km pipeline and infrastructure capable of collecting, compressing, and storing up to $14.6 \mathrm{Mt}$ of $\mathrm{CO}_{2}$ per year at maximum operational capacity. The $\mathrm{CO}_{2}$ for the ACTL project is sourced from the North West Sturgeon Refinery and Agrium Fertiliser Plant (Alberta, Canada) [274], and the injection was expected to begin in 2018 [273]. The total storage capacity is around $2 \mathrm{Gt}$ of $\mathrm{CO}_{2}$, and the total cost of the project is estimated at US\$1.2 billion [89].

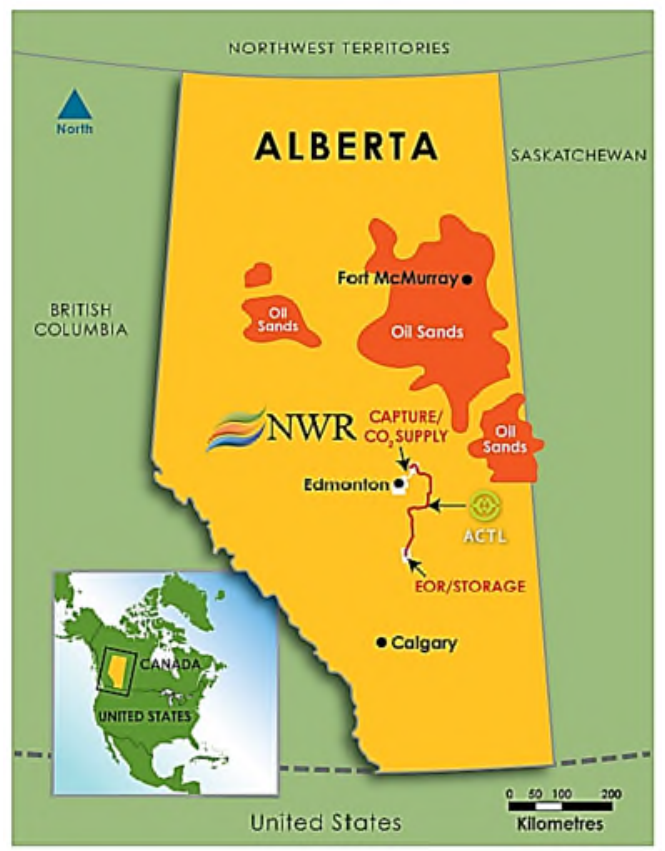

Figure 15: Alberta Carbon Trunk Line Project location (reprinted with permission from Heal and Kemp [287], Copyright 2017, Elsevier). 


\subsection{Otway Basin Project}

The Otway Basin Pilot Project (OBPP) is located in Australia, and is managed by the Cooperative Research Centre for Greenhouse Gas Technologies (CO2CRC) [288]. OBPP is considered as the largest geosequestration onshore project, and started in 2008 [30,289,290]. The $\mathrm{CO}_{2}$ for the OBPP is sourced from a natural $\mathrm{CO}_{2}$-rich gas deposit (Buttress gas well) [290], and injected into a $2000 \mathrm{~m}$ deep depleted gas reservoir (Waarre formation) (Figure 16) at a rate of 65445 t/a [291].


Figure 16: (AA') Cross section of the $\mathrm{CO}_{2}$ injection well (CRC-1) within the Otway Project. (BB') The Buttress gas well which is the source for the experiment and the CRC-1 injection well (reprinted with permission from Dance [292], Copyright 2017, Elsevier). Note: the dark coloured lines show faults within the subsurface. Faults (if pervious) are cracks in the earth's crust which could be vents for leakage.

Adverse environmental impacts of the OBPP on soils between 2007-2012 were explored by Schacht and Jenkins [293]. Prior and during storage of $\mathrm{CO}_{2}$ into the Waarre formation, gas concentrations including $\mathrm{CO}_{2}, \mathrm{CH}_{4}, \mathrm{~N}_{2}$, and $\mathrm{O}_{2}$ were measured for leakage detection. Fixed gas relationships and isotopic studies showed that $\mathrm{CO}_{2}$ found in the soil was of biogenic origin, and also there was no deep subsurface source of $\mathrm{CO}_{2}$. Therefore, the results showed that 
injected $\mathrm{CO}_{2}$ has no noticeable impact on the local ecosystem in and around the Otway Project site. Monitoring and investigations are still being carried out within the OBPP, especially to understand geomechanical processes, $\mathrm{CO}_{2}$ plume migration, caprock integrity and the possibility of fault reactivation [30]. In addition, preliminary probabilistic studies of seismic hazards of the $\mathrm{CO} 2 \mathrm{CRC}$ Otway Project revealed that the potential induced seismicity associated with $\mathrm{CO}_{2}$ injection and storage is very low [294].

\subsection{Boundary Dam Project}

The Boundary Dam storage project is located in Estevan (Saskatchewan, Canada), and is managed by SaskPower. This is the world's first commercial-scale post-combustion capture (lignite firing) and storage project, (Figure 17), capable of injecting $1 \mathrm{Mt}$ of $\mathrm{CO}_{2}$ per year, which shows the synergic nature of the CCS value chain. The $90 \%$ captured $\mathrm{CO}_{2}$ is utilised for EOR in the Weyburn field in southern Saskatchewan, which requires only a $66 \mathrm{~km}$ pipeline (built by Cenovus Energy), while the remaining $\mathrm{CO}_{2}$ is used for the Aquistore Project (managed by the PTRC), where $\mathrm{CO}_{2}$ is stored in a $3.4 \mathrm{~km}$ deep brine-sandstone formation.

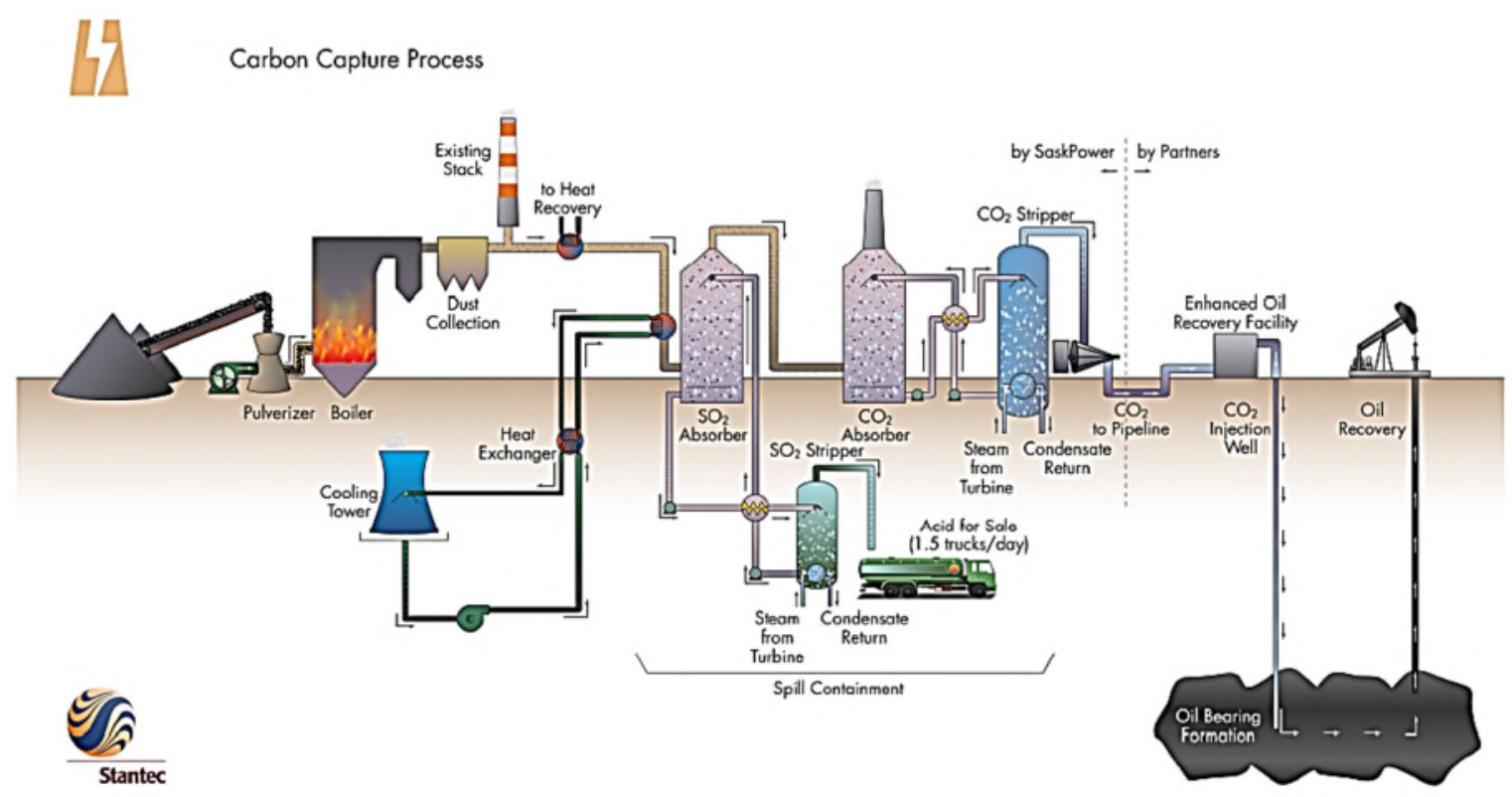

Figure 17: The Boundary Dam Project process illustration [295].

The deepest units within the Williston Basin, the Winnipeg and Deadwood formations, were chosen as the target zone for $\mathrm{CO}_{2}$ injection. These two geological formations possess greater storage capacity for $\mathrm{CO}_{2}$ than any oil reservoir in western Canada. The storage complex suitability was investigated using high-resolution 3D seismic images, and data obtained from 
injection and observation wells. The obtained data show there are no significant faults in the storage site, and no adverse effect by knolls on the surface of the underlying basement formation. In addition, it was revealed that there is a continuous regional sealing formation in the area [270].

\subsection{Cranfield Project}

The Cranfield storage project is located in the Cranfield oilfield in Natchez (Mississippi, USA), and is operated by the Southeast Regional Carbon Sequestration Partnership (SECARB), Department of Energy (DOE), National Energy Technology Laboratory (NETL), Southern States Energy Board (SSEB), Texas Bureau of Economic Geology, Denbury Resources, Advanced Resources International (ARI), Electric Power Research Institute (EPRI), and the University of Alabama (began in 2009). In this project, $1.5 \mathrm{Mt}$ per year of $\mathrm{CO}_{2}$, sourced from the Jackson Dome (Mississippi), was injected into saline Tuscaloosa sandstone formation occurring down-dip of the Cranfield oilfield [89]. The Tuscaloosa formation is a $15 \mathrm{~m}$ thick heterogeneous sandstone of fluvial sedimentology at a depth of $3000 \mathrm{~m}$ in the subsurface (Figure 18), and is widely spread across the region.



Figure 18: Cross section (AA') of lithofacies within the Cranfield Project with approximate location of $\mathrm{CO}_{2}$ injection. (reprinted with permission from Griffith et al. [296], Copyright 2017, Springer). 
The estimated total cost of storage is US\$93 million, and $4.7 \mathrm{Mt}$ of $\mathrm{CO}_{2}$ was stored until August 2013 [89,297-299]. Anderson et al. [300] investigated $\mathrm{CO}_{2}$ leakage at the Cranfield project site, between 2009 and 2014, by extensive geochemical monitoring of process-based soil gas ratios, light hydrocarbon concentrations, stable and radioactive isotopes for $\mathrm{CO}_{2}$ and $\mathrm{CH}_{4}$, noble gases, and perfluorocarbon concentrations. Their results suggested that although some gases were detected, their origin cannot be correlated to the subsurface $\mathrm{CO}_{2}$ reservoirs, and no associated leakage is recorded.

\subsection{Frio Brine Pilot Project}

The Frio Brine Pilot Project (2004-2006) is located in the Texas Gulf Coast (United States), and was operated by DOE and NETL, under the leadership of the Texas Bureau of Economic Geology. $\mathrm{CO}_{2}$ for the project was sourced from the South Liberty oilfield near Houston [301]. The $\mathrm{CO}_{2}$ injection in the Frio sandstone formation was conducted in two phases: a 10-day injection in 2004 (1600 $\mathrm{t}$ of $\mathrm{CO}_{2}$ at a depth of $1500 \mathrm{~m}$ ), and a 5-day injection in 2006 (250 $\mathrm{t}$ of $\mathrm{CO}_{2}$ at a depth of $\left.1600 \mathrm{~m}\right)$ [302].

Prior to implementation of the project, $\mathrm{CO}_{2}$ storage experience in the United States was limited to hydrocarbon formations [302]. The main objectives of this project were to demonstrate $\mathrm{CO}_{2}$ injection into brine formation without causing adverse health and environmental effects, to explore subsurface behaviour of injected $\mathrm{CO}_{2}$, and to develop required experience for the largescale injection demonstrations in high-permeability, high-volume sandstone [302,303]. On successful completion of the project in 2006, it was suggested that leakage-monitoring above the storage zone should be conducted as an alternative or as a complement to near-surface or surface monitoring [304]. A major success of the project was the ease of on-site analysis using downhole sampling techniques to detect injection tracers and changes in water chemistry, for instantaneous measurements.

\subsection{Citronelle Project}

The Citronelle storage project, is located at the Citronelle oilfield in Bucks County (Alabama, United States), and is managed by SECARB, Denbury Resources and Southern Energy. The project started in 2011, and stored $0.15 \mathrm{Mt}$ of $\mathrm{CO}_{2}$ within Paluxy formation (thickness of 335 $\mathrm{m}$ ), in a saline aquifer (southern flank of the Citronelle Dome), at a depth of 3000 to $3400 \mathrm{~m}$. The $\mathrm{CO}_{2}$ is sourced from the Plant Barry power station in Mobile (Alabama, USA), and 
transported via a $19 \mathrm{~km}$ long pipeline to the storage site [305]. Total storage cost is estimated at US\$111 million [89,306,307].

Although no soil gas baseline survey was reported for the Citronelle Project, Chen and Liu [308] performed geophysical sensing for $\mathrm{CO}_{2}$ storage using a Derivative of Refractive Microtremor (DoReMi) method to determine changes in geologic formation and migration of $\mathrm{CO}_{2}$ before and during injection through seismic measurements. The project is currently under post-injection process phase and no evidence of leakage is reported so far [309].

\subsection{Decatur Project}

The Decatur storage project (November 2011 - September 2015) is located in Decatur, Illinois Basin (United States), and was operated by Archer Daniels Midland, the Midwest Geological Sequestration Consortium (with Illinois State Geological Survey as leader), Schlumberger Carbon Services, and Richland Community College. The Mount Simon sandstone formation (Figure 19) was selected as the target formation due to its optimum saline sink and the presence of overlying Eau Claire shale which was expected to provide efficient sealing. The project aimed at assessment of the storage potential of the Mount Simon sandstone formation, and the integrity of the overlying Eau Claire shale as a seal. The total cost of the project was US\$208 million, and $\mathrm{CO}_{2}$ was sourced from an ethanol production plant in Decatur, and transported via a $1.9 \mathrm{~km}$ pipeline. After a year of operation, 317,000 $\mathrm{t}^{-\mathrm{CO}_{2}}$ at the rate of $1100 \mathrm{t} / \mathrm{d}$ was injected into the formation using a single injection well. $[89,247,310]$. It was revealed that additional storage of 3-4.5 $\mathrm{Mt}$ of $\mathrm{CO}_{2}$ in the same saline aquifer would be feasible in a follow-up project [247]. 


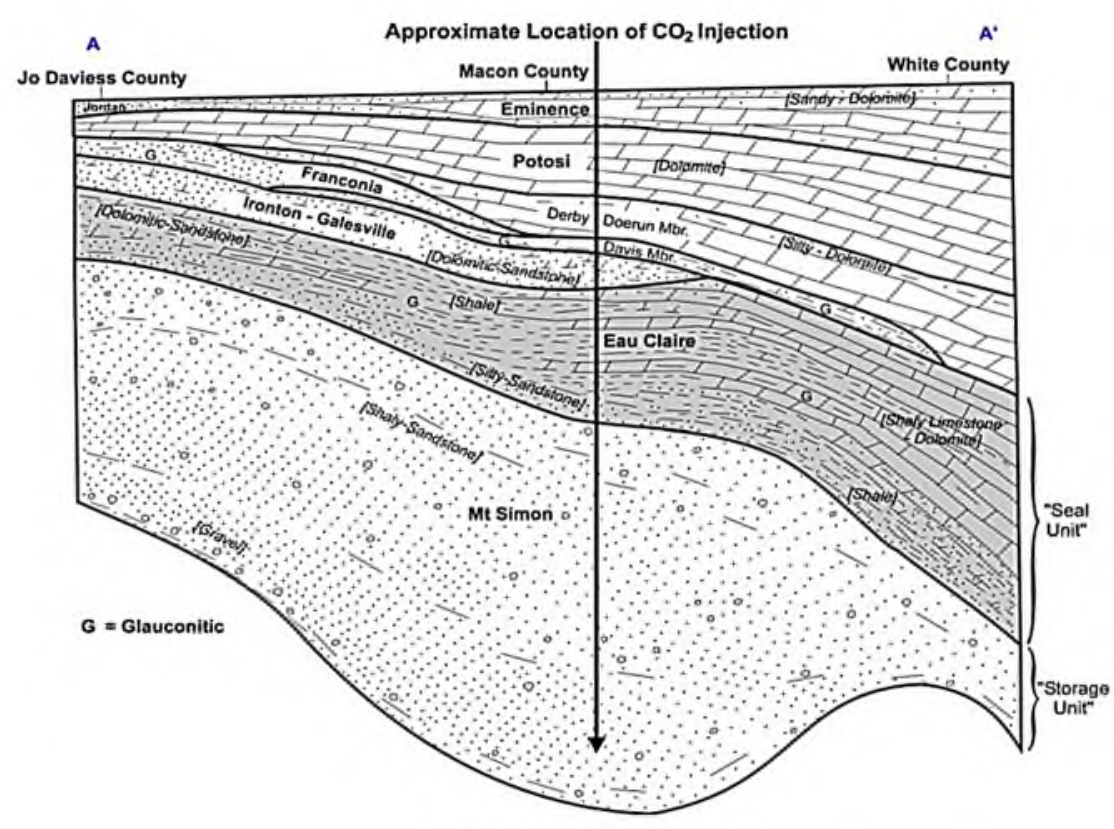

Figure 19: Cross section (AA') of lithofacies within the Decatur Project with approximate location of $\mathrm{CO}_{2}$ injection showing the $\mathrm{Mt}$. Simon formation as storage unit and the overlying Eau Claire formation as seal unit (reprinted with permission from Griffith et al. [296], Copyright 2017, Springer).

Streibel et al. [247] performed a comparative study of the Decatur and Ketzin projects, as examples of successful onshore $\mathrm{CO}_{2}$ storage, by considering project characteristics, monitoring approaches, pressure build-up, and public perception. Both projects aimed to demonstrate $\mathrm{CO}_{2}$ storage in saline aquifers, but in different fluvial depositional systems, reservoir temperature and pressure conditions, injection rate, and particularly amount of stored $\mathrm{CO}_{2}$ which was approximately 15 (by volume) times higher in the Decatur project. The results showed that: (i) the Decatur storage reservoir is thick, but the $\mathrm{CO}_{2}$ plume is relatively thin, making geophysical detection challenging; (ii) The Ketzin storage reservoir is much thinner, with a thick $\mathrm{CO}_{2}$ plume, which eases geophysical detection; (iii) geomechanical conditions at Decatur, in combination with the injection rate and pressure, induced microseismic activity, while no such activities were detected at Ketzin; (iv) the induced microseismic activity at Decatur was along pre-existing planes of weakness and could not be detected by geophysical tools; and (v) the project developers recognised the need to monitor the shallow groundwater and soil flux, but they also suggested that subsurface sampling/pressure monitoring and cased-hole logging would be necessary in the case of seal or well failure. 


\subsection{Northern Reef Trend Project}

The Northern Reef Trend project is located within the Michigan Basin, (Michigan, United States), and is operated by the Midwest Regional Carbon Sequestration Partnership (MRCSP), DTE Energy, Core Energy, and Battelle. The $\mathrm{CO}_{2}$ is sourced from a natural gas processing plant, transported via a 24-km pipeline, and stored in a depleted carbonate reservoir within the Northern Reef Trend. This formation is characterised by a series of highly compartmentalised reservoirs at about $1800 \mathrm{~m}$ in the subsurface where geologic history indicates an ancient coral reef environment. The project started in 2013, and it is planned that in 3 to 5 years of operation about $1 \mathrm{Mt}$ of $\mathrm{CO}_{2}$ will be injected in the oil field which has undergone waterflooding in recent years and is almost at the end of its productive life. The MRCSP is also tracking and monitoring the behaviour of injected $\mathrm{CO}_{2}$ to quantify how much $\mathrm{CO}_{2}$ is retained in the formation after the removal of oil. The total cost of the project is US\$23 million [89,311].

\subsection{Port Arthur Project}

The Port Arthur project (January 2013 - September 2015) is located in Port Arthur (Texas, United States), and was operated by Air Products and Chemicals, Denbury Onshore, Bureau of Economic Geology at the University of Texas at Austin, and Valero Energy Corporation. The $\mathrm{CO}_{2}$ was sourced from the existing steam methane reformers in the Valero Refinery in Port Arthur, and transported via a 19-km pipeline to Denbury's Green pipeline for further transportation over more than $100 \mathrm{~km}$ for EOR in the Oyster Bayou and West Hastings oilfields. By May 2013, over 222,000 t of $\mathrm{CO}_{2}$ was injected into the formation, resulting in an additional recovery of 1.6 to 3.1 million barrels of domestic oil annually. The total cost of the project is US\$431 million [89,312]. To the best of our knowledge, there is no known study on $\mathrm{CO}_{2}$ monitoring in the Port Arthur project, and it is very likely that a monitoring program will be proposed to confirm that $\mathrm{CO}_{2}$ is safely stored.

\subsection{Zama Project}

The Zama storage project is located near Zama City (Alberta, Canada), and is operated by PCOR (Plains $\mathrm{CO}_{2}$ Reduction Partnership) and Apache Canada. The project started in 2006 and aims at demonstration of commercial acid gas injection for hydrocarbon recovery, in order to reduce the cost of $\mathrm{CO}_{2}$ purification. The $\mathrm{CO}_{2}$ stream contains almost $70 \% \mathrm{CO}_{2}$ and $30 \% \mathrm{H}_{2} \mathrm{~S}$ and is sourced from a gas processing plant [89]. The Zama project is estimated to operate for 18 years and to store $1.3 \mathrm{Mt}$ of $\mathrm{CO}_{2}$ and $0.5 \mathrm{Mt}$ of $\mathrm{H}_{2} \mathrm{~S}$. Since 2006, 80,000 t of $\mathrm{H}_{2} \mathrm{~S}$ has been 
stored, which enabled the recovery of more than 35,000 barrels of oil. The storage reservoir of the Zama oilfield, the Keg River formation saline aquifer, is of Middle Devonian, and is at a depth of approximately $1500 \mathrm{~m}$. [89,313].

The co-injection of $\mathrm{CO}_{2}$ and $\mathrm{H}_{2} \mathrm{~S}$ (acid gas) into geologic formations for permanent storage is both environmentally and economically beneficial. Bennion and Bachu [314] studied the effect of $\mathrm{CO}_{2}$ and $\mathrm{H}_{2} \mathrm{~S}$ at in-situ reservoir conditions on permeability of inter-crystalline sandstone from the Wabamun Lake area (Alberta, Canada). It was revealed that interaction of $\mathrm{H}_{2} \mathrm{~S}$ saturated brines-rock is more aggressive than $\mathrm{CO}_{2}$-saturated brines-rock interaction. Moreover, it is important to note that co-injection of gas mixtures, particularly $\mathrm{CO}_{2}-\mathrm{H}_{2} \mathrm{~S}$, has been demonstrated to be safe, and viable for storage to a considerable extent. However, it is also essential to further explore the effect of acid gas injection and its implications on the physical reservoir quality of target formations using both experimental studies for short-term effects and numerical models for long-term prediction.

\subsection{Ordos Project}

The Ordos storage project is located in Inner Mongolia (China), and is managed by the Shenhua Group. This project began in 2010 at pilot scale, and will be operated at full scale by 2020 . The $\mathrm{CO}_{2}$ is sourced from a coal liquefaction plant, which is currently emitting $3.6 \mathrm{Mt}$ of $\mathrm{CO}_{2}$ per year, transported via a $200-\mathrm{km}$ onshore pipeline system, and is injected into a saline aquifer. It is reported that by 2014 , up to 150,000 t of $\mathrm{CO}_{2}$ was stored within the Ordos formation. The total estimated cost of the project is US $\$ 1.46$ billion [89,315]. A system for monitoring of ground, above-ground and under-ground was developed [316], and the vertical seismic profile (VSP) was used to track $\mathrm{CO}_{2}$ migration. The results showed that the injected $\mathrm{CO}_{2}$ remained within $450 \mathrm{~m}$ from the injection well, and no incidence of $\mathrm{CO}_{2}$ leakage was observed. However, continuous monitoring is suggested to track $\mathrm{CO}_{2}$ plume movement over a more extended period. 
Table 2: Major world $\mathrm{CO}_{2}$ storage projects (large-scale projects either operated previously or currently operating), [30,89].

\begin{tabular}{|c|c|c|c|c|c|}
\hline Name & Location & $\mathrm{CO}_{2}$ Source & $\mathrm{CO}_{2}$ Sink & Status & Other important information \\
\hline In Salah & $\begin{array}{l}\text { Tamanrasset, } \\
\text { Algeria }\end{array}$ & Oil at & $\begin{array}{l}\text { Oil and gas } \\
\text { reservoir }\end{array}$ & 2011 & $\begin{array}{l}\mathrm{CO}_{2} \text { injection stopped for fear about caprock integrity even though storage } \\
\text { complex was not compromised. }\end{array}$ \\
\hline Ketzin & $\begin{array}{l}\text { Brandenburg, } \\
\text { Germany }\end{array}$ & $\begin{array}{l}\text { Hydrogen } \\
\text { production } \\
\text { and oxyfuel } \\
\text { plant }\end{array}$ & $\begin{array}{l}\text { Saline } \\
\text { aquifer }\end{array}$ & 2008-2009 & $\begin{array}{l}\text { First European onshore } \mathrm{CO}_{2} \text { storage project, motivated by need for } \\
\text { information for the future } \mathrm{CCS} \text { policies in the EU. }\end{array}$ \\
\hline Sleipner & $\begin{array}{l}\text { Offshore, } \\
\text { Norway }\end{array}$ & Natural gas & $\begin{array}{l}\text { Saline } \\
\text { aquifer }\end{array}$ & 996 & $\begin{array}{l}\text { World's first commercial-scale } \mathrm{CO}_{2} \text { injection project, motivated by the } \\
\text { Norwegian carbon tax policy. }\end{array}$ \\
\hline $\begin{array}{l}\text { Weyburn } \\
\text {-Midale }\end{array}$ & $\begin{array}{l}\text { Saskatchewan, } \\
\text { Canada }\end{array}$ & $\begin{array}{l}\text { Coal } \\
\text { gasification }\end{array}$ & $\begin{array}{l}\text { Oil and gas } \\
\text { reservoir }\end{array}$ & since 2000 & $\begin{array}{l}\text { World's largest CCS project. In addition to EOR, the project was motivated } \\
\text { by need for R\&D in the area. In 2011, there were allegations that stored } \\
\mathrm{CO}_{2} \text { was leaking near injection site, but later investigations did not confirm } \\
\text { it. }\end{array}$ \\
\hline Snøhvit & $\begin{array}{l}\text { Offshore, } \\
\text { Norway }\end{array}$ & $\begin{array}{l}\text { LNG } \\
\text { processing }\end{array}$ & $\begin{array}{l}\text { Saline } \\
\text { aquifer }\end{array}$ & since 2007 & $\begin{array}{l}\text { Motivated by the carbon tax in Norway. The first offshore field where oil } \\
\text { is produced without the use of offshore installations. }\end{array}$ \\
\hline $\begin{array}{l}\text { Alberta } \\
\text { Carbon }\end{array}$ & $\begin{array}{l}\text { Alberta, } \\
\text { Canada }\end{array}$ & $\begin{array}{l}\text { Refinery and } \\
\text { fertiliser } \\
\text { plant }\end{array}$ & $\begin{array}{l}\text { Oil and gas } \\
\text { reservoir }\end{array}$ & from 2018 & $\begin{array}{l}\text { When in operation, the world's largest CCS project intended to generate } \\
\text { over one billion barrels of oil, with value of } \sim \$ 15 \text { billion in royalties. }\end{array}$ \\
\hline
\end{tabular}




\section{Trunk}

Line

Otway Victoria, Natural $\mathrm{CO}_{2}$ - Oil and gas since 2008 Motivated by the signing of the Kyoto Protocol in 2007, the largest

Basin Australia rich gas reservoir geosequestration onshore project in Australia, aimed at demonstrating transport and geological storage of $\mathrm{CO}_{2}$, testing the regulatory and scientific $\mathrm{CO}_{2}$ storage concepts, and evaluating response of public through engaging with stakeholders.

\begin{tabular}{|c|c|c|c|c|c|}
\hline $\begin{array}{l}\text { Boundary } \\
\text { Dam }\end{array}$ & $\begin{array}{l}\text { Saskatchewan, } \\
\text { Canada }\end{array}$ & $\begin{array}{l}\text { Post- } \\
\text { combustion } \\
\text { lignite-fired } \\
\text { plant }\end{array}$ & $\begin{array}{l}\text { Saline } \\
\text { aquifer }\end{array}$ & since 2014 & $\begin{array}{l}\text { World's first commercial-scale CCS project employing post-combustion } \\
\text { capture from lignite-fired plant, motivated by EOR, but also aims to sell } \\
\mathrm{CO}_{2} \text {, fly ash and sulphuric acid for industrial uses. A major turning point } \\
\text { was signing the MoU between SaskPower and UKCCSRC for a 3-year } \\
\text { research initiative aimed at improving performance and reducing costs of } \\
\text { CCS operations. }\end{array}$ \\
\hline Cranfield & $\begin{array}{l}\text { Mississippi, } \\
\text { USA }\end{array}$ & $\begin{array}{l}\text { Natural } \\
\text { source }\end{array}$ & $\begin{array}{l}\text { Oil and gas } \\
\text { reservoir }\end{array}$ & since 2009 & $\begin{array}{l}\text { First amongst the SECARB commercial-scale projects which reached and } \\
\text { exceeded the injection target with }>3 \mathrm{Mt} \text { of } \mathrm{CO}_{2} \text { injected and monitored } \\
\text { since the start of the project. }\end{array}$ \\
\hline $\begin{array}{l}\text { Frio } \\
\text { Brine }\end{array}$ & Texas, USA & $\begin{array}{l}\text { Oil } \\
\text { processing }\end{array}$ & $\begin{array}{l}\text { Saline } \\
\text { aquifer }\end{array}$ & 2004-2006 & First demonstration on $\mathrm{CO}_{2}$ storage in saline aquifer in the United States. \\
\hline
\end{tabular}




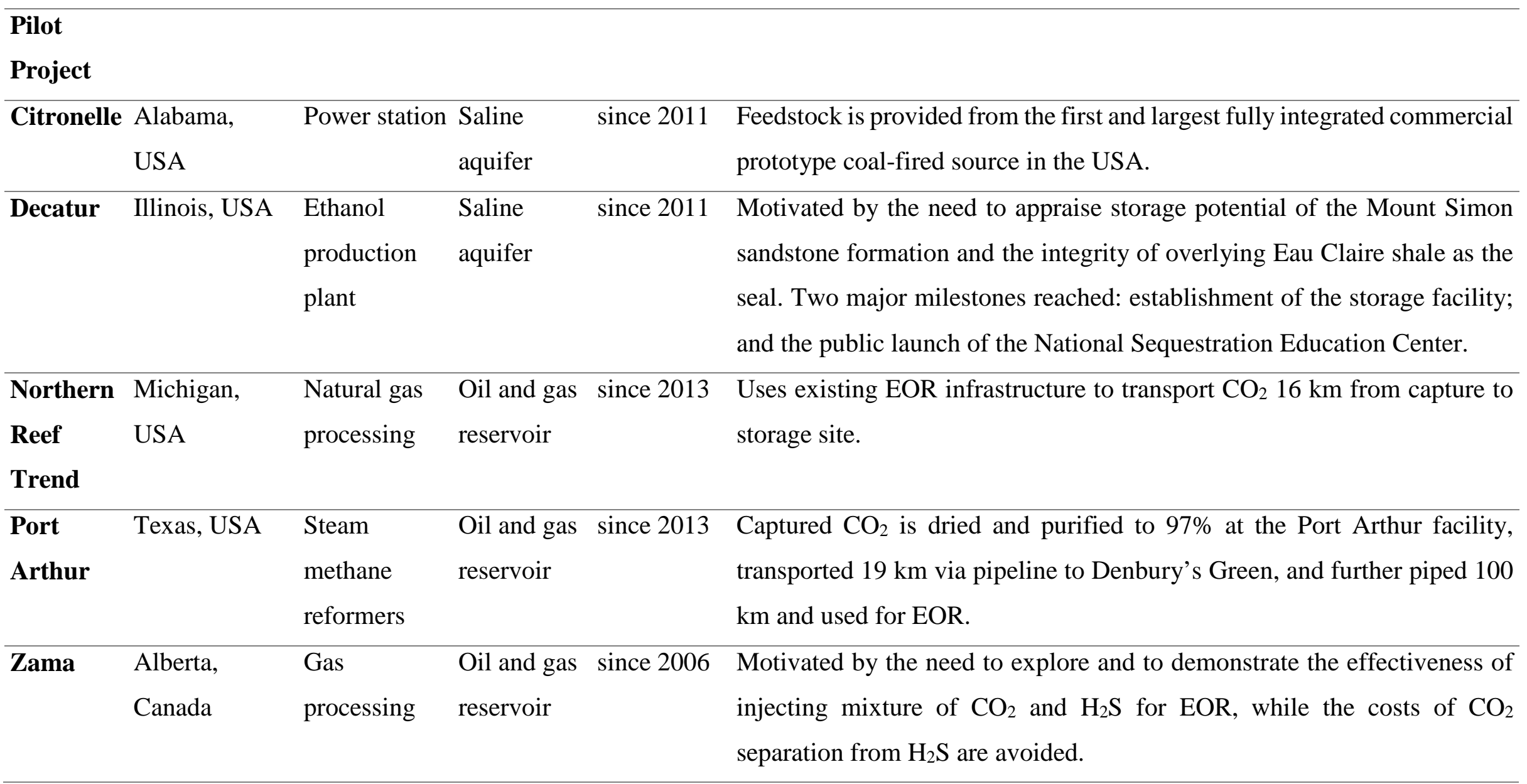




\begin{tabular}{|c|c|c|c|c|c|}
\hline Ordos & $\begin{array}{l}\text { Ordos, Inner } \\
\text { Mongolia, } \\
\text { China }\end{array}$ & $\begin{array}{l}\text { Coal } \\
\text { liquefaction }\end{array}$ & $\begin{array}{l}\text { Saline } \\
\text { aquifer }\end{array}$ & $\begin{array}{l}\text { since } 2010 \\
\text { at pilot } \\
\text { scale, from } \\
2020 \text { full } \\
\text { scale }\end{array}$ & $\begin{array}{l}\text { Managed by China's largest coal mining company. The coal liquefaction } \\
\text { plant where } \mathrm{CO}_{2} \text { is sourced for this project is located on a large deposit of } \\
\text { coal tar. }\end{array}$ \\
\hline
\end{tabular}




\section{General Conclusions and Future Outlook for $\mathrm{CO}_{2}$ Storage}

This work presents a review of state-of-the-art developments in carbon dioxide storage. It discusses critical issues that have been solved as well as challenges that require further attention for $\mathrm{CO}_{2}$ sequestration, storage site evaluation criteria, behaviour of $\mathrm{CO}_{2}$ in the reservoir, and methodologies for estimating $\mathrm{CO}_{2}$ storage capacity. In addition, the major world $\mathrm{CO}_{2}$ storage projects, including their states of developments were highlighted. Based on our review, it can be concluded that:

a) Although $\mathrm{CO}_{2}$ storage, as an emerging technology, is faced with technical challenges which are improving by ongoing research, there are also associated problems with public acceptability of the technology, implying that dispelling of misconceptions on CCS has not yet reached a significant maturity level.

b) Although it has been demonstrated that $\mathrm{CO}_{2}$ can be sequestered by means of mineral carbonation and deep ocean storage, the underground geological storage of $\mathrm{CO}_{2}$ is still the most viable choice due to economic factors, their wide geographical distribution, and environmental concerns.

c) Even though some researchers suggested that $\mathrm{CO}_{2}$ storage in saline aquifers is preferable (due to relative abundance and availability of huge storage volumes) over oil and gas reservoirs, they often neglect the costs associated with deployment of storage in saline aquifers. Oil and gas reservoirs usually have existing infrastructure that can support storage activities with minor modifications. In addition, they have been comprehensively characterised during exploration and production stages, and could utilise $\mathrm{CO}_{2}$ for both storage and EOR. Therefore, storage in oil and gas reservoirs can be a better alternative over saline aquifers.

d) Since geologic systems are often associated with uncertainties due to their heterogeneity, appropriate site evaluation is crucial for the development of all future storage projects. In addition, continuous monitoring for the existing projects must be undertaken.

e) $\mathrm{CO}_{2}$ transportation over long distances from sources to storage sites can incur considerable costs, and is not economically favourable. Therefore, the storage site should be ideally as close as possible to $\mathrm{CO}_{2}$ sources. In addition, where the point sources of $\mathrm{CO}_{2}$ are located far from ideal sedimentary formations, the high cost of transportation may be minimised by choosing an alternative storage option. Alternatively, single pipe facilities can be developed for a cluster of $\mathrm{CO}_{2}$ producers. 
f) Complex behaviour of injected $\mathrm{CO}_{2}$ within fluvial depositional structures may potentially lead to undesirable events, such as induced seismicity and leakage, if appropriate reservoir management strategies are not adopted. Thus, detailed geomechanical and geochemical assessments of sites are essential.

g) Although monitoring experience from the majority of projects suggested that $\mathrm{CO}_{2}$ storage can be effectively and securely achieved, issues like induced seismicity can still pose threats to storage projects if such potentials are not well investigated.

Although high-quality knowledge has already been attained covering many aspects of $\mathrm{CO}_{2}$ storage, the following challenges remain:

a) Despite the technically proven feasibility of $\mathrm{CO}_{2}$ storage, low levels of public awareness have greatly affected the pace of technology deployment. Ethical implications of $\mathrm{CO}_{2}$ storage development need further evaluation, and more effective ethic mechanisms should be adopted to promote public embracing of the technology. Development of scientist-policymaker-public communication strategies is essential to transfer and highlight the necessity of $\mathrm{CO}_{2}$ storage to society.

b) It is important to establish cost curves involved in the whole sequestration chain such as in the geographical relationship between $\mathrm{CO}_{2}$ sources and storage sinks. This will play a key role in decision making, especially during large-scale CCS deployment.

c) Detailed regional assessments are the key factor to establish how well an emission source would match suitable storage options, and what storage volumes are required. On a case-by-case basis, it is always important to assess risks associated with storage such as $\mathrm{CO}_{2}$ leakage and induced seismicity, as well as public acceptance of the technology.

d) Although legal and regulatory frameworks for facilitating $\mathrm{CO}_{2}$ storage implementation exist, it is important to make inter-subjective comparisons between frameworks for different countries or regions such as United States-Canada and the European Union, Australia, and Asia.

e) For further deployment of alternative storage options, such as serpentinite and basaltic formations, it is necessary to enhance our understanding in order to distinguish potential uncertainties and explore the corresponding mitigation strategies. This can include the understanding of $\mathrm{CO}_{2}$ migration in the presence of potential faults or excessive pressure build-up 
and the effect of $\mathrm{CO}_{2}$-rock interaction to facilitate or impede the migration, using both experimental and, particularly, numerical approaches.

f) Helping industry in terms of long-term stability or financial instruments is essential to enable timely deployment of large-scale commercial $\mathrm{CO}_{2}$ storage projects considering that $\mathrm{CCS}$ is a shortto medium-term climate change mitigation strategy.

g) There are currently limited data defining reservoir system strength variation in relation to reactions of rock minerals by $\mathrm{CO}_{2}$-enriched brine. Therefore, further research is required to focus on grain-size parameters of the reservoir formations to assess the effect of supercritical $\mathrm{CO}_{2}$ and how it alters reservoir quality, such as porosity and permeability, and its corresponding effects on $\mathrm{CO}_{2}$ migration. It is also important to take into consideration the effects of impurities such as $\mathrm{NO}_{2}$, $\mathrm{SO}_{2}$ and $\mathrm{H}_{2} \mathrm{~S}$ in such studies.

h) Numerical models capable of describing changes in reservoirs over longer periods of injection and storage could also be utilised to understand long-term effects of $\mathrm{CO}_{2}$ and impurities on physical reservoir quality. In addition, such numerical models can be potentially coupled with volumetric approaches to further depict the dynamic aspects of storage capacity estimation during and after the injection period.

i) Models, with higher performance capacity than existing ones, are required for building and calibrating 3D pre-injection and 4D post-injection reservoir geomechanical simulations in order to have a better assessment of fault and caprock integrity, especially in deep saline aquifers and depleted oil and gas formations. These models should take into consideration critical pore pressure for fault activation.

j) There is a necessity in demonstrating stability of borehole seals in the longer term, as their failure will govern $\mathrm{CO}_{2}$ leakage regardless of the quality of any caprock. It is also required to demonstrate the ability of remediation in the unlikely event of well leakage. 


\section{Abbreviations}

\begin{tabular}{|c|c|}
\hline ACTL & Alberta Carbon Trunk Line \\
\hline API & American Petroleum Institute \\
\hline ARI & Advanced Resources International \\
\hline CAS & Chinese Academy of Sciences \\
\hline CBM & Coal Bed Methane \\
\hline $\mathrm{CCS}$ & Carbon Capture and Storage \\
\hline CCSU & Carbon Capture Storage and Utilisation \\
\hline $\mathrm{CO} 2 \mathrm{CRC}$ & The Cooperative Research Centre for Greenhouse Gas Technologies \\
\hline CSLF & The Carbon Sequestration Leadership Forum \\
\hline DOE & Department of Energy \\
\hline DoReMi & Derivative of Refractive Microtremor \\
\hline ECBM & Enhanced Coal Bed Methane recovery \\
\hline EGS & Enhanced Geothermal System \\
\hline EOR & Enhanced Oil Recovery \\
\hline EPRI & Electric Power Research Institute \\
\hline FEP & Features, Events and Processes \\
\hline GHG & Greenhouse Gas \\
\hline HCPV & Hydrocarbon Pore Volume \\
\hline IMO & International Maritime Organisation \\
\hline InSAR & Interferometric Synthetic Aperture Radar \\
\hline IPCC & Intergovernmental Panel on Climate Change \\
\hline LNG & Liquefied Natural Gas \\
\hline MIT & Massachusetts Institute of Technology \\
\hline MoU & Memorandum of Understanding \\
\hline MRCSP & Midwest Regional Carbon Sequestration Partnership \\
\hline MVA & Monitoring, Verification and Accounting \\
\hline NETL & National Energy Technology Laboratory \\
\hline OBPP & Otway Basin Pilot Project \\
\hline OGCM & Ocean General Circulation Model \\
\hline OGIP & Original Gas in Place \\
\hline OOIP & Original Oil in Place \\
\hline OSPAR & Oslo Paris \\
\hline PCOR & Plains $\mathrm{CO}_{2}$ Reduction Partnership \\
\hline PFTs & Perfluorocarbon tracer compounds \\
\hline PTRC & Petroleum Technology Research Centre \\
\hline SECARB & Southeast Regional Carbon Sequestration Partnership \\
\hline SEM & Scanning Electron Microscope \\
\hline SSEB & Southern States Energy Board \\
\hline SWP & The Southwest Regional Partnership \\
\hline TRL & Technology Readiness Level \\
\hline UKCCSRC & UK Carbon Capture and Storage Research Centre \\
\hline US-DOE & United States Department of Energy \\
\hline USGS & United States Geological Survey \\
\hline VSP & Vertical Seismic Profile \\
\hline XRD & X-Ray Diffraction \\
\hline
\end{tabular}




\section{References}

[1] MacDowell N, Florin N, Buchard A, Hallett J, Galindo A, Jackson G, et al. An overview of CO2 capture technologies. Energy Environ Sci 2010;3:1645-69. doi:10.1039/c004106h.

[2] IEA. CO2 emissions from fuel combustion - Highlights. 2016.

[3] NASA - National Aeronautics and Space Administration. Carbon Dioxide 2017. https://climate.nasa.gov/vital-signs/carbon-dioxide/ (accessed August 10, 2017).

[4] Met-Office. Global climate in context as the world approaches $1{ }^{\circ} \mathrm{C}$ above pre-industrial for the first time 2016. http://www.metoffice.gov.uk/research/news/2015/global-average-temperature-2015.

[5] IPCC. Special Report on Carbon Dioxide Capture and Storage. Cambridge: 2005. doi:10.1021/cr2003272.

[6] ECF. Roadmap 2050. A practical guide to a prosperous, low-carbone Europe. Brussels: 2010. doi:10.2833/10759.

[7] IEA. CO2 Emissions from Fuel Combustion 2009. Paris: OECD Publishing; 2009. doi:10.1787/co2_fuel-2009-en-fr.

[8] Viebahn P, Vallentin D, Höller S. Prospects of carbon capture and storage (CCS) in China's power sector - An integrated assessment. Appl Energy 2015;157:229-44. doi:https://doi.org/10.1016/j.apenergy.2015.07.023.

[9] Hanak DP, Anthony EJ, Manovic V. A review of developments in pilot-plant testing and modelling of calcium looping process for $\mathrm{CO} 2$ capture from power generation systems. Energy Environ Sci 2015;8:2199-249. doi:10.1039/c5ee01228g.

[10] GCCSI. Accelerating the Uptake of CCS: Industrial Use of Captured Carbon Dioxide. 2011.

[11] DECC. CCS Roadmap - Supporting deployment of Carbon Capture and Storage in the UK. 2012.

[12] Yamasaki A. An overview of $\mathrm{CO} 2$ mitigation options for global warming - Emphasizing $\mathrm{CO} 2$ sequestration options. J Chem Eng Japan 2003;36:361-75. doi:10.1252/jcej.36.361.

[13] Mabon L, Shackley S. Public engagement in discussing carbon capture and storage. World Soc. Sci. Rep. 2013 - Chang. Glob. Environ., ISSC, UNESCO; 2013, p. 398-403.

[14] Bai M, Zhang Z, Fu X. A review on well integrity issues for CO2 geological storage and enhanced gas recovery. Renew Sustain Energy Rev 2016;59:920-6. doi:https://doi.org/10.1016/j.rser.2016.01.043.

[15] Abidoye LK, Khudaida KJ, Das DB. Geological Carbon Sequestration in the Context of Two-Phase Flow in Porous Media: A Review. Crit Rev Environ Sci Technol 2015;45:1105-47. doi:10.1080/10643389.2014.924184.

[16] Bachu S. Review of CO2 storage efficiency in deep saline aquifers. Int J Greenh Gas Control 2015;40:188-202. doi:https://doi.org/10.1016/j.ijggc.2015.01.007.

[17] De Silva GPD De, Ranjith PG, Perera MSA. Geochemical aspects of CO2 sequestration in deep saline aquifers: A review. Fuel 2015;155:128-43. doi:https://doi.org/10.1016/j.fuel.2015.03.045.

[18] Boot-Handford ME, Abanades JC, Anthony EJ, Blunt MJ, Brandani S, Mac Dowell N, et al. Carbon capture and storage update. Energy Environ Sci 2014;7:130-89. doi:10.1039/C3EE42350F.

[19] Burnside NM, Naylor M. Review and implications of relative permeability of CO2/brine systems and residual trapping of $\mathrm{CO} 2$. Int $\mathrm{J}$ Greenh Gas Control 2014;23:1-11. doi:https://doi.org/10.1016/j.ijggc.2014.01.013.

[20] Carroll AG, Przeslawski R, Radke LC, Black JR, Picard K, Moreau JW, et al. Environmental considerations for subseabed geological storage of CO2: A review. Cont Shelf Res 2014;83:11628. doi:https://doi.org/10.1016/j.csr.2013.11.012.

[21] Godec M, Koperna G, Gale J. CO2-ECBM: A Review of its Status and Global Potential. Energy Procedia 2014;63:5858-69. doi:http://dx.doi.org/10.1016/j.egypro.2014.11.619.

[22] Humez P, Lions J, Négrel P, Lagneau V. CO2 intrusion in freshwater aquifers: Review of geochemical tracers and monitoring tools, classical uses and innovative approaches. Appl 
Geochemistry 2014;46:95-108. doi:https://doi.org/10.1016/j.apgeochem.2014.02.008.

[23] Tang Y, Yang R, Bian X. A Review of CO2 Sequestration Projects and Application in China. Sci World J 2014;2014:381854. doi:10.1155/2014/381854.

[24] Li L, Zhao N, Wei W, Sun Y. A review of research progress on CO2 capture, storage, and utilization in Chinese Academy of Sciences. Fuel 2013;108:112-30. doi:https://doi.org/10.1016/j.fuel.2011.08.022.

[25] Song J, Zhang D. Comprehensive review of caprock-sealing mechanisms for geologic carbon sequestration. Environ Sci Technol 2013;47:9-22.

[26] Liu F, Lu P, Griffith C, Hedges SW, Soong Y, Hellevang H, et al. CO2-brine-caprock interaction: Reactivity experiments on Eau Claire shale and a review of relevant literature. Int J Greenh Gas Control 2012;7:153-67. doi:https://doi.org/10.1016/j.ijggc.2012.01.012.

[27] Pires JCM, Martins FG, Alvim-Ferraz MCM, Simões M. Recent developments on carbon capture and storage: An overview. Chem Eng Res Des 2011;89:1446-60. doi:https://doi.org/10.1016/j.cherd.2011.01.028.

[28] Zahid U, Lim Y, Jung J, Han C. CO2 geological storage: A review on present and future prospects. Korean J Chem Eng 2011;28:674-85. doi:10.1007/s11814-010-0454-6.

[29] Zhang M, Bachu S. Review of integrity of existing wells in relation to CO2 geological storage: What do we know? Int J Greenh Gas Control 2011;5:826-40. doi:https://doi.org/10.1016/j.ijggc.2010.11.006.

[30] Shukla R, Ranjith P, Haque A, Choi X. A review of studies on CO2 sequestration and caprock integrity. Fuel 2010;89:2651-64. doi:https://doi.org/10.1016/j.fuel.2010.05.012.

[31] Abu-Khader MM. Recent Progress in CO2 Capture/Sequestration: A Review. Energy Sources, Part A Recover Util Environ Eff 2006;28:1261-79. doi:10.1080/009083190933825.

[32] White CM, Smith DH, Jones KL, Goodman AL, Jikich SA, LaCount RB, et al. Sequestration of Carbon Dioxide in Coal with Enhanced Coalbed Methane RecoveryA Review. Energy \& Fuels 2005;19:659-724. doi:10.1021/ef040047w.

[33] Voormeij BD a, Simandl GJ. Geological and Mineral CO2 Sequestration Options: A Technical Review. Geosci Canada 2004;31:11-22.

[34] Na J, Xu T, Yuan Y, Feng B, Tian H, Bao X. An integrated study of fluid-rock interaction in a CO2based enhanced geothermal system: A case study of Songliao Basin, China. Appl Geochemistry 2015;59:166-77. doi:https://doi.org/10.1016/j.apgeochem.2015.04.018.

[35] Yang H, Xu Z, Fan M, Gupta R, Slimane RB, Bland AE, et al. Progress in carbon dioxide separation and capture: A review. J Environ Sci 2008;20:14-27. doi:http://dx.doi.org/10.1016/S10010742(08)60002-9.

[36] Bachu S. Sequestration of CO2 in geological media: criteria and approach for site selection in response to climate change. Energy Convers Manag 2000;41:953-70. doi:https://doi.org/10.1016/S0196-8904(99)00149-1.

[37] Burnol A, Thinon I, Ruffine L, Herri J-M. Influence of impurities (nitrogen and methane) on the CO2 storage capacity as sediment-hosted gas hydrates - Application in the area of the Celtic Sea and the Bay of Biscay. Int J Greenh Gas Control 2015;35:96-109. doi:https://doi.org/10.1016/j.ijggc.2015.01.018.

[38] Frerichs J, Rakoczy J, Ostertag-Henning C, Krüger M. Viability and Adaptation Potential of Indigenous Microorganisms from Natural Gas Field Fluids in High Pressure Incubations with Supercritical CO2. Environ Sci Technol 2014;48:1306-14. doi:10.1021/es4027985.

[39] Yang F, Pang Z, Lin L, Jia Z, Zhang F, Duan Z, et al. Hydrogeochemical and isotopic evidence for trans-formational flow in a sedimentary basin: Implications for CO2 storage. Appl Geochemistry 2013;30:4-15. doi:https://doi.org/10.1016/j.apgeochem.2012.08.024.

[40] Javaheri M, Jessen K. Residual Trapping in Simultaneous Injection of CO2 and Brine in Saline Aquifers. SPE West. North Am. Reg. Meet., Society of Petroleum Engineers; 2011, p. 603. 
doi:10.2118/144613-MS.

[41] Trémosa J, Castillo C, Vong CQ, Kervévan C, Lassin A, Audigane P. Long-term assessment of geochemical reactivity of $\mathrm{CO} 2$ storage in highly saline aquifers: Application to Ketzin, In Salah and Snøhvit storage sites. Int J Greenh Gas Control 2014;20:2-26. doi:https://doi.org/10.1016/j.ijggc.2013.10.022.

[42] Quattrocchi F, Boschi E, Spena A, Buttinelli M, Cantucci B, Procesi M. Synergic and conflicting issues in planning underground use to produce energy in densely populated countries, as Italy: Geological storage of $\mathrm{CO} 2$, natural gas, geothermics and nuclear waste disposal. Appl Energy 2013;101:393-412. doi:https://doi.org/10.1016/j.apenergy.2012.04.028.

[43] Li Z, Dong M, Li S, Huang S. CO2 sequestration in depleted oil and gas reservoirs-caprock characterization and storage capacity. Energy Convers Manag 2006;47:1372-82. doi:https://doi.org/10.1016/j.enconman.2005.08.023.

[44] Wang Z, Wang J, Lan C, He I, Ko V, Ryan D, et al. A study on the impact of SO2 on CO2 injectivity for CO2 storage in a Canadian saline aquifer. Appl Energy 2016;184:329-36. doi:https://doi.org/10.1016/j.apenergy.2016.09.067.

[45] Bachu S, Adams JJ. Sequestration of $\mathrm{CO} 2$ in geological media in response to climate change: capacity of deep saline aquifers to sequester $\mathrm{CO} 2$ in solution. Energy Convers Manag 2003;44:3151-75. doi:https://doi.org/10.1016/S0196-8904(03)00101-8.

[46] Bachu S. Screening and selection criteria, and characterisation techniques for the geological sequestration of carbon dioxide (CO2). In: Maroto-Valer MM, editor. Dev. Innov. Carbon Dioxide Capture Storage Technol., vol. 2, Woodhead Publishing; 2010, p. 27-56. doi:https://doi.org/10.1533/9781845699581.1.27.

[47] Procesi M, Cantucci B, Buttinelli M, Armezzani G, Quattrocchi F, Boschi E. Strategic use of the underground in an energy mix plan: Synergies among CO2, CH4 geological storage and geothermal energy. Latium Region case study (Central Italy). Appl Energy 2013;110:104-31. doi:https://doi.org/10.1016/j.apenergy.2013.03.071.

[48] CO2CRC. Injection \& storage 2015. http://old.co2crc.com.au/aboutccs/storage (accessed May 16, 2017).

[49] Mito S, Xue Z, Sato T. Effect of formation water composition on predicting CO2 behavior: A case study at the Nagaoka post-injection monitoring site. Appl Geochemistry 2013;30:33-40. doi:https://doi.org/10.1016/j.apgeochem.2012.08.020.

[50] Le Gallo Y, Couillens P, Manai T. CO2 Sequestration in Depleted Oil or Gas Reservoirs n.d. doi:10.2118/74104-MS.

[51] Cantucci B, Montegrossi G, Vaselli O, Tassi F, Quattrocchi F, Perkins EH. Geochemical modeling of $\mathrm{CO} 2$ storage in deep reservoirs: The Weyburn Project (Canada) case study. Chem Geol 2009;265:181-97. doi:https://doi.org/10.1016/j.chemgeo.2008.12.029.

[52] Wdowin M, Tarkowski R, Manecki M. Petrographic-mineralogical and textural changes in reservoir and sealing rocks (Zaosie anticline) as a result of a long-term experiment in CO2-brine-rock interactions. Gospod Surowcami Miner - Miner Resour Manag 2013;29:137. doi:10.2478/gospo2013-0044.

[53] Lee Y, Kim K, Sung W, Yoo I. Analysis of the Leakage Possibility of Injected CO2 in a Saline Aquifer. Energy \& Fuels 2010;24:3292-8. doi:10.1021/ef100073m.

[54] Han WS, Lee S-Y, Lu C, McPherson BJ, Esser R. Role of correlation structures of permeability field on residual trapping mechanisms and buoyancy-driven $\mathrm{CO} 2$ migration. Energy Procedia 2009;1:3493-8. doi:http://dx.doi.org/10.1016/j.egypro.2009.02.141.

[55] Armitage PJ, Worden RH, Faulkner DR, Aplin AC, Butcher AR, Espie AA. Mercia Mudstone Formation caprock to carbon capture and storage sites: petrology and petrophysical characteristics. J Geol Soc London 2013;170:119-32. doi:10.1144/jgs2012-049.

[56] Fleury, M., Pironon, J., Le Nindre, Y.M., Bildstein, O., Berne, P., Lagneau, V., et al. Evaluating 
Sealing Efficiency of Caprocks for CO2 Storage: an Overview of the Geocarbone-Integrity Program and Results. Oil Gas Sci Technol - Rev IFP 2010;65:435-44. doi:10.2516/ogst/2010007.

[57] Buttinelli M, Procesi M, Cantucci B, Quattrocchi F, Boschi E. The geo-database of caprock quality and deep saline aquifers distribution for geological storage of CO2 in Italy. Energy 2011;36:296883. doi:https://doi.org/10.1016/j.energy.2011.02.041.

[58] Zhao X, Liao X, Wang W, Chen C, Rui Z, Wang H. The CO2 storage capacity evaluation: Methodology and determination of key factors. J Energy Inst 2014;87:297-305. doi:10.1016/j.joei.2014.03.032.

[59] De Silva PNK, Ranjith PG. A study of methodologies for CO2 storage capacity estimation of saline aquifers. Fuel 2012;93:13-27. doi:https://doi.org/10.1016/j.fuel.2011.07.004.

[60] Kim Y, Jang H, Kim J, Lee J. Prediction of storage efficiency on CO2 sequestration in deep saline aquifers using artificial neural network. Appl Energy 2017;185, Part:916-28. doi:https://doi.org/10.1016/j.apenergy.2016.10.012.

[61] Meng Q, Jiang X. Numerical analyses of the solubility trapping of CO2 storage in geological formations. Appl Energy 2014;130:581-91. doi:https://doi.org/10.1016/j.apenergy.2014.01.037.

[62] Bachu S, Bonijoly D, Bradshaw J, Burruss R, Holloway S, Christensen NP, et al. CO2 storage capacity estimation: Methodology and gaps. Int J Greenh Gas Control 2007;1:430-43. doi:https://doi.org/10.1016/S1750-5836(07)00086-2.

[63] Kneafsey TJ, Pruess K. Laboratory Flow Experiments for Visualizing Carbon Dioxide-Induced, Density-Driven Brine Convection. Transp Porous Media 2010;82:123-39. doi:10.1007/s11242009-9482-2.

[64] Bachu S, Gunter WD, Perkins EH. Aquifer disposal of CO2: Hydrodynamic and mineral trapping. Energy Convers Manag 1994;35:269-79. doi:http://dx.doi.org/10.1016/0196-8904(94)90060-4.

[65] Hellevang H, Haile BG, Tetteh A. Experimental study to better understand factors affecting the $\mathrm{CO} 2$ mineral trapping potential of basalt. Greenh Gases Sci Technol 2017;7:143-57. doi:10.1002/ghg.1619.

[66] Sundal A, Hellevang H, Miri R, Dypvik H, Nystuen JP, Aagaard P. Variations in mineralization potential for $\mathrm{CO} 2$ related to sedimentary facies and burial depth - a comparative study from the North Sea. Energy Procedia 2014;63:5063-70. doi:http://dx.doi.org/10.1016/j.egypro.2014.11.536.

[67] Gunter WD, Bachu S, Benson S. The role of hydrogeological and geochemical trapping in sedimentary basins for secure geological storage of carbon dioxide. Geol Soc London, Spec Publ 2004;233:129-45. doi:10.1144/GSL.SP.2004.233.01.09.

[68] Wildgust N, Gilboy C, Tontiwachwuthikul P. Introduction to a decade of research by the IEAGHG weyburn-midale CO2 monitoring and storage project. Int J Greenh Gas Control 2013;16:S1-4. doi:10.1016/j.ijggc.2013.03.014.

[69] Ryerson FJ., Lake J., Whittaker S. d, Johnson JW. e. Natural CO2 accumulations in the western Williston Basin: A mineralogical analog for $\mathrm{CO} 2$ injection at the Weyburn site. Int J Greenh Gas Control 2013;16:S25-34. doi:10.1016/j.ijggc.2012.12.015.

[70] Hawkes CD., Gardner C. Pressure transient testing for assessment of wellbore integrity in the IEAGHG Weyburn-Midale CO2 Monitoring and Storage Project. Int J Greenh Gas Control 2013;16:S50-61. doi:10.1016/j.ijggc.2012.12.022.

[71] Preston C., Whittaker S., Rostron B., Chalaturnyk R., White D., Hawkes C., et al. IEA GHG Weyburn-Midale CO2 monitoring and storage project-moving forward with the Final Phase. Energy Procedia, vol. 1, 2009, p. 1743-50. doi:10.1016/j.egypro.2009.01.228.

[72] Heinemann N., Wilkinson M., Pickup GE., Haszeldine RS., Cutler NA. c. CO2 storage in the offshore UK Bunter Sandstone Formation. Int J Greenh Gas Control 2012;6:210-9. doi:10.1016/j.ijggc.2011.11.002.

[73] Li Q, Wei Y-N, Liu G, Lin Q. Combination of CO2 geological storage with deep saline water recovery in western China: Insights from numerical analyses. Appl Energy 2014;116:101-10. 
doi:https://doi.org/10.1016/j.apenergy.2013.11.050.

[74] Alexander D, Augustus A. Evaluating the Effects of CO2 Injection in Faulted Oil Reservoirs n.d. doi:10.2118/169933-MS.

[75] Zangeneh H, Jamshidi S, Soltanieh M. Coupled optimization of enhanced gas recovery and carbon dioxide sequestration in natural gas reservoirs: Case study in a real gas field in the south of Iran. Int J Greenh Gas Control 2013;17:515-22. doi:https://doi.org/10.1016/j.ijggc.2013.06.007.

[76] Smyth RC, Meckel TA. Best Management Practices for subseabed geologic sequestration of carbon dioxide. 2012 Ocean., 2012, p. 1-6. doi:10.1109/OCEANS.2012.6404971.

[77] SIS. Enhanced Oil Recovery (EOR). Schlumberger Inf Solut Ltd 2017. http://www.slb.com/services/technical_challenges/enhanced_oil_recovery.aspx (accessed April 20, 2017).

[78] Jaramillo P, Griffin WM, Matthews HS. Comparative Analysis of the Production Costs and LifeCycle GHG Emissions of FT Liquid Fuels from Coal and Natural Gas. Environ Sci Technol 2008;42:7559-65. doi:10.1021/es8002074.

[79] GCCSI. Appendix A: CO2 for use in enhanced oil recovery (EOR). Glob CCS Inst 2017. http://hub.globalccsinstitute.com/publications/accelerating-uptake-ccs-industrial-use-capturedcarbon-dioxide/appendix-co2-use (accessed April 20, 2017).

[80] International Energy Agency IEA. Storing CO 2 through Enhanced Oil Recovery, Combining EOR with CO2 storage (EOR) for profit. Paris: 2015.

[81] Marston P. Bridging the gap: An analysis and comparison of legal and regulatory frameworks for CO2-EOR and CO2-CCS. 2013.

[82] Porter RTJ, Fairweather M, Pourkashanian M, Woolley RM. The range and level of impurities in CO2 streams from different carbon capture sources. Int J Greenh Gas Control 2015;36:161-74. doi:https://doi.org/10.1016/j.ijggc.2015.02.016.

[83] Jarrell PM, Fox CE, Stein MH, Webb SL, Johns RT, Day LA. Practical Aspects of CO2 Flooding. TX, USA: Society of Petroleum Engineers; 2002.

[84] IEAGHG. Effects of Impurities on Geological Storage of CO2. Cheltenham, UK: 2011.

[85] Morgan H, Large D, Bateman K, Hanstock D, Gregory S. The effect of oxygen impurities on deep subsurface microbial activity at a CCS site. Energy Procedia n.d.

[86] Igunnu ET, Chen GZ. Produced water treatment technologies. Int J Low-Carbon Technol 2014;9:157. doi:10.1093/ijlct/cts049.

[87] EPA. Class II Oil and Gas Related Injection Wells. United States Environ Prot Agency n.d. https://www.epa.gov/uic/class-ii-oil-and-gas-related-injection-wells (accessed October 8, 2015).

[88] White D. Monitoring CO2 storage during EOR at the weyburn-midale field. Lead Edge 2009;28:838-42. doi:10.1190/1.3167786.

[89] MIT. Carbon Capture and Sequestration Technologies. Massachusetts Inst Technol 2015. https://sequestration.mit.edu/tools/projects/index.html (accessed October 1, 2015).

[90] Gao RS, Sun AY, Nicot J-P. Identification of a representative dataset for long-term monitoring at the Weyburn CO2-injection enhanced oil recovery site, Saskatchewan, Canada. Int J Greenh Gas Control 2016;54, Part 2:454-65. doi:https://doi.org/10.1016/j.ijggc.2016.05.028.

[91] Zaluski W, El-Kaseeh G, Lee S-Y, Piercey M, Duguid A. Monitoring technology ranking methodology for CO2-EOR sites using the Weyburn-Midale Field as a case study. Int J Greenh Gas Control 2016;54, Part 2:466-78. doi:https://doi.org/10.1016/j.ijggc.2016.06.012.

[92] Verdon JP. Using microseismic data recorded at the Weyburn CCS-EOR site to assess the likelihood of induced seismic activity. Int $\mathbf{J}$ Greenh Gas Control 2016;54, Part 2:421-8. doi:https://doi.org/10.1016/j.ijggc.2016.03.018.

[93] Jensen GKS. Weyburn oilfield core assessment investigating cores from pre and post $\mathrm{CO} 2$ injection: Determining the impact of CO2 on the reservoir. Int J Greenh Gas Control 2016;54, Part 2:490-8. doi:https://doi.org/10.1016/j.ijggc.2016.09.003. 
[94] Hutcheon I, Shevalier M, Durocher K, Bloch J, Johnson G, Nightingale M, et al. Interactions of $\mathrm{CO} 2$ with formation waters, oil and minerals and $\mathrm{CO} 2$ storage at the Weyburn IEA EOR site, Saskatchewan, Canada. Int J Greenh Gas Control 2016;53:354-70. doi:https://doi.org/10.1016/j.ijggc.2016.08.004.

[95] Perera MSA, Gamage RP, Rathnaweera TD, Ranathunga AS, Koay A, Choi X. A Review of CO2Enhanced Oil Recovery with a Simulated Sensitivity Analysis. Energies 2016;9.

[96] Tenasaka I. Global CCS Institute Bridging the Commercial Gap For Carbon Capture and Storage July 2011. Maryland, USA: 2011.

[97] Sweatman RE, Crookshank S, Edman S. Outlook and Technologies for Offshore CO2 EOR/CCS Projects. Offshore Technol. Conf., Offshore Technology Conference; 2011. doi:10.4043/21984-MS.

[98] Thomas, S. Enhanced Oil Recovery - An Overview. Oil Gas Sci Technol - Rev IFP 2008;63:9-19. doi:10.2516/ogst:2007060.

[99] Kuuskraa V, Ferguson R. Storing CO2 with enhanced oil recovery. Washington, D.C.: 2008.

[100] Krooss BM. c, Van Bergen F., Gensterblum Y., Siemons N., Pagnier HJM., David P. High-pressure methane and carbon dioxide adsorption on dry and moisture-equilibrated Pennsylvanian coals. Int $\mathbf{J}$ Coal Geol 2002;51:69-92. doi:10.1016/S0166-5162(02)00078-2.

[101] Gilliland ES., Ripepi N., Conrad M., Miller MJ., Karmis M. b. Selection of monitoring techniques for a carbon storage and enhanced coalbed methane recovery pilot test in the Central Appalachian Basin. Int J Coal Geol 2013;118:105-12. doi:10.1016/j.coal.2013.07.007.

[102] IEAGHG. CO2 storage in depleted gas fields. Oxford, UK: 2009.

[103] Lakeman B. Alberta Research Council Enhanced Coalbed Methane Recovery Project in Alberta, Canada. 2016.

[104] Gilliland E., Ripepi N., Karmis M. b, Conrad M. An examination of MVA techniques applicable for CCUS in thin, stacked coals of the central appalachian basin. 29th Annu. Int. Pittsburgh Coal Conf. 2012, PCC 2012, vol. 3, 2012, p. 1931-8.

[105] Baublys KA., Hamilton SK., Golding SD., Vink S., Esterle J. Microbial controls on the origin and evolution of coal seam gases and production waters of the Walloon Subgroup; Surat Basin, Australia. Int J Coal Geol 2015;147-148:85-104. doi:10.1016/j.coal.2015.06.007.

[106] Matter JM. b, Stute M., Snæbjörnsdottir SÓ., Oelkers EH. d e, Gislason SR., Aradottir ES., et al. Rapid carbon mineralization for permanent disposal of anthropogenic carbon dioxide emissions. Science (80- ) 2016;352:1312-4. doi:10.1126/science.aad8132.

[107] Pollyea RM., Fairley JP., Podgorney RK., Mcling TL. Physical constraints on geologic CO2 sequestration in low-volume basalt formations. Bull Geol Soc Am 2014;126:344-51. doi:10.1130/B30874.1.

[108] McGrail BP., Schaef HT., Ho AM., Chien Y-J., Dooley JJ., Davidson CL. Potential for carbon dioxide sequestration in flood basalts. J Geophys Res Solid Earth 2006;111. doi:10.1029/2005JB004169.

[109] Gislason SR., Broecker WS., Gunnlaugsson E., Snæbjörnsdóttir S., Mesfin KG., Alfredsson HA., et al. Rapid solubility and mineral storage of CO2 in basalt. Energy Procedia, vol. 63, 2014, p. 456174. doi:10.1016/j.egypro.2014.11.489.

[110] Van Pham TH, Aagaard P, Hellevang H. On the potential for $\mathrm{CO} 2$ mineral storage in continental flood basalts - PHREEQC batch- and 1D diffusion-reaction simulations. Geochem Trans 2012:5. doi:10.1186/1467-4866-13-5.

[111] Matter JM., Broecker WS., Gislason SR., Gunnlaugsson E., Oelkers EH., Stute M., et al. The CarbFix Pilot Project - Storing carbon dioxide in basalt. Energy Procedia, vol. 4, 2011, p. 5579-85. doi:10.1016/j.egypro.2011.02.546.

[112] Goldberg DS, Takahashi T, Slagle AL. Carbon dioxide sequestration in deep-sea basalt. Proc Natl Acad Sci U S A 2008;105:9920-5. doi:10.1073/pnas.0804397105.

[113] Seifritz W. $\mathrm{CO}_{2}$ disposal by means of silicates. Nature 1990;345:486-486. doi:10.1038/345486b0. 
[114] Andreani M. c, Luquot L., Gouze P., Godard M., Hoisé E., Gibert B. Experimental study of carbon sequestration reactions controlled by the percolation of $\mathrm{CO} 2$-rich brine through peridotites. Environ Sci Technol 2009;43:1226-31. doi:10.1021/es8018429.

[115] IEAGHG. Geological storage of CO2 in basalts. 2011.

[116] Rochelle CA., Camps AP. b, Long D., Milodowski A., Bateman K., Gunn D., et al. Can CO2 hydrate assist in the underground storage of carbon dioxide? Geol Soc Spec Publ 2009;319:171-83. doi:10.1144/SP319.14.

[117] Circone S., Stern LA., Kirby SH., Durham WB., Chakoumakos BC., Rawn CJ., et al. CO2 hydrate: Synthesis, composition, structure, dissociation behavior, and a comparison to structure I CH4 hydrate. J Phys Chem B 2003;107:5529-39.

[118] Oldenburg CM. Carbon sequestration in natural gas reservoirs: Enhanced gas recovery and natural gas storage. 2003.

[119] Jemai K, Kvamme B, Vafaei MT. Theoretical studies of CO2 hydrates formation and dissociation in cold aquifers using retrasocodebright simulator. WSEAS Trans Heat Mass Transf 2014;9:15068.

[120] Talaghat MR, Esmaeilzadeh F, Fathikaljahi J. Experimental and theoretical investigation of simple gas hydrate formation with or without presence of kinetic inhibitors in a flow mini-loop apparatus. Fluid Phase Equilib 2009;279:28-40. doi:10.1016/j.fluid.2009.01.017.

[121] Ghavipour M, Ghavipour M, Chitsazan M, Najibi SH, Ghidary SS. Experimental study of natural gas hydrates and a novel use of neural network to predict hydrate formation conditions. Chem Eng Res Des 2013;91:264-73. doi:https://doi.org/10.1016/j.cherd.2012.08.010.

[122] Ruffine L, Donval JP, Charlou JL, Cremière A, Zehnder BH. Experimental study of gas hydrate formation and destabilisation using a novel high-pressure apparatus. Mar Pet Geol 2010;27:115765. doi:https://doi.org/10.1016/j.marpetgeo.2010.03.002.

[123] Rehder G, Leifer I, Brewer PG, Friederich G, Peltzer ET. Controls on methane bubble dissolution inside and outside the hydrate stability field from open ocean field experiments and numerical modeling. Mar Chem 2009;114:19-30. doi:https://doi.org/10.1016/j.marchem.2009.03.004.

[124] Khabibullin T, Falcone G, Teodoriu C. Drilling through gas-hydrate sediments: Managing wellborestability risks. SPE Drill Complet 2011;26:287-94.

[125] Garapati N, Randolph JB, Saar MO. Brine displacement by CO2, energy extraction rates, and lifespan of a CO2-limited CO2-Plume Geothermal (CPG) system with a horizontal production well. Geothermics 2015;55:182-94. doi:https://doi.org/10.1016/j.geothermics.2015.02.005.

[126] Pruess K. On production behavior of enhanced geothermal systems with $\mathrm{CO} 2$ as working fluid. Energy Convers Manag 2008;49:1446-54. doi:10.1016/j.enconman.2007.12.029.

[127] Zhang L, Ezekiel J, Li D, Pei J, Ren S. Potential assessment of CO2 injection for heat mining and geological storage in geothermal reservoirs of China. Appl Energy 2014;122:237-46. doi:https://doi.org/10.1016/j.apenergy.2014.02.027.

[128] Pruess K. Enhanced geothermal systems (EGS) using CO2 as working fluid—A novel approach for generating renewable energy with simultaneous sequestration of carbon. Geothermics 2006;35:35167. doi:https://doi.org/10.1016/j.geothermics.2006.08.002.

[129] Plaksina T, White C. Modeling coupled convection and carbon dioxide injection for improved heat harvesting in geopressured geothermal reservoirs. Geotherm Energy 2016;4:2. doi:10.1186/s40517016-0044-x.

[130] Ré CL, Kaszuba JP, Moore JN, McPherson BJ. Fluid-rock interactions in CO2-saturated, granitehosted geothermal systems: Implications for natural and engineered systems from geochemical experiments and models. Geochim Cosmochim Acta 2014;141:160-78. doi:10.1016/j.gca.2014.06.015.

[131] Adams EE, Caldeira K. Ocean Storage of CO2. Elements 2008;4:319-24. doi:10.2113/gselements.4.5.319. 
[132] Khatiwala S, Tanhua T, Mikaloff Fletcher S, Gerber M, Doney SC, Graven HD, et al. Global ocean storage of anthropogenic carbon. Biogeosciences 2013;10:2169-91. doi:10.5194/bg-10-2169-2013.

[133] Hofmann M, Schellnhuber HJ. Ocean acidification: a millennial challenge. Energy Environ Sci 2010;3:1883-96. doi:10.1039/C000820F.

[134] Jacobson MZ. Review of solutions to global warming, air pollution, and energy security. Energy Environ Sci 2009;2:148-73. doi:10.1039/B809990C.

[135] IMO. Convention on the prevention of marine pollution by dumping of wastes and other matter (London Convention 1972). Compil. Full Texts London Conv. 19721996 Protoc. Thereto, London: International Maritime Organisation; 1997.

[136] ZeroCO2. CCS-International legislation. Zero Emiss Resour Organ 2015. http://www.zeroco2.no/introduction/ccs-international-legislation (accessed December 10, 2015).

[137] Xu Y, Ishizaka J, Aoki S. Simulations of the distribution of sequestered CO2 in the North Pacific using a regional general circulation model. Energy Convers Manag 1999;40:683-91. doi:https://doi.org/10.1016/S0196-8904(98)00138-1.

[138] Hill C, Bugnion V, Follows M, Marshall J. Evaluating carbon sequestration efficiency in an ocean circulation model by adjoint sensitivity analysis. J Geophys Res Ocean 2004;109:n/a--n/a. doi:10.1029/2002JC001598.

[139] Masuda Y, Yamanaka Y, Sasai Y, Magi M, Ohsumi T. Site selection in CO2 ocean sequestration: Dependence of $\mathrm{CO} 2$ injection rate on eddy activity distribution. Int J Greenh Gas Control 2009;3:67-76. doi:https://doi.org/10.1016/j.ijggc.2008.07.002.

[140] Sanna A, Uibu M, Caramanna G, Kuusik R, Maroto-Valer MM. A review of mineral carbonation technologies to sequester CO2. Chem Soc Rev 2014;43:8049-80. doi:10.1039/C4CS00035H.

[141] Assima GP, Larachi F, Molson J, Beaudoin G. Impact of temperature and oxygen availability on the dynamics of ambient $\mathrm{CO} 2$ mineral sequestration by nickel mining residues. Chem Eng $\mathrm{J}$ 2014;240:394-403. doi:https://doi.org/10.1016/j.cej.2013.12.010.

[142] Bobicki ER, Liu Q, Xu Z, Zeng H. Carbon capture and storage using alkaline industrial wastes. Prog Energy Combust Sci 2012;38:302-20. doi:https://doi.org/10.1016/j.pecs.2011.11.002.

[143] Lim M, Han G-C, Ahn J-W, You K-S. Environmental Remediation and Conversion of Carbon Dioxide (CO2) into Useful Green Products by Accelerated Carbonation Technology. Int J Environ Res Public Health 2010;7:203-28. doi:10.3390/ijerph7010203.

[144] Martínez I, Grasa G, Murillo R, Arias B, Abanades JC. Modelling the continuous calcination of $\mathrm{CaCO} 3$ in a Ca-looping system. Chem Eng J 2013;215-216:174-81. doi:https://doi.org/10.1016/j.cej.2012.09.134.

[145] Calabrò A, Deiana P, Fiorini P, Girardi G, Stendardo S. Possible optimal configurations for the ZECOMIX high efficiency zero emission hydrogen and power plant. Energy 2008;33:952-62. doi:https://doi.org/10.1016/j.energy.2008.01.004.

[146] Olajire AA. A review of mineral carbonation technology in sequestration of CO2. J Pet Sci Eng 2013;109:364-92. doi:https://doi.org/10.1016/j.petrol.2013.03.013.

[147] Matter JM, Kelemen PB. Permanent storage of carbon dioxide in geological reservoirs by mineral carbonation. Nat Geosci 2009;2:837-41.

[148] Cipolli F, Gambardella B, Marini L, Ottonello G, Zuccolini MV. Geochemistry of high-pH waters from serpentinites of the Gruppo di Voltri (Genova, Italy) and reaction path modeling of $\mathrm{CO} 2$ sequestration in serpentinite aquifers. Appl Geochemistry 2004;19:787-802. doi:https://doi.org/10.1016/j.apgeochem.2003.10.007.

[149] Bruni J, Canepa M, Chiodini G, Cioni R, Cipolli F, Longinelli A, et al. Irreversible water-rock mass transfer accompanying the generation of the neutral, $\mathrm{Mg}-\mathrm{HCO} 3$ and high- $\mathrm{pH}, \mathrm{Ca}-\mathrm{OH}$ spring waters of the Genova province, Italy. Appl Geochemistry 2002;17:455-74. doi:https://doi.org/10.1016/S0883-2927(01)00113-5.

[150] Knoope MMJ, Ramírez A, Faaij APC. The influence of uncertainty in the development of a CO2 
infrastructure network. Appl Energy 2015;158:332-47. doi:https://doi.org/10.1016/j.apenergy.2015.08.024.

[151] Kim A-R, Cho G-C, Kwon T-H. Site characterization and geotechnical aspects on geological storage of CO2 in Korea. Geosci J 2014;18:167-79. doi:10.1007/s12303-013-0065-4.

[152] Wei N, Li X, Wang Y, Dahowski RT, Davidson CL, Bromhal GS. A preliminary sub-basin scale evaluation framework of site suitability for onshore aquifer-based $\mathrm{CO} 2$ storage in China. Int $\mathrm{J}$ Greenh Gas Control 2013;12:231-46. doi:https://doi.org/10.1016/j.ijggc.2012.10.012.

[153] Grataloup S, Bonijoly D, Brosse E, Dreux R, Garcia D, Hasanov V, et al. A site selection methodology for $\mathrm{CO} 2$ underground storage in deep saline aquifers: case of the Paris Basin. Energy Procedia 2009;1:2929-36. doi:http://dx.doi.org/10.1016/j.egypro.2009.02.068.

[154] Meyer R, May F, Müller C, Geel K, Bernstone C. Regional search, selection and geological characterization of a large anticlinal structure, as a candidate site for CO2-storage in northern Germany. Environ Geol 2008;54:1607-18. doi:10.1007/s00254-007-0939-8.

[155] Birkholzer J, Tsang C-F. Introduction to the special issue on site characterization for geological storage of CO2. Environ Geol 2008;54:1579-81. doi:10.1007/s00254-007-0938-9.

[156] Bachu S. Sequestration of $\mathrm{CO} 2$ in geological media in response to climate change: road map for site selection using the transform of the geological space into the $\mathrm{CO} 2$ phase space. Energy Convers Manag 2002;43:87-102. doi:https://doi.org/10.1016/S0196-8904(01)00009-7.

[157] Hitchon B, Gunter WD, Gentzis T, Bailey RT. Sedimentary basins and greenhouse gases: a serendipitous association. Energy Convers Manag 1999;40:825-43. doi:https://doi.org/10.1016/S0196-8904(98)00146-0.

[158] van der Meer LGH. The conditions limiting CO2 storage in aquifers. Energy Convers Manag 1993;34:959-66. doi:http://dx.doi.org/10.1016/0196-8904(93)90042-9.

[159] Holloway S, Savage D. The potential for aquifer disposal of carbon dioxide in the UK. Energy Convers Manag 1993;34:925-32. doi:http://dx.doi.org/10.1016/0196-8904(93)90038-C.

[160] Govindan R., Babaei M., Korre A., Shi J-Q., Durucana S., Norden B., et al. CO2 storage uncertainty and risk assessment for the post-closure period at the Ketzin pilot site in Germany. Energy Procedia, vol. 63, 2014, p. 4758-65. doi:10.1016/j.egypro.2014.11.506.

[161] Szizybalski A, Kollersberger T, Möller F, Martens S, Liebscher A, Kühn M. Communication Supporting the Research on CO2 Storage at the Ketzin Pilot Site, Germany - A Status Report after Ten Years of Public Outreach. Energy Procedia 2014;51:274-80. doi:http://dx.doi.org/10.1016/j.egypro.2014.07.032.

[162] CO2CRC. CO2 storage demonstration projects around the world: active projects 2009.

[163] Neuzil CE, Pollock DW. Erosional Unloading and Fluid Pressures in Hydraulically "Tight" Rocks. J Geol 1983;91:179-93.

[164] Bachu S. Synthesis and model of formation-water flow, Alberta Basin, Canada. Am Assoc Pet Geol Bull 1995;79:1159-78.

[165] Quattrocchi F. In search of evidence of deep fluid discharges and pore pressure evolution in the crust to explain the seismicity style of the Umbria-Marche 1997-1998 seismic sequence (Central Italy). Ann Di Geofis 1999;42:609-36.

[166] Walter M, Swart R, Summons R. Oil and gas shows numerous in Nama Basin, southern Africa. Oil Gas J 1996;94:76-80.

[167] Sawyer D, Harding R, Pozlott C, Dickey P, Harding R, Pozlott C, et al. Carbon Capture and Storage - The Environmental and Economic Case and Challenges. Alberta: 2008.

[168] Wei N, Li X, Wang Y, Zhu Q, Liu S, Liu N, et al. Geochemical impact of aquifer storage for impure CO2 containing O2 and N2: Tongliao field experiment. Appl Energy 2015;145:198-210. doi:https://doi.org/10.1016/j.apenergy.2015.01.017.

[169] CO2CRC. CO2 dispersion. Coop Res Cent Greenh Gas Technol 2015. http://old.co2crc.com.au/images/imagelibrary/stor_diag/co2_dispersion_post_inject_media.jpg 
(accessed May 16, 2017).

[170] Quattrocchi F, Galli G, Gasparini A, Magno L, Pizzino L, Sciarra, et al. Very slightly anomalous leakage of $\mathrm{CO} 2, \mathrm{CH} 4$ and radon along the main activated faults of the strong L'Aquila earthquake (Magnitude 6.3, Italy). Implications for risk assessment monitoring tools \& public acceptance of $\mathrm{CO} 2$ and $\mathrm{CH} 4$ underground storage. Energy Procedia 2011;4:4067-75. doi:http://dx.doi.org/10.1016/j.egypro.2011.02.349.

[171] Voltattorni N, Sciarra A, Caramanna G, Cinti D, Pizzino L, Quattrocchi F. Gas geochemistry of natural analogues for the studies of geological $\mathrm{CO} 2$ sequestration. Appl Geochemistry 2009;24:1339-46. doi:https://doi.org/10.1016/j.apgeochem.2009.04.026.

[172] Pearce J, Czernichowski-Lauriol I, Lombardi S, Brune S, Nador A, Baker J, et al. A review of natural $\mathrm{CO} 2$ accumulations in Europe as analogues for geological sequestration. Geol Soc London, Spec Publ 2004;233:29-41. doi:10.1144/GSL.SP.2004.233.01.04.

[173] Annunziatellis A, Beaubien SE, Bigi S, Ciotoli G, Coltella M, Lombardi S. Gas migration along fault systems and through the vadose zone in the Latera caldera (central Italy): Implications for CO2 geological storage. Int J Greenh Gas Control 2008;2:353-72. doi:https://doi.org/10.1016/j.ijggc.2008.02.003.

[174] Pearce JM, Holloway S, Wacker H, Nelis MK, Rochelle C, Bateman K. Natural occurrences as analogues for the geological disposal of carbon dioxide. Energy Convers Manag 1996;37:1123-8. doi:http://dx.doi.org/10.1016/0196-8904(95)00309-6.

[175] Miocic JM, Gilfillan SM V, Roberts JJ, Edlmann K, McDermott CI, Haszeldine RS. Controls on $\mathrm{CO} 2$ storage security in natural reservoirs and implications for $\mathrm{CO} 2$ storage site selection. Int $\mathrm{J}$ Greenh Gas Control 2016;51:118-25. doi:https://doi.org/10.1016/j.ijggc.2016.05.019.

[176] Verdon JP, Kendall J-M, Stork AL, Chadwick RA, White DJ, Bissell RC. Comparison of geomechanical deformation induced by megatonne-scale CO2 storage at Sleipner, Weyburn, and In Salah. Proc Natl Acad Sci 2013;110:E2762-71. doi:10.1073/pnas.1302156110.

[177] Jeandel E, Battani A, Sarda P. Lessons learned from natural and industrial analogues for storage of carbon dioxide. Int J Greenh Gas Control 2010;4:890-909. doi:https://doi.org/10.1016/j.ijggc.2010.06.005.

[178] Rutqvist J. The Geomechanics of CO2 Storage in Deep Sedimentary Formations. Geotech Geol Eng 2012;30:525-51. doi:10.1007/s10706-011-9491-0.

[179] Skerlec GM. Evaluating Top and Fault Seal. Treatise Pet. Geol. / Handb. Pet. Geol. Explor. Oil Gas Traps, American Association of Petroleum Geologists; 1999.

[180] Lowry DC. Economic Evaluation of Prospects with a Top Seal Risk. Eval. fault cap rock seals AAPG Hedb., The American Association of Petroleum Geologist; n.d., p. 261-8. doi:10.1306/1060769H23172.

[181] Middleton RS, Carey JW, Currier RP, Hyman JD, Kang Q, Karra S, et al. Shale gas and non-aqueous fracturing fluids: Opportunities and challenges for supercritical CO2. Appl Energy 2015;147:500 9. doi:https://doi.org/10.1016/j.apenergy.2015.03.023.

[182] IEAGHG. Induced seismicity and its implications for CO2 storage. Cheltenham, UK: 2013.

[183] Buttinelli M, Improta L, Bagh S, Chiarabba C. Inversion of inherited thrusts by wastewater injection induced seismicity at the Val d'Agri oilfield (Italy). Sci Rep 2016;6:37165.

[184] Improta L., Valoroso L., Piccinini D., Chiarabba C. A detailed analysis of wastewater-induced seismicity in the Val d'Agri oil field (Italy). Geophys Res Lett 2015;42:2682-90. doi:10.1002/2015GL063369.

[185] Verdon JP. Significance for secure CO2 storage of earthquakes induced by fluid injection. Environ Res Lett 2014;9:64022.

[186] Maxwell SC, Shemeta JE, Campbell E, Quirk DJ. Microseismic Deformation Rate Monitoring n.d. doi:10.2118/116596-MS.

[187] Nicholson C, Wesson RL. Earthquake Hazard Associated With Deep Well Injection - A Report to 
the U.S. Environmental Protection Agency. vol. 1951. 1990.

[188] LeNeveu DM. CQUESTRA, a risk and performance assessment code for geological sequestration of carbon dioxide. Energy Convers Manag 2008;49:32-46. doi:https://doi.org/10.1016/j.enconman.2007.06.001.

[189] Nordbotten JM, Celia MA, Bachu S, Dahle HK. Semianalytical Solution for CO2 Leakage through an Abandoned Well. Environ Sci Technol 2005;39:602-11. doi:10.1021/es035338i.

[190] Scherer GW., Celia MA., Prévost J-H., Bachu S., Bruant R., Duguid A., et al. Leakage of CO2 Through Abandoned Wells: Role of Corrosion of Cement. 2005. doi:10.1016/B978-0080445700/50136-7.

[191] Ide ST, Friedmann SJ, Herzog HJ. CO2 leakage through existing wells: current technology and regulations. 8th Int Conf Greenh Gas Control Technol 2006:1-6.

[192] Connell L, Down D, Lu M, Hay D, Heryanto D. An investigation into the integrity of wellbore cement in $\mathrm{CO} 2$ storage wells: Core flooding experiments and simulations. Int J Greenh Gas Control 2015;37:424-40. doi:https://doi.org/10.1016/j.ijggc.2015.03.038.

[193] Quattrocchi F, Boschi E. Case histories in scientific and pseudo-scientific mass-media communication in energy/heat production from underground (geogas storage, geothermics, hydrocarbons), in the frame of NIMBY syndrome enhancement in Europe: The proposal of a new European direct. Offshore Mediterr. Conf., 2015.

[194] IEAGHG. Long term integrity of CO2 storage - well abandonment. 2009.

[195] Gaus I. Role and impact of CO2-rock interactions during CO2 storage in sedimentary rocks. Int J Greenh Gas Control 2010;4:73-89. doi:https://doi.org/10.1016/j.ijggc.2009.09.015.

[196] MacQuarrie KTB, Mayer KU. Reactive transport modeling in fractured rock: A state-of-the-science review. Earth-Science Rev 2005;72:189-227. doi:https://doi.org/10.1016/j.earscirev.2005.07.003.

[197] Wang JG, Peng Y. Numerical modeling for the combined effects of two-phase flow, deformation, gas diffusion and CO2 sorption on caprock sealing efficiency. J Geochemical Explor 2014;144, Part:154-67. doi:https://doi.org/10.1016/j.gexplo.2013.12.011.

[198] Vilarrasa V, Rutqvist J. Thermal effects on geologic carbon storage. Earth-Science Rev 2017;165:245-56. doi:https://doi.org/10.1016/j.earscirev.2016.12.011.

[199] Chiquet P. b, Broseta D., Thibeau S. Wettability alteration of caprock minerals by carbon dioxide. Geofluids 2007;7:112-22. doi:10.1111/j.1468-8123.2007.00168.x.

[200] Siemons N, Bruining H, Castelijns H, Wolf K-H. Pressure dependence of the contact angle in a CO2-H2O-coal system. J Colloid Interface Sci 2006;297:755-61. doi:https://doi.org/10.1016/j.jcis.2005.11.047.

[201] Yang D, Tontiwachwuthikul P, Gu Y. Interfacial Interactions between Reservoir Brine and CO2 at High Pressures and Elevated Temperatures. Energy \& Fuels 2005;19:216-23. doi:10.1021/ef049792z.

[202] Yang D, Tontiwachwuthikul P, Gu Y. Interfacial Tensions of the Crude Oil + Reservoir Brine + $\mathrm{CO} 2$ Systems at Pressures up to $31 \mathrm{MPa}$ and Temperatures of $27^{\circ} \mathrm{C}$ and $58^{\circ} \mathrm{C}$. J Chem Eng Data 2005;50:1242-9. doi:10.1021/je0500227.

[203] Li S., Dong M., Li Z., Huang S., Qing H., Nickel E. Gas breakthrough pressure for hydrocarbon reservoir seal rocks: Implications for the security of long-term CO2 storage in the Weyburn field. Geofluids 2005;5:326-34. doi:10.1111/j.1468-8123.2005.00125.x.

[204] Hildenbrand A., Schlömer S. d, Krooss BM. c. Gas breakthrough experiments on fine-grained sedimentary rocks. Geofluids 2002;2:3-23. doi:10.1046/j.1468-8123.2002.00031.x.

[205] Sminchak J, Gupta N. Aspects of induced seismic activity and deep-well sequestration of carbon dioxide. Environ Geosci 2003;10:81-9. doi:10.1306/eg.04040302009.

[206] Beaubien SE, Jones DG, Gal F, Barkwith AKAP, Braibant G, Baubron J-C, et al. Monitoring of near-surface gas geochemistry at the Weyburn, Canada, CO2-EOR site, 2001-2011. Int J Greenh Gas Control 2013;16, Supple:S236-62. doi:https://doi.org/10.1016/j.ijggc.2013.01.013. 
[207] Farrell NJC, Healy D, Taylor CW. Anisotropy of permeability in faulted porous sandstones. J Struct Geol 2014;63:50-67. doi:https://doi.org/10.1016/j.jsg.2014.02.008.

[208] Zhao DF, Liao XW, Yin DD. An experimental study for the effect of CO2-brine-rock interaction on reservoir physical properties. J Energy Inst 2015;88:27-35. doi:https://doi.org/10.1016/j.joei.2014.05.001.

[209] Hellevang H, Aagaard P, Jahren J. Will dawsonite form during CO2 storage? Greenh Gases Sci Technol 2014;4:191-9. doi:10.1002/ghg.1378.

[210] Hellevang H, Aagaard P, Oelkers EH, Kvamme B. Can dawsonite permanently trap CO2? Environ Sci Technol 2005;39:8281-7. doi:10.1021/es0504791.

[211] Palandri JL, Rosenbauer RJ, Kharaka YK. Ferric iron in sediments as a novel CO2 mineral trap: $\mathrm{CO} 2-\mathrm{SO} 2$ reaction with hematite. Appl Geochemistry 2005;20:2038-48. doi:https://doi.org/10.1016/j.apgeochem.2005.06.005.

[212] Li D, Jiang X. A numerical study of the impurity effects of nitrogen and sulfur dioxide on the solubility trapping of carbon dioxide geological storage. Appl Energy 2014;128:60-74. doi:https://doi.org/10.1016/j.apenergy.2014.04.051.

[213] Saeedi A, Piane CD, Esteban L, Xie Q. Flood characteristic and fluid rock interactions of a supercritical CO2, brine, rock system: South West Hub, Western Australia. Int J Greenh Gas Control 2016;54, Part 1:309-21. doi:https://doi.org/10.1016/j.ijggc.2016.09.017.

[214] Soong Y, Howard BH, Dilmore RM, Haljasmaa I, Crandall DM, Zhang L, et al. CO2/brine/rock interactions in Lower Tuscaloosa formation. Greenh Gases Sci Technol 2016;6:824-37. doi:10.1002/ghg.1611.

[215] Tarkowski R., Wdowin M., Manecki M. Petrophysical examination of CO2-brine-rock interactions-results of the first stage of long-term experiments in the potential Zaosie Anticline reservoir (central Poland) for CO2 storage. Environ Monit Assess 2015;187. doi:10.1007/s10661014-4215-6.

[216] Cantucci B. Geochemical modelling of water-rock interaction in $\mathrm{CO} 2$ storage geological reservoirs: The Weyburn project (Canada) as case study. 2007.

[217] Wang K, Xu T, Wang F, Tian H. Experimental study of CO2-brine-rock interaction during CO2 sequestration in deep coal seams. Int $J$ Coal Geol 2016;154-155:265-74. doi:https://doi.org/10.1016/j.coal.2016.01.010.

[218] Zhou Q, Birkholzer JT, Tsang C-F, Rutqvist J. A method for quick assessment of CO2 storage capacity in closed and semi-closed saline formations. Int J Greenh Gas Control 2008;2:626-39. doi:https://doi.org/10.1016/j.ijggc.2008.02.004.

[219] Goodman A, Hakala A, Bromhal G, Deel D, Rodosta T, Frailey S, et al. U.S. DOE methodology for the development of geologic storage potential for carbon dioxide at the national and regional scale. Int J Greenh Gas Control 2011;5:952-65. doi:10.1016/j.ijggc.2011.03.010.

[220] Bradshaw J, Bachu S, Bonijoly D, Burruss R, Holloway S, Christensen NP, et al. CO2 storage capacity estimation: Issues and development of standards. Int J Greenh Gas Control 2007;1:62-8. doi:https://doi.org/10.1016/S1750-5836(07)00027-8.

[221] Zhao X, Liao X. Evaluation Method of CO2 Sequestration and Enhanced Oil Recovery in an Oil Reservoir, as Applied to the Changqing Oilfields, China. Energy \& Fuels 2012;26:5350-4. doi:10.1021/ef300783c.

[222] Zhao X, Liao X, He L. The evaluation methods for CO2 storage in coal beds, in China. J Energy Inst 2016;89:389-99. doi:10.1016/j.joei.2015.03.001.

[223] NETL. Site screening, site selection and initial characterization for storage of $\mathrm{CO} 2$ in deep geologic formations. 2010.

[224] Cantucci B, Buttinelli M, Procesi M, Sciarra A, Anselmi M. Algorithms for CO2 storage capacity estimation: Review and case study. 2016. doi:10.1007/978-3-319-27019-7_2.

[225] Gluyas J, Mathias S. Geological storage of carbon dioxide (CO2): Geoscience, technologies, 
environmental aspects and legal frameworks. 2013. doi:10.1533/9780857097279.

[226] Jin M, Pickup G, Mackay E, Todd A, Sohrabi M, Monaghan A, et al. Static and dynamic estimates of CO2-storage capacity in two saline formations in the UK. SPE J 2012;17:1108-18.

[227] Xiao C, Tian L, Yang Y, Zhang Y, Gu D, Chen S. Comprehensive application of semi-analytical PTA and RTA to quantitatively determine abandonment pressure for $\mathrm{CO} 2$ storage in depleted shale gas reservoirs. J Pet Sci Eng 2016;146:813-31. doi:10.1016/j.petrol.2016.07.021.

[228] CSLF. Phase II Final Report from the Task Force for Review and Identification of Standards for CO2 Storage Capacity Estimation. 2007.

[229] Szulczewski ML, MacMinn CW, Herzog HJ, Juanes R. Lifetime of carbon capture and storage as a climate-change mitigation technology. Proc Natl Acad Sci U S A 2012;109:5185-9. doi:10.1073/pnas.1115347109.

[230] Brennan ST, Burruss RC, Merrill MD, Freeman PA, Ruppert LF. A probabilistic assessment methodology for the evaluation of geologic carbon dioxide storage. US Geol Surv Open-File Rep 2010;1127:31.

[231] Blondes MS, Brennan ST, Merrill MD, Buursink ML, Warwick PD, Cahan SM, et al. National assessment of geologic carbon dioxide storage resources: methodology implementation. Reston, VA: 2013.

[232] IEAGHG. Building the cost curves for CO2 storage: North America. 2005.

[233] Lake LW. Enhanced oil recovery. Prentice Hall Englewood Cliffs, NJ; 1989.

[234] NETL. Comparison of Publicly Available Methods for Development of Geologic Storage Estimates for Carbon Dioxide in Saline Formations. Morgantown, WV, USA: 2013.

[235] Ringrose PS, Mathieson AS, Wright IW, Selama F, Hansen O, Bissell R, et al. The In Salah CO2 Storage Project: Lessons Learned and Knowledge Transfer. Energy Procedia 2013;37:6226-36. doi:http://dx.doi.org/10.1016/j.egypro.2013.06.551.

[236] Pamukcu Y, Hurter S, Jammes L, Vu-Hoang D, Pekot L. Characterizing and predicting short term performance for the In Salah Krechba field CCS joint industry project. Energy Procedia 2011;4:3371-8. doi:http://dx.doi.org/10.1016/j.egypro.2011.02.259.

[237] Mathieson A, Midgely J, Wright I, Saoula N, Ringrose P. In Salah CO2 Storage JIP: CO2 sequestration monitoring and verification technologies applied at Krechba, Algeria. Energy Procedia 2011;4:3596-603. doi:http://dx.doi.org/10.1016/j.egypro.2011.02.289.

[238] Mathieson A, Wright I, Roberts D, Ringrose P. Satellite imaging to monitor CO2 movement at Krechba, Algeria. Energy Procedia 2009;1:2201-9. doi:http://dx.doi.org/10.1016/j.egypro.2009.01.286.

[239] Raikes S, Mathieson A, Roberts D, Ringrose P. Integration of 3D Seismic with Satellite Imagery at In Salah CO2 Sequestration Project, Algeria. SEG Tech Progr Expand Abstr 2008;27:2856-8. doi:10.1190/1.3063938.

[240] White JA., Chiaramonte L., Ezzedine S., Foxall W., Hao Y., Ramirez A., et al. Geomechanical behavior of the reservoir and caprock system at the in Salah CO2 storage project. Proc Natl Acad Sci U S A 2014;111:8747-52. doi:10.1073/pnas.1316465111.

[241] Rutqvist J, Vasco DW, Myer L. Coupled reservoir-geomechanical analysis of CO2 injection at In Salah, Algeria. Energy Procedia doi:http://dx.doi.org/10.1016/j.egypro.2009.01.241.

[242] Stork AL, Verdon JP, Kendall J-M. The microseismic response at the In Salah Carbon Capture and Storage (CCS) site. Int J Greenh Gas Control 2015;32:159-71. doi:https://doi.org/10.1016/j.ijggc.2014.11.014.

[243] Goertz-Allmann BP, Kühn D, Oye V, Bohloli B, Aker E. Combining microseismic and geomechanical observations to interpret storage integrity at the In Salah CCS site. Geophys J Int 2014;198:447. doi:10.1093/gji/ggu010.

[244] Deflandre J-P, Estublier A, Baroni A, Fornel A, Clochard V, Delépine N. Assessing Field Pressure 
and Plume Migration in CO2 Storages: Application of Case-specific Workflows at in Salah and Sleipner. Energy Procedia 2013;37:3554-64. doi:http://dx.doi.org/10.1016/j.egypro.2013.06.248.

[245] Ringrose PS, Roberts DM, Gibson-Poole CM, Bond C, Wightman R, Taylor M, et al. Characterisation of the Krechba $\mathrm{CO} 2$ storage site: Critical elements controlling injection performance. Energy Procedia 2011;4:4672-9. doi:http://dx.doi.org/10.1016/j.egypro.2011.02.428.

[246] Bhowmik S, Srinivasan S, Bryant SL. Inferring migration of CO2 plume using injection data and a probabilistic history matching approach. Energy Procedia 2011;4:3841-8. doi:http://dx.doi.org/10.1016/j.egypro.2011.02.320.

[247] Streibel M, Finley RJ, Martens S, Greenberg S, Möller F, Liebscher A. From Pilot to Demo Scale Comparing Ketzin results with the Illinois Basin-decatur Project. Energy Procedia 2014;63:632334. doi:http://dx.doi.org/10.1016/j.egypro.2014.11.665.

[248] Möller F, Liebscher A, Martens S, Schmidt-Hattenberger C, Streibel M. Injection of CO2 at Ambient Temperature Conditions - Pressure and Temperature Results of the "cold injection" Experiment at the Ketzin Pilot Site. Energy Procedia 2014;63:6289-97. doi:http://dx.doi.org/10.1016/j.egypro.2014.11.660.

[249] Bock M, Scheck-Wenderoth M, Group G. Research on Utilization of Geo-energy. Energy Procedia 2013;40:249-55. doi:http://dx.doi.org/10.1016/j.egypro.2013.08.029.

[250] Guen Y Le, Huot M, Loizzo M, Poupard O. Well integrity risk assessment of Ketzin injection well (ktzi-201) over a prolonged sequestration period. Energy Procedia 2011;4:4076-83. doi:http://dx.doi.org/10.1016/j.egypro.2011.02.350.

[251] Würdemann H, Möller F, Kühn M, Heidug W, Christensen NP, Borm G, et al. CO2SINK—From site characterisation and risk assessment to monitoring and verification: One year of operational experience with the field laboratory for $\mathrm{CO} 2$ storage at Ketzin, Germany. Int J Greenh Gas Control 2010;4:938-51. doi:https://doi.org/10.1016/j.ijggc.2010.08.010.

[252] Martens S, Kempka T, Liebscher A, Lüth S, Möller F, Myrttinen A, et al. Europe's longest-operating on-shore $\mathrm{CO} 2$ storage site at Ketzin, Germany: a progress report after three years of injection. Environ Earth Sci 2012;67:323-34. doi:10.1007/s12665-012-1672-5.

[253] Ghosh R, Sen MK, Vedanti N. Quantitative interpretation of CO2 plume from Sleipner (North Sea), using post-stack inversion and rock physics modeling. Int J Greenh Gas Control 2015;32:147-58. doi:https://doi.org/10.1016/j.ijggc.2014.11.002.

[254] Lu P, Zhu C, Aagaard P. Reducing Uncertainties in Model Predictions via History Matching of CO2 Plume Migration at the Sleipner Project, Norwegian North Sea. AGU Fall Meet. Abstr., 2012.

[255] Torp TA, Gale J. Demonstrating storage of CO2 in geological reservoirs: The Sleipner and SACS projects. Energy 2004;29:1361-9. doi:https://doi.org/10.1016/j.energy.2004.03.104.

[256] Moritis G. CO2 sequestration adds new dimension to oil, gas production. Oil Gas J 2003;101:3944.

[257] Kaarstad O. Emission-free fossil energy from Norway. Energy Convers Manag 1992;33:781-6. doi:http://dx.doi.org/10.1016/0196-8904(92)90084-A.

[258] Angeli M, Faleide JI, Gabrielsen RH. Evaluating Seal Quality for Potential Storage Sites in the Norwegian North Sea. Energy Procedia 2013;37:4853-62. doi:http://dx.doi.org/10.1016/j.egypro.2013.06.395.

[259] Arts R, Eiken O, Chadwick A, Zweigel P, van der Meer L, Zinszner B. Monitoring of CO2 injected at Sleipner using time-lapse seismic data. Energy 2004;29:1383-92. doi:https://doi.org/10.1016/j.energy.2004.03.072.

[260] Head MJ, Riding JB, Eidvin T, Chadwick RA. Palynological and foraminiferal biostratigraphy of (Upper Pliocene) Nordland Group mudstones at Sleipner, northern North Sea. Mar Pet Geol 2004;21:277-97. doi:https://doi.org/10.1016/j.marpetgeo.2003.12.002.

[261] Gregersen U, Michelsen O, Sørensen JC. Stratigraphy and facies distribution of the Utsira formation and the Pliocene sequences in the northern North Sea. Mar Pet Geol 1997;14:893-914. 
doi:http://dx.doi.org/10.1016/S0264-8172(97)00036-6.

[262] Hansen H, Eiken O, Aasum TO. Tracing the path of carbon dioxide from a gas/condensate reservoir, through an amine plant and back into a subsurface aquifer - Case study: The Sleipner area, Norwegian North Sea. Offshore Eur. Conf. - Proc., 2005, p. 473-87.

[263] Gale J, Christensen NP, Cutler A, Torp TA. Demonstrating the Potential for Geological Storage of CO2: The Sleipner and GESTCO Projects. Environ Geosci 2001;8:160-5. doi:10.1046/j.15260984.2001.008003160.x.

[264] Nooner SL, Eiken O, Hermanrud C, Sasagawa GS, Stenvold T, Zumberge MA. Constraints on the in situ density of $\mathrm{CO} 2$ within the Utsira formation from time-lapse seafloor gravity measurements. Int J Greenh Gas Control 2007;1:198-214. doi:https://doi.org/10.1016/S1750-5836(07)00018-7.

[265] Mackenzie, F. T., Lerman, A., Ver LMB. Recent past and future of the global carbon cycle. Stud. Geol. 47th ed., Tulsa, OK: American Association of Petroleum Geologists; 2001, p. 51-82.

[266] Arts, Rob; Chadwick, Andy; Eiken, Ola; Thibeau, Sylvain; Nooner S. Ten years' experience of monitoring CO2 injection in the Utsira Sand at Sleipner, offshore Norway. 2008.

[267] Jensen G, Nickel E, Whittaker S, Rostron B. Site assessment update at Weyburn-Midale CO2 sequestration project, Saskatchewan, Canada: New results at an active $\mathrm{CO} 2$ sequestration site. Energy Procedia 2011;4:4777-84. doi:http://dx.doi.org/10.1016/j.egypro.2011.02.442.

[268] Whittaker S, Rostron B, Hawkes C, Gardner C, White D, Johnson J, et al. A decade of CO2 injection into depleting oil fields: Monitoring and research activities of the IEA GHG Weyburn-Midale CO2 Monitoring and Storage Project. Energy Procedia 2011;4:6069-76. doi:http://dx.doi.org/10.1016/j.egypro.2011.02.612.

[269] Sacuta N, Anderson K. Creating core CCS messages: Focus Group Testing and Peer Review of Questions and Answers from the IEAGHG Weyburn-midale CO2 Monitoring and Storage Project. Energy Procedia 2014;63:7061-9. doi:http://dx.doi.org/10.1016/j.egypro.2014.11.741.

[270] Worth K, White D, Chalaturnyk R, Sorensen J, Hawkes C, Rostron B, et al. Aquistore Project Measurement, Monitoring, and Verification: From Concept to $\mathrm{CO} 2$ Injection. Energy Procedia 2014;63:3202-8. doi:http://dx.doi.org/10.1016/j.egypro.2014.11.345.

[271] Harsh AH, Anne VA. Carbon dioxide capture, utilization and storage (CCUS). 76th Eur. Assoc. Geosci. Eng. Conf. Exhib. 2014 Exp. Energy - Inc. SPE Eur. 2014, 2014, p. 5133-5.

[272] Jensen GKS, Nickel EH, Rostron BJ. Refinement of the Weyburn-Midale geological and hydrogeological model: Developing a better framework to determine reservoir response to injected CO2 and subsequent CO2 movement. Int J Greenh Gas Control 2013;16, Supple:S5-14. doi:https://doi.org/10.1016/j.ijggc.2013.02.013.

[273] GCCSI. Alberta Carbon Trunk Line ("ACTL”) with North West Sturgeon Refinery CO2 Stream. Glob CCS Inst 2017. https://www.globalccsinstitute.com/projects/alberta-carbon-trunk-line-actlnorth-west-sturgeon-refinery-co2-stream (accessed May 18, 2017).

[274] Cole S, Itani S. The Alberta Carbon Trunk Line and the Benefits of CO2. Energy Procedia 2013;37:6133-9. doi:http://dx.doi.org/10.1016/j.egypro.2013.06.542.

[275] Burrowes G. of carbonate rocks during tertiary recovery from a billion barrel oil field, Weyburn, Saskatchewan: the geoscience framework (IEA Weyburn $\mathrm{CO} 2$ monitoring and storage project). 2001.

[276] Riding JB, Rochelle CA. The IEA Weyburn CO2 Monitoring and Storage Project - Final report of the European research team. 2005.

[277] Strutt MH., Baubron JC., Beaubien SE., Cardellini C., Granieri D., Jones DG., et al. Soil gas as a monitoring tool of deep geological sequestration of carbon dioxide: Results from the three year Monitoring of the Encana Eor Project, Weyburn, Saskatchewan (Canada). 2005. doi:10.1016/B978008044704-9/50285-8.

[278] Emberley S, Hutcheon I, Shevalier M, Durocher K, Mayer B, Gunter WD, et al. Monitoring of fluidrock interaction and $\mathrm{CO} 2$ storage through produced fluid sampling at the Weyburn $\mathrm{CO} 2$-injection 
enhanced oil recovery site, Saskatchewan, Canada. Appl Geochemistry 2005;20:1131-57. doi:https://doi.org/10.1016/j.apgeochem.2005.02.007.

[279] Wegelin A. Reservoir Characteristics Of The Weyburn Field, Southeastern Saskatchewan. J Can Pet Technol 1987;26:60-6. doi:10.2118/87-04-05.

[280] Rah N. Petrology and economic geology of the Upper Devonian Birdbear Formation in southeastern Saskatchewan. 1970.

[281] Romanak KD, Wolaver B, Yang C, Sherk GW, Dale J, Dobeck LM, et al. Process-based soil gas leakage assessment at the Kerr Farm: Comparison of results to leakage proxies at ZERT and Mt. Etna. Int J Greenh Gas Control 2014;30:42-57. doi:https://doi.org/10.1016/j.ijggc.2014.08.008.

[282] Boyd AD, Liu Y, Stephens JC, Wilson EJ, Pollak M, Peterson TR, et al. Controversy in technology innovation: Contrasting media and expert risk perceptions of the alleged leakage at the Weyburn carbon dioxide storage demonstration project. Int J Greenh Gas Control 2013;14:259-69. doi:https://doi.org/10.1016/j.ijggc.2013.01.011.

[283] Negrescu M. Economic Modelling of an Oil and Gas Project Involving Carbon Capture and Storage - Snohvit LNG Project (Barents Sea, Norway). Eur. Conf. Exhib., London, UK: Society of Petroleum Engineers; 2007. doi:10.2118/107430-MS.

[284] Negrescu M. Economic Modeling of an Oil and Gas Project Involving Carbon Capture and Storage: Snohvit LNG Field (Barents Sea, Norway). SPE Proj. Facil. Constr., Society of Petroleum Engineers; 2008. doi:10.2118/107430-PA.

[285] Chiaramonte L, White JA, Trainor-Guitton W. Probabilistic geomechanical analysis of compartmentalization at the Snøhvit CO2 sequestration project. J Geophys Res Solid Earth 2015;120:1195-209. doi:10.1002/2014JB011376.

[286] Taikkiso. Carbon Capture and Storage. Taikkiso Co, Ltd 2017. http://www.taikkiso.com/products_detail_30.htm (accessed May 9, 2017).

[287] Heal K, Kemp T. North West Sturgeon Refinery Project Overview - Carbon Capture Through Innovative Commercial Structuring in the Canadian Oil Sands. Energy Procedia 2013;37:7046-55. doi:http://dx.doi.org/10.1016/j.egypro.2013.06.641.

[288] Ranasinghe N. Regulating a Pilot Project in the Absence of Legislation Specific to Carbon Storage. Energy Procedia 2013;37:6202-15. doi:http://dx.doi.org/10.1016/j.egypro.2013.06.549.

[289] Steeper T. CO2CRC Otway Project Social Research: Assessing CCS Community Consultation. Energy Procedia 2013;37:7454-61. doi:http://dx.doi.org/10.1016/j.egypro.2013.06.688.

[290] Sharma S, Cook P, Jenkins C, Steeper T, Lees M, Ranasinghe N. The CO2CRC Otway Project: Leveraging experience and exploiting new opportunities at Australia's first CCS project site. Energy Procedia 2011;4:5447-54. doi:http://dx.doi.org/10.1016/j.egypro.2011.02.530.

[291] Hortle A, de Caritat P, Stalvies C, Jenkins C. Groundwater monitoring at the Otway project site, Australia. Energy Procedia 2011;4:5495-503. doi:http://dx.doi.org/10.1016/j.egypro.2011.02.535.

[292] Dance T. Assessment and geological characterisation of the CO2CRC Otway Project CO2 storage demonstration site: From prefeasibility to injection. Mar Pet Geol 2013;46:251-69. doi:https://doi.org/10.1016/j.marpetgeo.2013.06.008.

[293] Schacht U, Jenkins C. Soil gas monitoring of the Otway Project demonstration site in SE Victoria, Australia. Int J Greenh Gas Control 2014;24:14-29. doi:https://doi.org/10.1016/j.ijggc.2014.02.007.

[294] Stirling M, Litchfield N, Gerstenberger M, Clark D, Bradley B, Beavan J, et al. Preliminary Probabilistic Seismic Hazard Analysis of the CO2CRC Otway Project Site, Victoria, Australia. Bull Seismol Soc Am 2011;101:2726-36. doi:10.1785/0120110049.

[295] Miller L, Cameron D. Carbon Capture and the Boundary Dam Project. Saskatoon, Canada: 2011.

[296] Griffith CA, Dzombak DA, Lowry G V. Physical and chemical characteristics of potential seal strata in regions considered for demonstrating geological saline $\mathrm{CO} 2$ sequestration. Environ Earth Sci 2011;64:925-48. doi:10.1007/s12665-011-0911-5.

[297] Freifeld B, Zakim S, Pan L, Cutright B, Sheu M, Doughty C, et al. Geothermal Energy Production 
Coupled with CCS: a Field Demonstration at the SECARB Cranfield Site, Cranfield, Mississippi, USA. Energy Procedia 2013;37:6595-603. doi:http://dx.doi.org/10.1016/j.egypro.2013.06.592.

[298] Meckel T, Hovorka S. Above-Zone Pressure Monitoring as a Surveillance Tool for CarbonSequestration Projects n.d. doi:10.2118/139720-MS.

[299] Tao Q, Bryant SL, Meckel TA. Modeling above-zone measurements of pressure and temperature for monitoring CCS sites. Int J Greenh Gas Control 2013;18:523-30. doi:https://doi.org/10.1016/j.ijggc.2012.08.011.

[300] Anderson JS, Romanak KD, Yang C, Lu J, Hovorka SD, Young MH. Gas source attribution techniques for assessing leakage at geologic $\mathrm{CO} 2$ storage sites: Evaluating a $\mathrm{CO} 2$ and $\mathrm{CH} 4$ soil gas anomaly at the Cranfield CO2-EOR site. Chem Geol 2017;454:93-104. doi:https://doi.org/10.1016/j.chemgeo.2017.02.024.

[301] GCCSI. Frio Brine Pilot Project 2010. https://hub.globalccsinstitute.com/publications/strategicplan-implementation-report/frio-brine-pilot-project (accessed August 8, 2017).

[302] Hovorka S. Frio brine pilot: The first US sequestration test. Southwest Hydrol 2009;8:26-31.

[303] CSLF. Strategic Plan Implementation Report Table of Contents. Texas, USA: 2010.

[304] Hovorka SD. Frio Brine Storage Experiment-Lessons Learned. 8th Int. Conf. Greenh. Gas Control Technol., 2006, p. 6-13.

[305] Koperna GJ, Carpenter SM, Petrusak R, Trautz R, Rhudy D, Esposito R. Project Assessment and Evaluation of the Area of Review (AoR) at the Citronelle SECARB Phase III Site, Alabama USA. Energy Procedia 2014;63:5971-85. doi:http://dx.doi.org/10.1016/j.egypro.2014.11.632.

[306] Koperna Jr. GJ, Kuuskraa V, Riestenberg D, Rhudy R, Trautz R, Esposito R, et al. The Secarb anthropogenic test: The first U.S. integrated capture, transportation and storage test. 28th Annu. Int. Pittsburgh Coal Conf. 2011, PCC 2011, vol. 3, 2011, p. 2201-11.

[307] Esposito R, Harvick C, Shaw R, Mooneyhan D, Trautz R, Hill G. Integration of Pipeline Operations Sourced with $\mathrm{CO} 2$ Captured at a Coal-fired Power Plant and Injected for Geologic Storage: SECARB Phase III CCS Demonstration. Energy Procedia 2013;37:3068-88. doi:http://dx.doi.org/10.1016/j.egypro.2013.06.193.

[308] Chen S-E, Liu Y. Geophysical sensing for CO2 sequestration and enhanced oil recovery. Geotech. Spec. Publ., 2011, p. 41-8. doi:10.1061/47626(405)6.

[309] NETL. Citronelle Project - Paluxy Formation, Citronelle, Alabama Southeast Regional Carbon Sequestration Partnership. 2017.

[310] Couëslan ML, Butsch R, Will R, Locke RA. Integrated reservoir monitoring at the Illinois Basin Decatur Project. Energy Procedia 2014;63:2836-47. doi:http://dx.doi.org/10.1016/j.egypro.2014.11.306.

[311] Kelley M, Abbaszadeh M, Mishra S, Mawalkar S, Place M, Gupta N, et al. Reservoir Characterization from Pressure Monitoring during CO2 Injection into a Depleted Pinnacle Reef MRCSP Commercial-scale CCS Demonstration Project. Energy Procedia 2014;63:4937-64. doi:http://dx.doi.org/10.1016/j.egypro.2014.11.524.

[312] Atkinson W. Carbon capture and sequestration: Real progress taking place. Pollut Eng 2014;46:302.

[313] Trivedi JJ, Babadagli T, Lavoie RG, Nimchuk D. Acid Gas Sequestration During Tertiary Oil Recovery: Optimal Injection Strategies and Importance of Operational Parameters. J Can Pet Technol 2007;46. doi:10.2118/07-03-06.

[314] Bennion B, Bachu S. Drainage and Imbibition Relative Permeability Relationships for Supercritical $\mathrm{CO}$ /Brine and H2S/Brine Systems in Intergranular Sandstone, Carbonate, Shale, and Anhydrite Rocks. Soc. Pet. Eng., Society of Petroleum Engineers; 2008. doi:10.2118/99326-PA.

[315] Luo T, Zhou L, Jiao Z, Bai Y, Wang S. The Ordos Basin: A Premier Basin for Integrating geological CO2 Storage with Enhanced oil Recovery Projects in China. Energy Procedia 2014;63:7772-9. doi:http://dx.doi.org/10.1016/j.egypro.2014.11.811. 
[316] Zhao X, Ma R, Zhang F, Zhong Z, Wang B, Wang Y, et al. The latest monitoring progress for Shenhua CO2 storage project in China. Int J Greenh Gas Control 2017;60:199-206. doi:https://doi.org/10.1016/j.ijggc.2017.03.004. 